Víctor Lara Bermejo

La cortesía en la

Península Ibérica

Dialectología del Sprachbund suroccidental 
Las formas de tratamiento en el ámbito hispánico y lusófono representan uno de los temas más complejos y, a la vez, más estudiados. La diversidad de alternativas y usos a ambos lados del Atlántico es bien conocida, aunque la mayoría de estudios se concentra en casos aislados de una ciudad o región muy determinada, o bien muestra un análisis descriptivo de los pronombres de cortesía. Además, los especialistas han prestado más atención a la casuística de las variedades americanas y menos a la situación del español y portugués europeos. Este estudio pretende dar cuenta de la evolución de las formas de tratamiento en la Península Ibérica en los últimos cien años, con un especial énfasis en el fenómeno de nivelación que se atestigua en la zona suroccidental. De forma pionera, se expone el comportamiento geolingüístico, sociolingüístico y gramatical de dicha nivelación, aplicando métodos estadísticos y los programas de cartografía más actuales. Todo ello, auspiciado por una metodología innovadora y un corpus cuantitativo que refleja la estrecha relación que guardan el español y el portugués, no solo en la cortesía, sino a nivel lingüístico, derivando en un Sprachbund que tiene como foco el suroccidente de la Península Ibérica.

\section{VÍCTOR LARA BERMEJO}

Doctor en Filosofía y Lingüística por la Universidad Autónoma de Madrid, su investigación académica se centra sobre todo en las formas de tratamiento del español y del portugués y cómo ambas lenguas se influyen en la Península Ibérica. Asimismo, ha liderado otros trabajos pioneros, como el empleo causativo de ciertos verbos intransitivos, y se ha ocupado de la geolingüística y dialectología iberorromances. 
La cortesía en la Península Ibérica 


\section{FONDO HISPÁNICO DE LINGÜÍSTICA Y FILOLOGÍA}

Vol. 29

Colección dirigida por

Juan Pedro Sánchez Méndez \& M. ${ }^{a}$ Teresa Echenique Elizondo

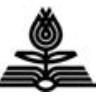

PETER LANG

Bern · Berlin · Bruxelles · New York · Oxford - Warszawa 
Víctor Lara Bermejo

\title{
La cortesía en la Península Ibérica
}

\author{
Dialectología del Sprachbund suroccidental
}


Bibliographic information published by die Deutsche Nationalbibliothek Die Deutsche Nationalbibliothek lists this publication in the Deutsche Nationalbibliografie; detailed bibliographic data is available on the Internet at http://dnb.d-nb.de).

Die Druckvorstufe dieser Publikation wurde vom Schweizerischen Nationalfonds zur Förderung der wissenschaftlichen Forschung unterstützt.

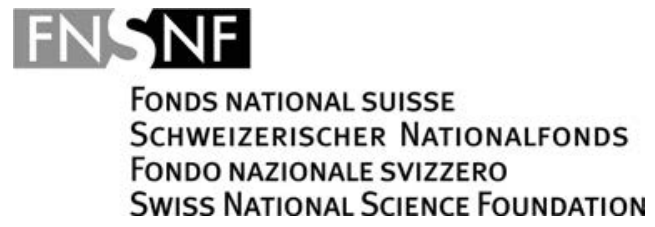

ISSN 1663-2648 • ISBN 978-3-0343-3392-4 (Print)

E-ISBN 978-3-0343-3389-4 (E-PDF • E-ISBN 978-3-0343-3390-0 (EPUB)

E-ISBN 978-3-0343-3391-7 (MOBI) ・ DOI 10.3726/b14493

PETER LANG

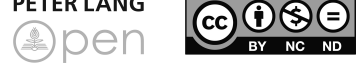

Open Access: This work is licensed under a Creative Commons Attribution Non Commercial No Derivatives 4.0 unported license. To view a copy of this license, visit https://creativecommons.org/licenses/by-nc-nd/4.0/

Esta publicación ha sido revisada por pares.

(C) Víctor Lara Bermejo, 2018

Wabernstrasse 32, CH-3007 Bern

bern@peterlang.com, www.peterlang.com 


\section{La cortesía en la Península Ibérica: dialectología del Sprachbund suroccidental}

Introducción ............................................................................. 7

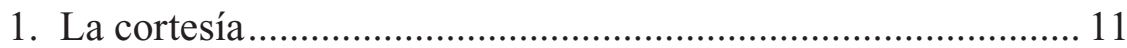

1.1. La cortesía a nivel universal ......................................... 15

1.2. La cortesía en español peninsular ................................... 21

1.3. La cortesía en portugués europeo................................... 29

1.4. La cortesía en el español y portugués americanos ........... 32

1.5. Conclusión..................................................................... 34

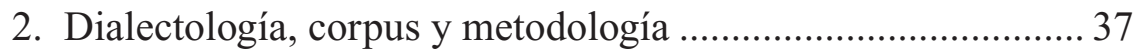

2.1. Extensión de fenómenos lingüísticos ............................. 40

2.1.1. Sintaxis versus semántica................................... 40

2.1.2. Index versus concord........................................ 41

2.1.3. Relaciones de caso ........................................... 42

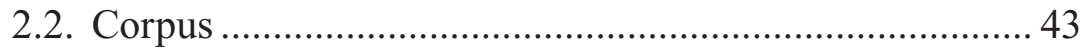

2.2.1. Corpus geolingüístico....................................... 44

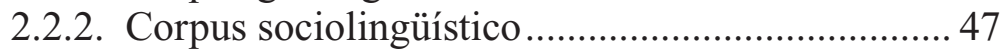

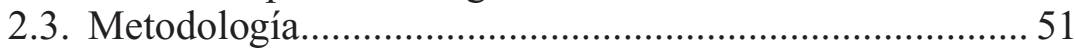

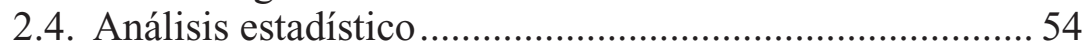

3. Geografía de la cortesía en el suroccidente peninsular............ 55

4. Sociolingüística de la cortesía en el suroccidente peninsular .....73

4.1. Estudio estadístico........................................................... 75

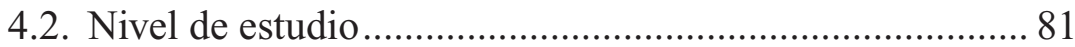

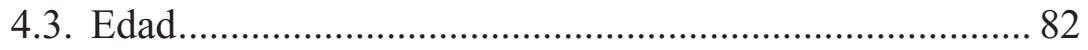

4.3.1. Cambio en tiempo real y aparente....................... 87

4.4. Análisis de las variables sociales en el portugués ............ 89

4.4.1. Sexo ........................................................................ 90

4.4.2. Edad............................................................... 91

4.4.3. Zona ALPI ...................................................... 92 
5. Lingüística de la cortesía en el suroccidente peninsular......... 95 5.1. La concordancia sujeto - verbo...................................... 96

5.2. La concordancia en los pronombres átonos .................. 112

5.3. La concordancia del posesivo....................................... 118

5.4. Situación comunicativa .............................................. 120

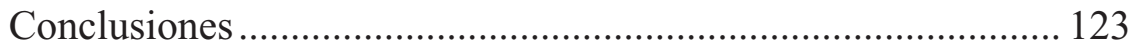

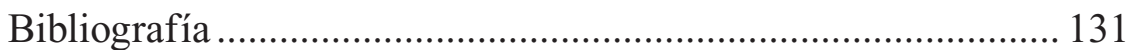




\section{Introducción}

El sistema alocutivo del español peninsular no ha sido profundamente estudiado. A diferencia de los numerosos estudios sobre el voseo o el ustedeo en el español hablado en América, no existen obras monográficas sobre las particularidades de la segunda persona en España. Si bien el sistema en singular no ofrece diferencias, ya que la oposición tú / usted se mantiene para todo el territorio peninsular, el plural presenta ciertas particularidades, concretamente en la zona occidental de Andalucía. El estándar peninsular prescribe la distinción entre vosotros / ustedes para la informalidad y formalidad, respectivamente, mientras Andalucía occidental niveló el sistema plural a favor de ustedes. A pesar de esta simplificación, los elementos sintácticos con referencia ustedes no siguen un patrón normativo en la concordancia, ya que, dependiendo del área geográfica dentro de la cual se da dicho fenómeno y de la función sintáctica del elemento dado, ustedes puede inducir concordancias de segunda persona del plural ( $2 \mathrm{pl})$ o de tercera persona del plural (3pl). Este uso vernáculo, completamente estigmatizado y tachado de rural y propio de clases iletradas, contradice el modelo prestigioso que impera en España, en el que vosotros ha de concordar en $2 \mathrm{pl}$ y ustedes, en $3 \mathrm{pl}$.

Si bien la bibliografía al respecto no se pone de acuerdo en delimitar geográficamente el fenómeno, su aparición se ha asociado siempre a las provincias de Huelva, Sevilla, Cádiz, Córdoba y Málaga. Asimismo, algunos autores afirman que solo el reflexivo se concuerda en 3pl, mientras que otros opinan que todos los elementos sintácticos adoptan la 2pl. El único punto en el que convergen es en la concordancia del pretérito perfecto simple, cuya desinencia siempre adoptaría la 3pl. Pragmáticamente, no hay unanimidad en postular qué produjo la nivelación precisamente en el pronombre de respeto. La heterogeneidad de clases sociales que se concentraron en Sevilla y Cádiz cuando estos eran importantes puertos comerciales con América ha sido una de las ideas más reivindicadas. En este panorama social, la solución por ustedes habría sido la alternativa para no ofender a un grupo de personas, dentro de las cuales algunas serían tratadas de manera formal y otras, informal. La alta jerarquización de la sociedad andaluza en los siglos XVIII y XIX ha sido otra de las razones que 
se han esgrimido. La moda solidaria que recorrió España en dichos siglos, favoreciendo el empleo de vosotros en contextos donde, previamente, se usaba ustedes, habría sido vehementemente rechazada por los hidalgos y señores andaluces, que impusieron el mantenimiento de ustedes como manera de perpetuar la distancia y la jerarquización.

El portugués europeo tampoco ha llamado la atención en el estudio de su sistema de formas de tratamiento plural. Aunque contamos con diversas obras y artículos que versan sobre el recorrido de a vossa mercê - você durante los siglos y como este, de ser un pronombre de cortesía, pasó a convertirse en forma igualitaria e incluso ofensiva, no existe un estudio pormenorizado de la nivelación en plural a favor de vocês y a costa del tradicional vós. Aunque la sociedad lusa diferenciaba aún en el siglo XVII la informalidad y la formalidad mediante vós y vocês, respectivamente, la estigmatización del primer pronombre conllevó la universalización del segundo. Sin embargo, no todos los elementos concuerdan en $3 \mathrm{pl}$, como exigiría su sintaxis. Los clíticos de objeto, el posesivo y el adjunto de compañía aún adoptan morfemas de 2pl, es decir, propios de vós, sin que ello ponga en entredicho el prestigio, ya que el estándar es el que promueve dichas discordancias. Además, a diferencia del andaluz, la nivelación de vocês es la norma, siendo la distinción entre vós y vocês un uso penalizado y poco prestigioso. En términos geográficos, la norma niveladora alcanza la mitad sur del país, mientras que la mitad norte aún conserva el estadio distinguidor anterior.

En este libro se pretende hacer un doble estudio. Por un lado, sincrónico, en el que se presente la situación actual de la nivelación de ustedes a costa de vosotros en Andalucía occidental, así como de la generalización de vocês como nuevo pronombre de $2 \mathrm{pl}$ en Portugal. Por otro lado, diacrónico, en el que se comparen los resultados actuales con los manejados en obras que tratan de estos fenómenos y con los datos de atlas lingüísticos de mediados del siglo $\mathrm{xx}$.

Para ello, trataremos en primer lugar de analizar las diversas teorías que existen sobre el concepto de cortesía y cómo ha ido evolucionando el sistema de tratamientos en distintas lenguas y qué ha producido dicha evolución. Estudiaremos el sistema latino y el desarrollo en el español, analizando las formas de tratamiento de las variedades latinoamericanas y peninsulares, así como en el portugués europeo y brasileño. Asimismo, detallaremos la situación de lenguas germánicas y cómo han evolucionado desde su origen. En el siguiente capítulo, explicaremos el marco teórico 
en el que se basa esta investigación, así como sus objetivos concretos. Seguidamente, describiremos el corpus y la metodología seguida, primero el corpus geolingüístico, basado en los materiales de los atlas recolectados en el último siglo, y en segundo lugar, el corpus sociolingüístico, elaborado específicamente para esta investigación. En consecuencia, describiremos la metodología confeccionada para el trabajo de campo, en el que se han previsto varias escenas de dos series de televisión que los informantes tenían que doblar, con el fin de expresar todos los elementos sintácticos con referencia ustedes / vocês, de forma espontánea. Analizaremos el marco teórico en el que se inscribe dicha tesis: la sociolingüística, y describiremos las variables sociales y lingüísticas que se ha previsto correlacionar con la variable dependiente.

En los capítulos 3 y 4 se ofrece el análisis de los resultados. En primer lugar, del corpus geolingüístico y, a continuación, del sociolingüístico. Para ello se analizan los datos del Atlas lingüístico de la Península Ibérica, primera obra sobre la que puede reconstruir la existencia de esta variable un siglo atrás. Y, a continuación, se analizan y contrastan esos datos con los del corpus sociolingüístico construido ad hoc para esta investigación.

El capítulo siguiente se reservará al análisis pormenorizado de los datos, de acuerdo con los resultados del análisis geolingüístico y estadístico. Por tanto, presentaremos la difusión geográfica del fenómeno en la actualidad y la extensión de la $3 \mathrm{pl}$ en los elementos con referencia ustedes, así como las posibles diferencias de acuerdo con la situación comunicativa. Estudiaremos las variables sociales que inciden en el uso de la particularidad vernácula o en la tendencia al patrón estándar y discutiremos la variable desde el punto de vista lingüístico, tratando de aclarar las razones por las que el pretérito perfecto simple sucumbe antes a la $3 \mathrm{pl}$ que el resto de tiempos verbales, el reflexivo en 3 pl puede combinarse con morfología verbal de $2 \mathrm{pl}$, el acusativo adopta antes que el dativo la $3 \mathrm{pl}$ o por qué el posesivo es el último elemento en acoplarse a la concordancia innovadora. Asimismo, observaremos el comportamiento lingüístico de vocês.

Por último, reservaremos el último capítulo a las conclusiones para resumir los resultados que se han extraído de la comparación de los datos del Atlas lingüístico de la Península Ibérica y los recogidos con la nueva metodología, de acuerdo con tres parámetros: geográfico, gramatical y pragmático. Finalmente, expondremos la nómina de obras consultadas para este trabajo. 



\section{La cortesía}

El fenómeno sobre el que se ocupa este estudio ha de tener en cuenta el condicionante diafásico. A diferencia del comportamiento de otros pronombres u otras personas, la segunda afecta a las relaciones que se establecen entre los interlocutores que participan en el acto comunicativo. El adecuado uso de una forma de segunda persona atenderá, sobre todo, a parámetros sociales, más que conceptuales, con el fin de tener éxito en el acto comunicativo y en el desarrollo del diálogo que se establezca con la persona aludida. A todos estos factores pragmáticos que inciden en la elección de una fórmula de tratamiento, sea esta pronominal o nominal, los denominamos de una manera muy general como cortesía. La cortesía es un comportamiento pragmático que se atestigua en todas las culturas y, por tanto, en todas las lenguas del mundo. Cada sociedad establece unos modelos distintos para expresar deferencia, de complejidad muy variable.

Los estudios sobre la cortesía son relativamente recientes y pueden tener como punto de partida el célebre artículo publicado a principios de la década de 1960 por Brown \& Gilman (1960). Fueron ellos quienes introdujeron en la terminología lingüística los tecnicismos formas $T$, formas $V$, poder o solidaridad, que aún hoy se siguen utilizando. Los tratamientos $\mathrm{T}$ ( $\mathrm{T}$ proviene del latín $\mathrm{TU}$ ) se refieren a aquellos en los que se establece una relación de intimidad (como entre dos amigos), se quiere expresar cercanía o incluso se quiere marcar la asimetría existente entre un interlocutor que está por encima de otro (de manera que el subordinado recibe la forma T). Las formas V (del latín vos), no obstante, denotan distancia (como entre dos desconocidos), asimetría (como en el trato de alguien de menor edad hacia un anciano, el cual recibiría $\mathrm{V}$ ) o poder (el jefe recibe por parte del subordinado una forma V). No es de extrañar, a la luz de esta división, que con las formas $\mathrm{T}$ se recurra a expresar la informalidad y que las formas V se suelan usar para contextos formales. Por otro lado, los conceptos de poder y solidaridad designan, respectivamente, la capacidad de una persona de controlar el comportamiento de otra y el hecho de neutralizar las diferencias de poder entre los interlocutores, tratándolos por igual, sin distinción de estrato social, sexo, edad u otra variable social. La solidaridad tiende al uso de pronombres $\mathrm{T}$, mientras que el poder exige 
la recepción de $\mathrm{V}$ por parte del que ostenta el cargo más alto. No obstante, podemos hallar dos interlocutores que intercambian $\mathrm{V}$, a pesar de tener el mismo nivel de poder, por el hecho de marcar la distancia que entre ambos desean que haya.

La investigación de Brown \& Gilman se basa en el análisis de las formas de tratamiento empleadas en distintos contextos históricos. Así, tras la Revolución Francesa, la tradición de usar V en una sociedad muy jerarquizada, monárquica y estamental, dio paso a una propaganda a favor de las formas T, como manera de igualar a todos los habitantes, entonces recién llamados ciudadanos:

In France, the nonreciprocal power semantic was dominant until the Revolution, when the Committee for the Public Safety condemned the use of $V$ as a feudal remnant and ordered a universal reciprocal $T$ (Brown \& Gilman 1960: 265-266).

A lo largo de la historia, apuntan, cada sociedad ha ido evolucionando a un espectro que propiciaba la solidaridad frente al poder. Prueba de ello es la tendencia favorecida tras la Segunda Guerra Mundial y a los sistemas comunistas que trataban a los ciudadanos de camaradas.

La división tan meridiana que Brown \& Gilman delinearon en su trabajo no estuvo exenta de crítica, ya que se les tachó de haber sido muy reduccionistas. No sería hasta que Brown \& Levinson publicaron su popular obra Politeness: some universals in language usage (1987) cuando el estudio de la cortesía formuló nuevos términos analíticos y una nueva corriente interpretativa. Para ellos, en todo ámbito de cortesía hay que diferenciar varios conceptos: no solo el poder y la solidaridad, sino también la distancia y el factor social. La solidaridad y la distancia son dos conceptos parejos, ya que hacen referencia a la simetría que existe entre los participantes del acto pragmático, es decir, a aquello que los une para un intercambio informal, de igual a igual o incluso de intimidad. El poder alude a la asimetría que existe entre dos personas dadas, es decir, qué características posee un interlocutor para que el otro le tenga que tratar con una forma más deferente o lo contrario. Por último, el factor social responde a los protocolos que una cultura en concreto impone en el intercambio pragmático y que influyen a la hora de evaluar el poder, la distancia o la solidaridad, y qué estrategias hay que seguir para cumplir las condiciones impuestas por una situación comunicativa concreta.

Para que todo intercambio pragmático se produzca satisfactoriamente, los interlocutores han de tener en cuenta la 'cara' (face) del contrario 
y buscar estrategias que respeten dicha cara. La noción de face alude al concepto que cada persona tiene de sí misma y que desea que los demás también tengan. La cara consta de dos vertientes: negativa y positiva. La cara negativa es aquella que busca la libertad del propio individuo, reclama intimidad, rechaza las imposiciones de otros interlocutores para que no se inmiscuyan en la imagen que tiene de uno mismo y respeten su territorio y distancia. La cara positiva, en cambio, es la imagen que la persona tiene de sí misma y que trata que los demás compartan.

Ya que todos los hablantes constan de cara positiva y negativa, todos tienen que respetar y satisfacer la face de los demás y la propia, valiéndose de estrategias que, a menos que se trate de una urgencia o una situación extrema, minimicen cualquier posible acto de amenaza a ambas caras o face-threatening act (FTA). Como hemos apuntado, la cara negativa de cada persona busca mantener su territorio, libertad e impedir intromisiones externas a su parcela. Por tanto, los actos que más amenazan esta vertiente de la cara suelen ser órdenes, peticiones, consejos, amenazas, advertencias, promesas, cumplidos o expresiones de admiración o rechazo a la persona en cuestión. Por otro lado, si la cara positiva refleja la imagen que uno tiene de sí mismo y que desea que los demás también tengan, los actos que más la amenazan son expresiones de desaprobación, críticas, quejas, reprimendas, insultos, contradicciones, expresiones de desacuerdo e incluso el uso de formas de tratamiento que marquen distancia entre los interlocutores.

Para frenar los FTA, el hablante tiene que recurrir a estrategias que los rebajen (estrategias que influirán también en la elección de una forma de tratamiento, Jucker \& Taatvitsainen 2003). Para ello, tiene dos tipos de cortesía: la positiva y la negativa. La primera trata de satisfacer la cara positiva del interlocutor, esto es, la imagen que tiene de sí mismo y que pretende que sea compartida por los demás. Por tanto, la cortesía positiva se alcanza no poniendo distancia entre los participantes, tratándose como amigos, aprobando los actos del otro, con expresiones de admiración, bromas, atendiendo a los intereses del otro...

La cortesía negativa, en cambio, trata de respetar la cara negativa, esto es, intenta no entrar en el espacio que el hablante considera que es suyo, procura no imponer y respetar la libertad del rival. Por consiguiente, la cortesía negativa se alcanza mediante alocutivos que marquen la distancia o el poder entre los participantes, impersonalizando el trato, evitando imperativos, absteniéndose de pedir opiniones del interlocutor, siendo indirectos, optando por un plural mayestático, etcétera. 
La investigación de Brown \& Levinson ha sido ampliamente criticada, sobre todo por estudiosos de la cortesía en regiones asiáticas (Matsumoto 1988, Nwoye 1992, Ide 1993 o Werkhofer 1992). Análisis más recientes sobre la pertinencia de una forma de tratamiento o de una estrategia determinada para satisfacer el concepto de cortesía de una sociedad concreta apuntan a los estudios de Watts (2003), quien presenta otra perspectiva del concepto de cortesía. En su trabajo sobre qué se ha entendido por cortesía durante varios siglos en el Reino Unido, concluye que la sociedad de los siglos XVI y XVII asociaba la cortesía a una característica natural de la aristocracia, de algunos individuos de una clase social determinada, quienes innatamente heredaban dicho don. La clave para ser cortés residía en los buenos modales y una pronunciación particular. Este concepto de cortesía se popularizó en el siglo XVIII:

Standard English became almost synonymous with polite English or the English of polite society [...] The concept of politeness was appropriated as the basis of a hegemonic discourse in which the ability to control a specific language variety was interpreted as providing access to high social status from which power could be exercised. Determining who was a member of 'polite society', however, was in the hands of those who had already gained access (2003: 39-40).

La cortesía en Gran Bretaña se definía por un je ne sais quoi, que, de acuerdo con Watts, pertenecía a un grupo selecto, cuyos miembros ostentaban los cargos de poder del Estado, de la política, de las finanzas y de la moral de la época. Por tanto, la cortesía se entendía como una cuestión de cómo esa misma gente en el poder percibía que debían ser tratados entre sí y por aquellos de las demás clases sociales.

La tesis de Watts de relacionar la ideología imperante de una sociedad con el concepto de cortesía se puede materializar en distintos ejemplos que hemos recabado. La tendencia contemporánea en la Europa occidental parece, como ya apuntaban Brown \& Gilman (1960), favorecer el retroceso de las formas $\mathrm{V}$ o puramente deferenciales, en un claro aumento de tratamientos $\mathrm{T}$ o de solidaridad por la noción de democracia. Braun (1988) señala, entre muchos ejemplos, el caso del noruego. El pronombre singular informal es $d u$ y el de plural dere, mientras que en la forma $D e$ se recoge la formalidad, independientemente del número. Sin embargo, en su trabajo de campo confrontando diversas lenguas, apreció hace ya treinta años el retroceso de De como alocutivo $\mathrm{V}$ de plural, espacio cada vez más copado por el informal dere. 
Asimismo, bajo el mandato de Felipe II, se llegó a legislar sobre la idoneidad de cada forma de tratamiento, en consonancia con la sociedad tan jerárquica del momento que, entonces, ya no percibía vós como pronombre de cortesía. El mismo patrón se manifestó en la Alemania del siglo XVIII, cuando el sintagma Eure Gnaden (Sie) sustituyó al pronombre $i h r$, que había ampliado su valencia incluso al ámbito de la informalidad (Hickey 2003, Howe 1996). De nuevo, observamos que esos usos tan estrictos contrastan con la tendencia hacia la solidaridad que varios autores han caracterizado en distintos países europeos. Paulston (1984) con respecto a Suecia, Kocher (1967) con respecto a la ex Yugoslavia, Benigni \& Bates (1977) con respecto a Italia o De Jonge \& Nieuwenhuijsen (2012) con respecto a España, muestran que el empleo de formas $\mathrm{T}$ ha experimentado un incremento espectacular como mejor forma de materializar los valores de democracia (de comunismo en el caso de la antigua Yugoslavia) y de diluir lo máximo posible las divergencias sociales.

\subsection{La cortesía a nivel universal}

Las expresiones de cortesía suelen codificarse lingüísticamente de tres maneras: la tercera persona, la pluralidad, la forma abstracta (Siewierska 2004). En el primer caso, tenemos la situación del italiano estándar, con el pronombre lei (Rohlfs 1968) o incluso el francés, que, en contextos de extrema formalidad, recurre a il/elle como método para marcar respeto.
(1) Et, monsieur, qu'est-ce qu'il désire?
Y, señor, qué es lo que 3sG.NOM desear-3sG.PRES.IND. ('Y, señor, ¿qué desea usted?')

Aunque en la oración (1), monsieur es el referente y antecedente de il, tercera persona del singular masculino, el empleo de la 3 sg aumenta el grado de deferencia en comparación a la otra posible formulación reflejada en la oración (2).
(2) Et, monsieur, qu'est-ce que vous désirez? $\mathrm{Y}$, señor, qué es lo que 2PL.NOM. desear-2PL.PRES.IND. ('Y, señor, ¿qué desea usted?')


También en el español peninsular se han dado a lo largo de la historia otros pronombres de tercera persona para marcar cortesía: él, ella. Sin embargo, Lapesa (2000) apunta que el trato de este pronombre sin ningún honorífico previo que lo antecediera no se consideraba lo suficientemente respetuoso entre hidalgos. Así, en el siglo XVII, se encuentran numerosos comentarios del carácter menos respetuoso de él, ella, ya que no se explicitaba el sustantivo merced y, por tanto, era visto como una negación por parte del hablante de la merced de su interlocutor. Aunque el uso de él, ella era real, estaba marcado socialmente y significaba torpeza a la hora de saber dirigirse a un interlocutor en un trato ascendente. Esta característica se representaba en obras del Siglo de Oro para caricaturizar a los hablantes más iletrados, como se ejemplifica en La Dorotea, de Lope de Vega.

Quedo, señora dama, quedo; que si a mí me pierden el respeto, ella ha dado la causa (Lapesa 2000: 335).

El empleo de él / ella aún permanece de manera residual en el judeoespañol y en áreas asturianas, así como en la franja occidental de Castilla y León, hasta Salamanca (Lapesa 2000, Lara 2018).

En el caso de la estrategia de la pluralidad, es sobradamente conocido que el francés opta por la misma para marcar cualquier respeto (vous), sin distinguir el número de interlocutores:

When oppositions in the grammatical category of number are used to signal social deixis, non-singular number is typically associated with greater social distance, status or respect than the singular number (Siewierska 2004: 216).

Pero no es la única lengua. El rumano puede comportarse de manera semejante (Cojocaru 2003, Roibu \& Constantinescu 2010, Heine \& Song 2011). Aunque existe una forma en singular, dumneata, la forma plural, dumneavoastra, es la menos marcada y muestra cortesía independientemente del número de referentes. Ambas proceden de sintagmas nominales formados por el sustantivo domnia 'merced', 'gracia' y el posesivo (ta para singular, voastra para plural). El proceso de gramaticalización y de estabilización de estas formas como honoríficos en rumano procede del auge que la sociedad feudal experimentó en Rumanía entre los siglos $\mathrm{x}$ y xIV, que impuso dichas fórmulas. Estas fórmulas terminaron su proceso de gramaticalización en el siglo XVI. En el siglo XIX, dumneata y 
dumneavoastra concurrieron como formas de cortesía, sin que entre ellas hubiera una diferencia en el grado de deferencia. Fue a principios del siglo $\mathrm{xx}$ cuando dumneavoastra se especificó como pronombre de formalidad mayor que dumneata, que quedó para un contexto semiformal.

Muchos de los tratamientos que hoy día se conjugan con una tercera persona provienen de antiguos sintagmas nominales que, con el paso del tiempo, han terminado gramaticalizándose, dando como resultado un pronombre, cuya única función es expresar cortesía (Siewierska 2004: 224). Aparte de vuestra merced o a vossa mercê, el holandés sufrió un cambio análogo. Su forma actual es $U$, cuya evolución procede de Uwe Edelheid 'vuestra nobleza' (Booij 2002). Helmbrecht (2005) revisa las distintas estrategias de cortesía pronominal en las lenguas europeas y llega a la conclusión de que existen tres posibilidades: la falta de distinción pronominal; la distinción binaria o ternaria en la segunda persona; la distinción binaria o ternaria en la tercera persona. De acuerdo con el autor, las lenguas que se proveen de una diferenciación cortés en la tercera persona para un referente externo, que no se encuentra presente en el momento de la comunicación, forzosamente poseen una distinción pronominal en la segunda persona. Asimismo, Helmbrecht concluye que los pronombres actuales de tratamiento formal pueden derivar de sintagmas nominales (como vuestra merced-usted), de antiguos o actuales pronombres de segunda persona del plural (como you / vous), de pronombres de tercera persona del singular (en bajo-alemán), de pronombres de tercera persona del plural (como en alemán estándar Sie) o de reflexivos (en húngaro), tal como muestra el mapa 1. 


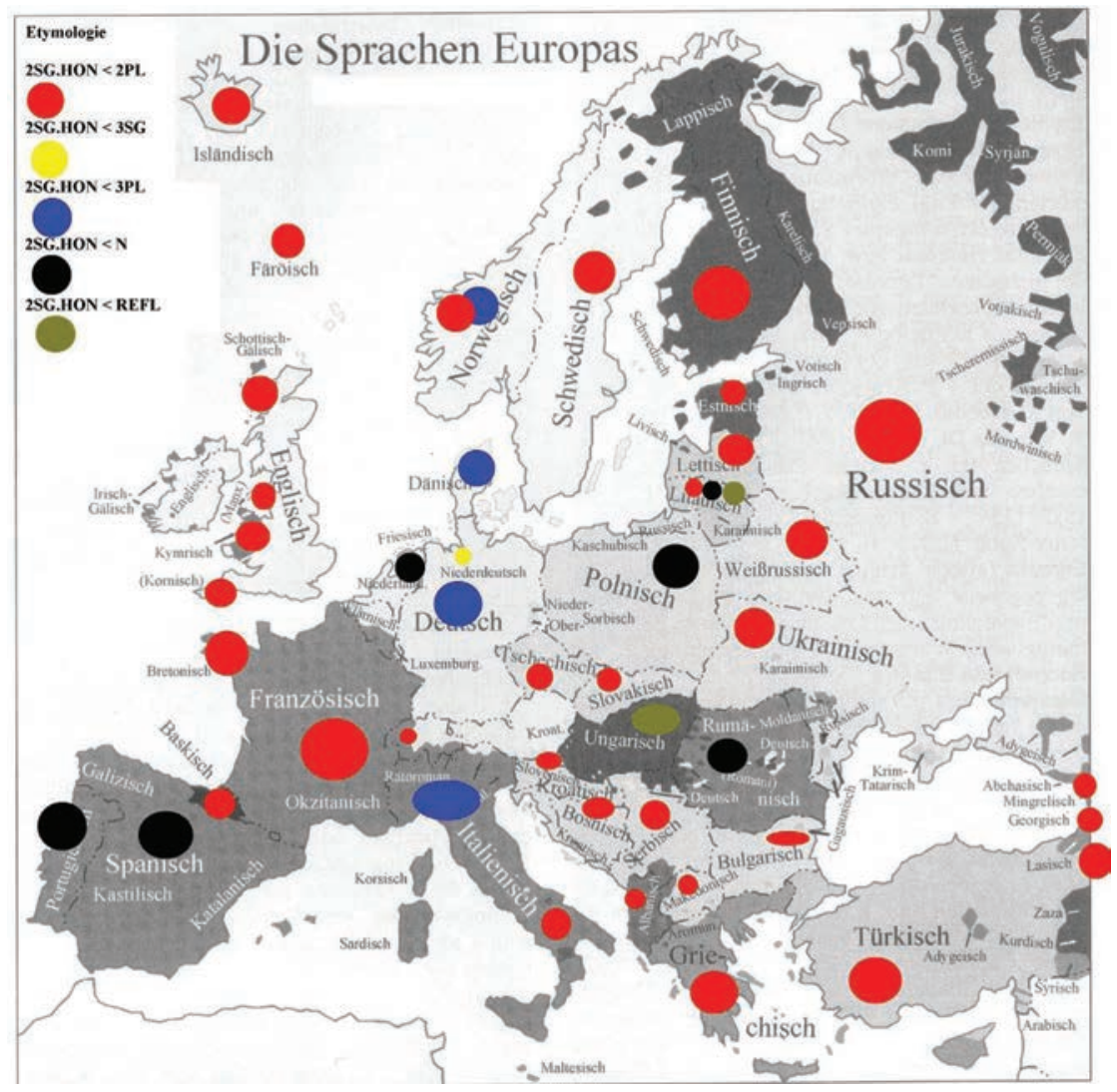

Mapa 1: Estrategias de cortesía en Europa (Helmbrecht 2005: 438).

Independientemente de la forma de tratamiento, la inducción de la tercera o la segunda persona sí parece ser clave para expresar un grado mayor o menor de cortesía. De igual modo, el número gramatical puede aumentar o disminuir la distancia con el interlocutor. Es la combinación de ambas estrategias la que da como resultado una jerarquía que Head (1978) propuso en su estudio lingüístico y que se reproduce en (i).

(i) $2 \mathrm{sg}>2 \mathrm{pl}>3 \mathrm{sg}>3 \mathrm{pl}$

El continuum especifica que si una lengua emplea la categoría de número para expresar cortesía, el no singular será el preferido para connotar un mayor grado de deferencia. Asimismo, si una lengua elige la categoría de 
persona, la tercera siempre dará un matiz de mayor respeto. Si ambas se combinan, observamos que la $3 \mathrm{sg}$ es más formal que la $2 \mathrm{pl}$, mientras que la $3 \mathrm{pl}$ es la estrategia más cortés de todas, mientras que la 2 sg connota la mayor informalidad. De acuerdo con este estudio, no es de extrañar que ya el latín escogiera TU y reservara para el plural (vos) la formalidad, aunque terminó incluyendo otros elementos abstractos que obligaban a la $3 \mathrm{sg} / 3 \mathrm{pl}$ para expresar más cortesía, como MAIESTAS VOSTRA (Châtelain 1880).

No obstante, las lenguas que no tienen una flexión rica o semi-rica en su paradigma verbal materializan la cortesía mediante otros medios. Es ahí cuando surgen numerosas formas de tratamiento que tratan de establecer una distinción entre los interlocutores de acuerdo con su posición social, parentesco o edad (si bien suele haber una forma generalizadora, ya que no es siempre posible conocer de antemano la posición social de nuestro interlocutor). Braun (1988) expone que el inglés de Estados Unidos diferencia el grado de cortesía en función del empleo del nombre o el apellido de la persona. Según la investigación, el contexto T se suele reflejar apelando al interlocutor con su nombre de pila, mientras que la distancia se aplica añadiendo al apellido el título correspondiente al estatus del interlocutor (sir Smith, professor Brown). También resulta un terreno fértil para circunloquios u otras estrategias sintácticas (condicional, verbos modales) o pragmáticas (pregunta, evasión del imperativo).

Sin embargo, la permanencia de una forma de tratamiento particular (ya sea pronominal o nominal) no siempre es exitosa. De hecho, cuando una forma ( $\mathrm{T}$ o $\mathrm{V}$ ) se vuelve ampliamente difundida en el espectro social, suele suceder una de las siguientes alternativas: o la universalización del tratamiento pierde su valor original y adopta uno nuevo o lo acaba perdiendo sin alcanzar ningún valor específico, conllevando a la desaparición o marginalización de dicha forma. Dentro de la primera hipótesis encontramos el caso de you, en inglés. Su uso primero fue el de segunda persona del plural (2pl) y forma de cortesía al estilo de vous en francés, pero acabó generalizándose para cualquier tratamiento, desplazando a la forma thou (2sg) (si bien la antigua forma aún se atestigua en el norte de Inglaterra, Evans 1969). Esta universalización de you provino de las clases elevadas, que se trataban así como forma distintiva. Poco a poco, se extendió a las clases medias y terminó ocupando todo el espectro social (Howe 1996, Raumoling-Brunberg 2005, Walker 2007).

La segunda posibilidad puede ejemplificarse mediante el pronombre vós del español medieval. Su uso fue heredado de la situación del latín 
tardío, donde el pronombre servía para dirigirse a una persona de manera formal y a un grupo de personas tanto en un contexto formal como informal (Cano 2004, Eberenz 2000, Menéndez Pidal 2005). Sin embargo, el surgimiento de dicha forma sirvió para dirigirse al emperador, en contraposición al resto de la sociedad. Su generalización ya se atestiguaba en el español más temprano y, con el tiempo, los hablantes percibieron que ya no comportaba la carga de cortesía del inicio, por lo que, incluso, en el siglo XVI-XVII, su empleo era ofensivo y acabó desapareciendo en el español peninsular.

Ya sea en el contexto de la desaparición de una forma de tratamiento o su ulterior especialización distinta a la primera para la que fue creada, se produce cierta inestabilidad e incerteza por parte de los hablantes de cómo dirigirse a los demás. Es ahí cuando empiezan a surgir nuevas formas que sustituyen las desgastadas o las niveladas que ya no poseen ninguna distinción pragmática. Niculescu (1974) apunta para el caso del italiano las innovaciones vostra signoria ('vuestra señoría') o vostra eccellenza ('vuestra excelencia'), como manera de suplir el tradicional voi, cuyos usos se entremezclaban con los de $t u$. Hickey (2003) y Heine \& Song (2011) apuntan que la alta jerarquización de la sociedad germana en el siglo XVII influyó en el esparcimiento de la forma Eure Gnaden ('vuestras gracias') como método de discernir las clases más elevadas de las más bajas, puesto que, previamente, el pronombre $i h r$ se empleaba para cualquier trato formal, independientemente del estatus social.

Cabe preguntarse si esta tendencia relativamente frecuente de supleción de una forma por otra ocurre en mayor medida en contextos $\mathrm{V}$ o T. Aalberse \& Stoop (2015) afirman que el inglés y el holandés son excepcionales porque, a diferencia de otras lenguas indoeuropeas, en las que el pronombre $\mathrm{T}$ es estable, en estas dos ha sido desbancado por un pronombre V. Sin embargo, los autores no han tenido en cuenta, al menos, la situación del portugués y español americanos, donde los pronombres $\mathrm{V}$ han desbancado en mayor o menor medida los pronombres $\mathrm{T}$. De acuerdo con Hummel et al. (2010), usted es el pronombre T en ciertas capas sociales, sin que haya ocurrencias de tú. En casi todas las zonas geográficas de Brasil, você en singular ha copado los usos de $t u$ y es, actualmente, el pronombre $\mathrm{T}$, cuando, en inicio, era $\mathrm{V}$. En plural no existe vestigio de vós, siendo vocês, antiguo pronombre $\mathrm{V}$, la forma $\mathrm{T}$. Uno de los rasgos más característicos del español americano es el voseo, es decir, el empleo del antiguo vos (forma $\mathrm{V}$ ) como pronombre de intimidad (forma T). En plural, 
el español hablado en América no conoce la forma T vosotros (cuyos últimos vestigios se remontan al siglo XIX) y usa la forma V, ustedes, para contextos T (Hummel et al. 2010).

$\mathrm{Y}$ es precisamente la inestabilidad de la forma $\mathrm{T}$ en plural lo que ha promovido este estudio, circunscrito al ámbito del andaluz y el portugués europeo. A continuación, detallaremos el estado de la cuestión sobre ambos fenómenos, cuyo comportamiento analizaremos pormenorizadamente en capítulos posteriores.

\subsection{La cortesía en español peninsular}

En español, los pronombres o las formas de tratamiento se han ido modificando con el paso de los siglos, para satisfacer las necesidades pragmáticas de los hablantes. Como ya hemos indicado, el paradigma de segunda persona que, en primera instancia, se manifestó en español fue el heredado del latín. Así, en época medieval, el sistema responde al representado en la tabla 1:

Tabla 1: Pronombres de tratamiento del español medieval y formas concordantes.

\begin{tabular}{|l|l|l|l|l|}
\hline & SUJETO & CLÍTICO & $\begin{array}{l}\text { TÉRMINO DE } \\
\text { PREPOSICIÓN }\end{array}$ & POSESIVO \\
\hline INFORMAL SINGULAR & Tú & Te & Ti / contigo & Tuyo \\
\hline INFORMAL PLURAL & Vós & $($ V)os & Vós & Vuestro \\
\hline FORMAL SINGULAR & Vós & $($ V)os & Vós & Vuestro \\
\hline FORMAL PLURAL & Vós & $($ V)os & Vós & Vuestro \\
\hline
\end{tabular}

De hecho, para Cano (2008: 135), nós y vós podían usarse con valor singular: nós, por las altas jerarquías y vós, en el tratamiento entre nobles; ambos usos arrancan del latín tardío. El trato de vós se usaba de manera ascendente o en tratos de informalidad entre iguales de alto rango, mientras que tú solo podía emplearse de manera descendente o en un contexto muy familiar y de intimidad. La historia de vós es análoga a lo ya especificado con respecto al vos latino. Si bien al principio su uso se restringía al rey, las capas altas de la sociedad (nobleza y clero) empezaron a exigir ser tratados por vós. Con el paso del tiempo, la alta burguesía, debido a su 
condición adinerada y de poder, reclamó de igual manera ser tratada por vós, ya que aspiraba a asemejarse en su estatus a la clase más elevada. De esta manera, el pronombre poco a poco se fue generalizando y haciendo extensivo a mayor cota de población, por lo que su connotación deferencial fue perdiendo valor paulatinamente (Lapesa 2000, Cano 2004, Menéndez Pidal 2005). En el siglo XVII, el empleo de vós revirtió su uso primigenio y pasó a utilizarse de manera despectiva o en un trato descendente, de superior a inferior. Su convivencia con nuevas formas de tratamiento, como vuestra merced, vuestra majestad, vuestra excelencia o vuestra señoría, así como su carácter altamente sincrético, favoreció su progresivo desuso hasta su desaparición (su obsolescencia en el español peninsular se ha fechado a finales del siglo XVII) a favor, por un lado, de ustedes, como nueva forma genérica de deferencia, y vosotros, como nuevo pronombre de segunda persona de plural.

La polivalencia que vós adquirió a lo largo del español medieval permitió que surgieran nuevas formas que compitieron con este pronombre para referirse a una segunda persona del plural. De entre todas las que surgieron (vós todos, vós mismos), fue el sintagma vós otros (junto con nós otros) el que acabó imponiéndose en la lengua. La primera documentación de vós otros data del siglo XIII, pero fue entre los siglos XIV y XV cuando se incrementa su frecuencia, pugnando con vós por la 2 pl. En principio, esta forma se caracterizaba por su contraste frente a vós, es decir, contraponía las nociones de exclusión-inclusión con respecto al interlocutor:

[el rey a sus vasallos] e tajemosles las cabeças. E sobredes dos de vos otros al tejado de la camara con las cabeças, mostrandolas a todos, e dezit a grandes bozes: "Muertos son los traydores Rages e Joel [...]" (El cavallero de Zifar, apud De Jonge \& Nieuwenhuijsen 2012: 250).

Sin embargo, su aparición llegó a copar poco a poco todos los usos de vós con referencia $2 \mathrm{pl}$ informal. Precisamente esa polivalencia de vós, el fuerte sincretismo que dicho pronombre tenía, ya que hacía referencia a varias personas gramaticales ( $2 \mathrm{sg}$ y $2 \mathrm{pl}$ ), en distintos contextos sintácticos (pronombre tónico y átono) y en diferentes ámbitos pragmáticos (formales e informales), así como la progresiva depreciación de su significado (recordemos que al final de su existencia su empleo era peyorativo), provocó que triunfara la forma compleja. Por tanto, vós otros evolucionó de su uso contrastivo inicial y se lexicalizó en la actual forma vosotros con referencia 2pl informal (Rini 1999). 
Según Gili Gaya (1946), Spìtzer (1947), Alvar \& Pottier (1983), Nowikow (1994) y De Jonge \& Nieuwenhuijsen (2012), el uso de vosotros está plenamente establecido en el español peninsular en los siglos XV y XVI. Esto se aprecia bien al comparar los dos manuscritos de El libro de Calila e Dimna, uno de finales del siglo xIV y otro de finales del Xv. Si cotejamos el mismo pasaje en el intervalo de un siglo, encontramos el siguiente contraste:

E dixoles: "Vos sodes mis hermanos e mis amygos para demandar el tuerto que yo rresçibi; pues ayudadme e guysad commo aya derecho, ca bien podria acaesçer a vos lo que a mi acaesçio" (De Jonge \& Nieuwenhuijsen 2012: 251).

E dixoles: "Vos otros sodes mis hermanos e amigos para caluniar el tuerto que yo rreçeby; pues ayudatme e guisat commo yo aya derecho, ca puede ser que vos acaezca a vosotros lo que acaeçio a my" (De Jonge \& Nieuwenhuijsen 2012: 251).

Si comparamos dos versiones del Zifar, una manuscrita del siglo xv y la otra impresa de principios del xvi, observamos el asentamiento de nosotros y vosotros como pronombres de primera y segunda personas del plural:

“Ay amigas sseñoras!” dixo el vno dellos, "e ¿por que vos amanesçio mal dia por la nuestra venida? ca sabe Dios que nos non cuydamos fazer enojo a ninguno nin ala vuestra señora nin a vosotras, nin somos venidos a esta tierra por fazer enojo a ninguno [...]" (De Jonge \& Nieuwenhuijsen 2012: 252).

“Ay amigas o señoras!” dixo el vno dellos, “e ¿por que vos amanesçio mal dia por nuestra venida? que sabe Dios que nosotros non pensamos fazer enojo a ninguno nin a vuestra señora nin a vosotras, nin somos venidos a esta tierra por fazer enojo a ninguno [...]" (De Jonge \& Nieuwenhuijsen 2012: 252).

Para Nieuwenhuijsen (2006), vosotros ofrecía unas ventajas comunicativas evidentes, ya que desambiguaba el número gramatical de la segunda persona y se oponía a vos átono, que no llegó a perder la consonante labiodental hasta finales del siglo XV.

Igual suerte tuvo nós otros, que se lexicalizó en nosotros sustituyendo a nós, con un valor de exclusión-inclusión inicial, pero que se generalizó más tarde para todos los uso de 1pl. Para Gili Gaya (1946), nós otros no solo excluía la pluralidad de la segunda persona, sino que el que expresaba nós otros se excluía también de una tercera o cuarta, es decir, quería diferenciarse de cualquier otro, independiente del número gramatical del o de los excluidos. Así, da dos ejemplos del Calila e Dimna, en el siglo XIII, como ejemplos más tempranos hallados de nós otros: 
[...] mas tome cada vno de nós otros quanto despienda e soterremos los que y fincaren en algunt lugar apartado (Gili Gaya 1946: 54).

[...] Si pudieres gujsar que seas y con nós otros, con consentimiento de mi marido e con su plazer, fazlo (Gili Gaya 1946: 190).

Sin embargo, el uso de nós otros sigue siendo excepcional aún en el siglo XIV. Hay que tener en cuenta, además, que el Calila e Dimna es un texto que representa la lengua del siglo XIII con muchas dificultades, dado lo tardío de los manuscritos.

Ante la duda de qué forma fue la primera (nós otros o vós otros), Gili Gaya compara los casos de otras lenguas romances donde surgió o se da dialectalmente la forma compleja. La ocurrencia de voi alteri en dialectos septentrionales de Italia, donde no se da no obstante noi alteri, ya llevó a Meyer-Lübke a concluir que fue en la segunda persona del plural donde nació la coda alteros y que se propagó por analogía a la primera persona del plural. Esta opinión sigue siendo la más generalizada.

García et al. (1990) analizan la correlación del surgimiento de vós otros / nós otros con la depreciación de vós y la erosión fonética del pronombre átono vos en os. Por un lado, la aparición de vós otros incitó la analogía de la primera persona del plural, ya que era la polivalencia de vós la que hacía, por cuestiones comunicativas, necesario romper la fuerte ambigüedad. Si bien los usos primigenios fueron de carácter enfático y contrastivo, el hecho de que vosotros y nosotros aparecieran siempre en contextos sintácticos tónicos, es decir, como sujeto y, sobre todo, como término de un sintagma preposicional (en español no es necesario explicitar el sujeto y, por tanto, resulta más forzada su aparición dentro de la oración) funcionó como aclarador del referente de los interlocutores. Aunque es cierto que la urgencia comunicativa no hace necesario, en principio, precisar el referente en la primera persona, esta pudo haber imitado a la segunda persona del plural por la alta relación paradigmática que ambos pronombres tienen. Además, en la primera persona del plural, gracias a la innovación nosotros, también se habría roto el sincretismo entre pronombre tónico nós y átono nos. Sin embargo, para estos autores, las ventajas comunicativas del uso de vosotros son incontestables para concretar el referente (recordemos que vós hacía referencia a una segunda persona del singular formal, una segunda persona del plural informal y una segunda persona del plural formal), ya que solo puede aludir a una $2 \mathrm{pl}$ informal. Además, tanto nosotros como vosotros eran incontestablemente plurales, 
mientras que vós no siempre lo era y nós podía usarse con un valor mayestático.

Puesto que el valor contrastivo de vós otros se daba con respecto al vós singular, resolviendo el problema del número gramatical, estos autores argumentan que las formas en otros tuvieron que surgir antes en la segunda que en la primera persona y, a su vez, antes en contextos de contraste que en contextos neutros.

Junto con la lexicalización de vosotros aparecen numerosos sintagmas nominales como formas de tratamiento de respeto. De entre ellas, vuestra majestad era la elegida para la alocución al rey; vuestra excelencia para la nobleza, vuestra señoría para el clero y, como forma genérica, vuestra merced. Esta última era la empleada de manera ascendente hacia las capas de la sociedad que no encajaban en las definidas por las otras fórmulas. La falta de acuerdo social en las fórmulas de tratamiento era evidente, por lo que, como ya hemos apuntado, Felipe II llegó a legislar con qué fórmula se trataba a qué espectro de la sociedad. Esta obra fue la Premática en que se manda guardar la de los tratamientos y cortesías, de 1583. Incluso Juan de Luna en 1619 describió qué tratamientos se dirigían a qué ámbito de la sociedad, ya que creía necesario fijar los márgenes que se estaban perdiendo.

El primero y más baxo es tú, que se da a los niños, o a las personas que queremos mostrar grande familiaridad o amor. Vos se dice a los criados o vasallos. Vuesasté, vuesa merced, vuestra merced, que significan una mesma cosa, se da a todos, grandes y pequeños. Vuestra señoría, a los condes, marqueses y obispos, a los cuales se debe de derecho. Vuestra excelencia, a los duques, virreyes, y generales de armadas. Vuesa alteza, a los hermanos del rey o a los príncipes soberanos. A los reyes, vuesa magestad. A los cecesiásticos se dice vuesa merced, como al común de los legos. A los frailes, vuesa reverencia. A los prelados de un monasterio, vuesa paternidad [...] (Lapesa 2000: 319, apud Schevill - Bonilla 1914: 329-330).

Vuestra merced aumentó su frecuencia conforme el paso de los años (entre otras cosas por la pujanza de una burguesía y de un nuevo estamento que se negaba a recibir vós e imponían un trato más respetuoso, Tuten 2008, Líbano Zumalacárregui 1991), se generalizó como forma no marcada de cortesía y, a su vez, experimentó un proceso de gramaticalización, con su correspondiente pérdida de peso fónico (vuessa merced, vuessansted, voacé, vuested, vusted, usted) (Pla Cárceles 1923). De ahí surgió su reanálisis como forma alocutiva formal por defecto y como pieza gramatical, expresada en un pronombre (usted-es) cuya referencia era una segunda persona 
de deferencia. Según la documentación, la forma usted(es) se asienta como paso último en la evolución de vuestra merced solo en el siglo XVIII.

El español peninsular actual mantiene un sistema bimembre de tratamiento en la segunda persona. Así, los pronombres correspondientes a la informalidad son tú para el singular y vosotros para el plural, y a la formalidad son usted para el singular y ustedes para el plural. Las relaciones de simetría se marcan con desinencias de segunda persona, mientras que el respeto obliga a concordancias de tercera (tabla 2).

Tabla 2: Pronombres de tratamiento del español europeo contemporáneo y formas concordantes.

\begin{tabular}{|l|l|l|l|l|l|}
\hline & SUJETO & CLÍTICO & VERBO & $\begin{array}{l}\text { TÉRMINO DE } \\
\text { PREPOSICIÓN }\end{array}$ & POSESIVO \\
\hline FORMAL SG & Usted & $\mathrm{Se} / \mathrm{la} / \mathrm{lo} / \mathrm{le}$ & $3 \mathrm{sg}$ & Usted & $\mathrm{Su}$ \\
\hline INFORMAL SG & Tú & $\mathrm{Te}$ & $2 \mathrm{sg}$ & $\mathrm{Ti} /$ contigo & $\mathrm{Tu}$ \\
\hline FORMAL PL & Ustedes & $\begin{array}{l}\mathrm{Se} / \text { las } / \mathrm{los} / \\
\text { les }\end{array}$ & $3 \mathrm{pl}$ & Ustedes & $\mathrm{Su}$ \\
\hline INFORMAL PL & Vosotros & Os & $2 \mathrm{pl}$ & Vosotros & Vuestro \\
\hline
\end{tabular}

Este cuadro es el resultado de los distintos cambios que a lo largo de los siglos ha ido sufriendo el sistema de alocutivos en el español, de acuerdo con las reconstrucciones históricas más generalizadas. Sin embargo, Fernández (2012) supone en su tesis doctoral la relativa incorporación tardía de vosotros como alocutivo informal en el español peninsular. Gracias al manejo de un corpus documental suministrado por gramáticas, diccionarios de uso, piezas literarias menores, cartas, manuales de español para extranjeros y documentos judiciales, como confesiones, actas de juicios en los que se transcribía literalmente las versiones de los testigos e imputados y demás escritos en los que era obligatorio reflejar el habla del individuo, independientemente de la norma, la autora expone que, en el siglo XVIII, vosotros se encontraba muy limitado en la oralidad. De hecho, eran las clases altas las que más manejo de vosotros tenían, ya que lo utilizaban para dirigirse a sus inferiores $\mathrm{y}$, a su vez, como fórmula de intimidad y familiaridad con sus iguales. Asimismo, el aumento del tuteo en las esferas elevadas de la centuria de 1700 pudo motivar el mantenimiento de vosotros. Por ello, la autora concluye que, debido al empleo tan reducido de vosotros, el pronombre $2 \mathrm{pl}$ no marcado tenía que ser ustedes, por lo que la situación actual del español peninsular estándar se fraguó 
en la época y tuvo su impulso en el siglo XIX. Es en Andalucía occidental donde la evolución se vio frenada por un estamento terrateniente muy reacio a tolerar que sus subalternos los trataran por vosotros, por lo que, de acuerdo con la autora, el empleo de ustedes se mantuvo como fórmula de respeto, aunque no llevó aparejado la concordancia en tercera persona. Esta situación resulta similar a la situación actual del español ecuatoguineano, donde se utiliza ustedes más desinencia de segunda persona. Para Lipski (2011), ello se debe a que los colonos trataban en segunda persona a la población, pero esta tenía obligación de usar ustedes. La recepción de la segunda persona, pero la emisión constante del pronombre ustedes produjo el hibridismo. Fernández (2012) no aclara esta posibilidad en la Andalucía de la época, pero sí afirma que la confusión se empezó a dar durante el siglo XVIII. De la misma opinión son Alvar et al. (1965-1968), Mondéjar (1970), Fontanella de Weinberg (1999), Lapesa (2000), Carrasco Santana (2002), Cano (2004), Penny (2004), Menéndez Pidal (2005), RAE (2009), que circunscriben la génesis del fenómeno a dicha centuria y a las provincias de Huelva, Cádiz, Sevilla y, en menor medida, Córdoba y Málaga.

La motivación pragmática para Fontanella de Weinberg (1992) o Lipski (1996) se justificaría por la amalgama de clases sociales que concitó el descubrimiento de América y que coincidieron en Sevilla a la espera de partir al Nuevo Mundo. Por tanto, según esta hipótesis, la nivelación a ustedes, el pronombre de deferencia, pretendía no ofender a los de estatus más elevado o, simplemente, utilizarlo era una forma de resolver el conflicto que suscitaba la heterogeneidad de un grupo dentro del cual había personas a las que el interlocutor podía tratar con confianza, pero otras a las que debía mostrar respeto.

En cuanto al comportamiento gramatical de clíticos y formas verbales, así como del posesivo, todos los autores convergen en afirmar que ustedes se concuerda sistemáticamente con una $2 \mathrm{pl}$, a excepción del pretérito perfecto simple, cuya flexión se construiría en 3pl, sin ningún tipo de vacilación. En cuanto a los pronombres átonos, estos también adoptarían una morfología de $2 \mathrm{pl}$, salvo en el reflexivo, cuya solución más frecuente es se, en combinación con un verbo en $2 \mathrm{pl}$ (ustedes se caéis). Asimismo, el posesivo se habría resuelto en el sintagma de ustedes. Solo RAE (2009) afirma que existen registros de la concatenación de vosotros más ustedes como se ejemplifica en (3): 


\section{(3) Vosotros ustedes sois hermanos}

Hasta la localización de los materiales extraviados del Atlas Lingüistico de la Península Ibérica, la distribución geográfica de este fenómeno en Andalucía solo podía estudiarse en el Atlas lingüistico y etnográfico de Andalucía (ALEA), elaborado por Manuel Alvar a principios de la segunda mitad del siglo Xx, con Gregorio Salvador y Antonio Llorente. Tras encuestar más de doscientos enclaves de la geografía andaluza, el ALEA ofrece mapas con las transcripciones de palabras y frases obtenidas de la repetición de un cuestionario elaborado al efecto. En su recopilación, observamos ejemplos del uso del pronombre vosotros como forma de tratamiento informal de segunda persona de plural. En el mapa 1.822, aparecen cartografiadas las variantes dialectales, con una clara dicotomía entre ustedes en Andalucía occidental y vosotros en las provincias orientales. Asimismo, el ALEA ofrece mapas del área en el que ustedes se concuerda con una flexión verbal de segunda del plural, rasgo que acota a las provincias de Huelva, Sevilla, Cádiz, Málaga y la margen izquierda del Guadalquivir en Córdoba. Según el ALEA, en todas las circunstancias en las que un pronombre personal tiene la significación de vosotros, Andalucía occidental prefiere ustedes con una conjugación en segunda persona del plural. Asimismo, no existiría ustedes como variante informal de vosotros en Jaén, Almería y Granada y en partes de Córdoba, áreas donde ustedes siempre tendría una referencia cortés, cuya flexión verbal correspondería sistemáticamente a la tercera del plural.

De igual forma, el ALEA, en su mapa n. ${ }^{\circ} 1.872$, especifica el tipo de interlocutor al que se dirige la pregunta en cuestión: ¿Adónde vais (niños)?, comparándolo con los mapas $1.873,1.874$ y 1.875 , cuyos interlocutores corresponden a amigos, abuelos y ustedes respectivamente. Los resultados muestran una sistematización en el uso del pronombre personal ustedes, independientemente del grado de confianza del interlocutor, y una flexión verbal de segunda persona del plural en Andalucía occidental. En cambio, los datos atestiguan una distinción clara en Andalucía oriental de la simetría en la jerarquía social entre los interlocutores, optando por ustedes en los casos en los que la pregunta va dirigida a ancianos y desconocidos y por una concordancia de tercera persona del plural. En la lámina respectiva a los amigos, Andalucía oriental prefiere vosotros y la concordancia en segunda persona del plural.

Con respecto al pronombre átono os, el mapa 1.823 del sexto tomo reduce todas sus funciones sintácticas al mismo patrón de conducta de los 
hablantes. Es decir, los resultados elaborados en el ALEA para este rasgo concreto ponen en la misma escala os con valor de dativo no argumental, en régimen de complemento directo, indirecto, o reflexivo, lo cual suscita ciertas dudas, ya que la extensión gramatical de la concordancia suele estar regida por ciertas jerarquías. Es más, como veremos a lo largo del estudio, los datos del ALPI referidos a esta particularidad difieren de los del ALEA, y permiten realizar un análisis más exhaustivo a la hora de analizar la extensión de la concordancia a las formas verbales y pronominales. Por tanto, aunque el ALEA es una fuente de documentación valiosa para el estudio dialectal de Andalucía, resulta insuficiente para el estudio de la gramática, quizás porque sus creadores dieron más importancia al aspecto fonético y léxico.

\subsection{La cortesía en portugués europeo}

El portugués europeo ha seguido una senda similar a la del andaluz occidental. Aunque su evolución del latín dio como resultado un paradigma de tratamientos idéntico al del español (tabla 3), el uso masivo de vós para todos los estratos sociales propició la aparición de nuevas formas de cortesía en la misma época que aconteció en el español peninsular.

Tabla 3: Pronombres de tratamiento del portugués antiguo.

\begin{tabular}{|l|l|l|}
\hline & FORMAL & INFORMAL \\
\hline SINGULAR & Vós & Tu \\
\hline PLURAL & Vós & Vós \\
\hline
\end{tabular}

A pesar del fuerte sincretismo, la opción vós outros no acabó imponiéndose, por lo que vós se mantuvo como pronombre 2pl informal (Cintra 1972). Sin embargo, el antiguo empleo polivalente de alocutivo formal fue cediendo en singular a formas innovadoras como a vossa majestade, a vossa excelência, a vossa senhoria o a vossa mercê. La historia de la evolución de a vossa mercê hasta el actual você es análoga a la de vuestra merced-usted. Originariamente -los ejemplos más antiguos son del siglo XIV-, a vossa mercê era la fórmula empleada para dirigirse al rey, que era el único capacitado en otorgar mercedes. Sin embargo, el empeño 
de las clases altas en asemejarse pragmáticamente con lo más elevado de la sociedad provocó que este sintagma se usara también para nobles y clérigos afines y cercanos al rey y, posteriormente, para todo el estamento nobiliario (Faraco 1996, Menon 2006):

Vossa Mercee saberá que pelos vertuosos Rex passados foram dados certos privilegios e liberdades aos moradores desta cidade d Evora [...] Senhor seja Vossa Mercee de nom consentirdes tall agravo nos ser feito e nos manter as ditas liberdades [...] (Menon 2006 apud Évora: 75-79 [287-291], XXXVII Capitulos de Cortes, 1456).

Más tarde, la alta burguesía, en muy buena condición por su estatus económico, exigió ser tratada por a vossa mercê por clases más bajas de la sociedad, por lo que la utilización de esta fórmula se fue generalizando paulatinamente, hasta ser la forma por defecto de tratamiento respetuoso. Para suplir los usos tan elitistas que dicha forma tenía originariamente, se impuso a vossa majestade para el rey y a vossa excelência y a vossa senhoria para la nobleza y el clero, respectivamente. Al igual que en el español de la misma época, a vossa mercê podía combinarse con formas verbales $2^{\mathrm{a}}$ y $3^{\mathrm{a}}$ personas, a pesar de que sintácticamente fuera un sintagma nominal. La ausencia de pronombre favorecía la morfología verbal de $2 \mathrm{pl}$, mientras que su explicitación inducía la $3 \mathrm{sg}$. Su frecuencia de uso propició su gramaticalización, ya que fue evolucionando a vossemercê, vossemecê, vosmecê, voncê, vossê, hasta terminar en el actual você (tabla 4).

Tabla 4: Pronombres de tratamiento del portugués moderno.

\begin{tabular}{|l|l|l|}
\hline & FORMAL & INFORMAL \\
\hline SINGULAR & Você & Tu \\
\hline PLURAL & Vocês & Vós \\
\hline
\end{tabular}

Con posterioridad, el portugués contemporáneo ha generalizado en el plural la forma vocês (tabla 5), de forma semejante a lo acaecido en Andalucía occidental, Canarias y América.

Tabla 5: Pronombres de tratamiento del portugués contemporáneo.

\begin{tabular}{|l|l|l|}
\hline & FORMAL & INFORMAL \\
\hline SINGULAR & Você / O senhor & Tu \\
\hline PLURAL & Vocês & Vocês \\
\hline
\end{tabular}


A diferencia de la nivelación en Andalucía, el empleo de vocês como única forma de plural de segunda persona está plenamente asentado en la lengua normativa, siendo vós una forma totalmente desprestigiada, que aún pervive en el habla vernácula del centro-norte del país o en textos ceremoniosos y litúrgicos. Y al igual que en el caso andaluz, vocês admite discordancias en sus clíticos (tabla 6).

Tabla 6: Concordancias de vocês en el portugués europeo.

\begin{tabular}{|l|l|l|l|l|}
\hline SUJETO & CLÍTICOS & POSESIVO & VERBO & $\begin{array}{l}\text { TÉRMINO DE } \\
\text { PREPOSICIÓN }\end{array}$ \\
\hline Vocês & $\mathrm{Se} /$ Vos & O vosso & $3 \mathrm{pl}$ & $\begin{array}{l}\text { Vocês / } \\
\text { convosco }\end{array}$ \\
\hline
\end{tabular}

Si comparamos los elementos gramaticales con referencia a vocês expuestos en la tabla 6 , observamos una clara hibridación en cuanto a la persona. Mientras que el verbo, el pronombre reflexivo y el término de un sintagma preposicional, cuyo enlace no sea la preposición com, se construyen con formas de $3 \mathrm{pl}$ (como exige vocês), el posesivo, la forma preposicional de compañía y los pronombres átonos de objeto requieren formas de 2pl. Faraco (1996) afirma que el único vestigio de morfología de segunda persona del plural que resta actualmente en Portugal es el posesivo vosso, muy común en todo el país, mientras que los usos de vós son residuales en pocas variedades vernáculas. Buzaglo et al. (2013), no obstante, afirman que vós como segunda persona de plural se ha conservado en dialectos norteños, en contra de lo que ocurre en el sur y se propugna en el estándar. Sin embargo, el uso de vós para un solo alocutario ha desaparecido totalmente. El rasgo conservador y dialectal de vós como forma de tratamiento en plural se mantiene en las provincias de Viana do Castelo, Braga, Vila Real, Braganza, Oporto, Aveiro, Viseu, Guarda, Coimbra y Castelo Branco.

Esta nivelación data del siglo XVIII y no sería hasta el siglo XIX cuando la generalización se asentó (Cintra 1972, Menon 2006). Si bien no se sabe con certeza qué propició la eliminación de vosotros en Andalucía occidental, Faraco (1996) apunta que la universalización de você( $(s)$ a costa de vós en Portugal se debe a un cambio desde arriba. Para el autor, la clase alta urbana de la época se trataba por este pronombre como rasgo distintivo, lo cual provocó que la clase media quisiera asemejarse en todo a esta y, por tanto, introdujo el mismo sistema de tratamiento, hasta que acabó generalizándose 
a todas las capas de la sociedad. Este cambio, proveniente de zonas urbanas, habría sido fuertemente rechazado en áreas muy rurales, en las que, bien se mantuvo vós, bien se eligió una forma intermedia en la gramaticalización de a vossa mercê a você, como vossemecê. En cualquier caso, vocês se convirtió en la variante prestigiosa, mientras que vós, al que muchos asociaban con el uso peyorativo de ofensa en singular, terminó siendo la variante estigmatizada en el estándar. No obstante, como ya discutimos, no todos los elementos con referencia a vocês, sintácticamente de $3 \mathrm{pl}$, concuerdan con la morfología propia de la innovación, sino que los clíticos de objeto (vos), el posesivo (o vosso) y la forma seguida de la preposición com (convosco) aún mantienen desinencias propias de $2 \mathrm{pl}$ o vós.

\subsection{La cortesía en el español y portugués americanos}

Como hemos observado, ha sido la forma $\mathrm{T}$ la menos estable en ambas variedades. Pero la situación europea no es la única en padecer la inestabilidad del pronombre T. Tanto el español americano como el portugués de Brasil están inmersos en cambios lingüísticos que atañen a las formas $\mathrm{T}$ del singular, las cuales empiezan a ser desbancadas por formas que han sido tradicionalmente $\mathrm{V}$.

En el caso de las distintas variedades del español de América, el uso más descrito es el del pronombre vos en sustitución de tú. Aunque su delimitación geográfica ha sido revisada con relativa periodicidad, es su estatus social y lingüístico el que mayor atención ha suscitado. En Hummel et al. (2010) se especifica, por ejemplo, el carácter estigmatizado del que goza en la península del Yucatán frente al elemento de prestigio que representa en el Río de la Plata. Pero es su excesiva hibridación la que mayores trabajos concita, si bien de índole descriptiva. Así, el voseo puede inducir tan solo morfología tuteante o una mezcla de ambas. Y dentro de esta última categoría, puede promover distintas desinencias voseantes que varían en función del área geográfica (Kany 1996, Lipski 1996, Fontanella de Weinberg 1999, Carricaburo 1997). A ello hay que añadir una tendencia por parte de la forma usted a surgir en contextos de intimidad (Hummel et al. 2010), en pugna con tú y, a veces, con vos. 
Independientemente del estatus que posea el pronombre vos en las distintas regiones americanas, lo cierto es que, como en el caso de vocês y ustedes, induce una doble concordancia (tabla 7).

Tabla 7: Pronombres en el voseo.

\begin{tabular}{|l|l|l|l|l|}
\hline Sujeto & $\begin{array}{l}\text { Sintagma pre- } \\
\text { posicional }\end{array}$ & Reflexivo & $\begin{array}{l}\text { Acusativo/ } \\
\text { Dativo }\end{array}$ & Posesivo \\
\hline Vos & Vos & $\mathrm{Te} / \mathrm{Os}$ & $\mathrm{Te} / \mathrm{Os}$ & $\mathrm{Tu} /$ Vuestro \\
\hline
\end{tabular}

Aunque el clítico hegemónico es te, aún perviven con muy poca fuerza uso de os en Cuba y de vuestro en Uruguay (Bertolotti \& Coll 2003). La morfología verbal también presenta un comportamiento doble, ya que el voseo se manifiesta en el presente de indicativo, en el imperativo y, con matices, en el presente de subjuntivo, aunque no en el resto de tiempos (con excepciones esporádicas de ciertas formas de futuro y de perfecto simple) (Fontanella de Weinberg 1979, Bertolotti 2007).

La situación del portugués brasileño es análoga al del español de América. Mientras que, como ante la falta de distinción entre vosotros ustedes en América, tampoco cuenta con la oposición vós - vocês en plural, la situación del singular presenta una inestabilidad manifiesta, a la luz de los continuos estudios que se llevan a cabo sobre las formas de tratamiento del singular en distintas zonas de Brasil. Así, a diferencia del rechazo que parece advertirse en el pronombre você en singular en la variedad europea continental para el trato íntimo (Vázquez \& Mendes da Luz 1971, Cintra 1972, Cunha \& Cintra 1992, Brito et al. 2006, Carreira 2003, Cook 1997), el brasileño ha desechado casi por completo $t u$, y ha nivelado en você el tratamiento íntimo o informal (Brito et al. 2006). Esta innovación se ha explicado por el esfuerzo por parte de las clases medias de imitar los usos de los miembros de clase alta, los cuales se trataban por você con el fin de establecer un rasgo distintivo que los pudiera diferenciar del resto de estamentos sociales. La generalización de você a todo el espectro de la sociedad, hasta asentarse incluso en las clases trabajadoras provocó la desaparición de su connotación cortés y lo convirtió en el pronombre íntimo o informal. Las nuevas estrategias que suplieron los antiguos usos de você recayeron en los alocutivos o senhor / a senhora y sus plurales, ya que vocês (en plural) es también el pronombre informal (Lopes \& Cavalcante 2011, Rumeu 2012). 
Menon (2006) analiza una serie de cartas de varios siglos y concluye que en el siglo XIX, você se correlacionaba en usos con $t u$, tanto en Portugal como en Brasil. Fue en este último país donde triunfó la innovación y, actualmente, $t u$ se halla en zonas muy restringidas. $O$ senhor se convirtió en la forma menos marcada de formalidad en ambos países (tabla 8).

Tabla 8: Formas de tratamiento del portugués de Brasil.

\begin{tabular}{|l|l|l|}
\hline & FORMALIDAD & INFORMALIDAD \\
\hline SINGULAR & O senhor / a senhora & Você - tu \\
\hline PLURAL & Os senhores / as senhoras & Vocês \\
\hline
\end{tabular}

El uso de você se ha generalizado tanto que incluso ha evolucionado en su gramaticalización. A diferencia de en Portugal, donde el paso de a vossa mercê ha culminado en você, en Brasil se pueden hallar formas como ocê o cê como estadios más innovadores del mismo pronombre (Nascentes 1956, Scherre et al. 2009). No obstante, estos estadios parecen adecuarse más a usos condicionados socialmente, es decir, la expresión de las formas ocê y cê se correlaciona con hablantes rurales, más jóvenes y de clase baja, mientras que você aparece en mayor proporción en zonas urbanas, de clase alta y en hablantes adultos, así como en función de sujeto y referencia inespecífica (Gonçalves 2008).

Sin embargo, algunos autores empiezan a evidenciar una reutilización de $t u$ como forma igualitaria e íntima, desbancando a você en los mismos contextos en los que, previamente, este pronombre había desplazado a $t u$. Alves (2010) apunta a que $t u$ es la forma considerada estándar en la zona de Maranhão y que su uso se correlaciona con hablantes jóvenes y escolarizados. Scherre et al. (2011) comentan que tu parece ser un rasgo del portugués de Brasilia, como forma dialectal de tratamiento entre iguales, si bien la falta de concordancia con el verbo sigue siendo la norma.

\subsection{Conclusión}

Hemos visto que tanto el español y el portugués (de ambos lados del Atlántico) presentan un estadio múltiple de sus formas de tratamiento que, en algunos casos, obedece al patrón estándar y prestigioso (como el 
portugués europeo) y, en otros, se evalúan como particularidades vernáculas que contradicen la norma (como el andaluz occidental). En todos los fenómenos de estas dos lenguas que hemos mostrado, no ha habido, por regla general, un estudio exhaustivo que se encargue de analizar en profundidad el comportamiento geográfico, social y lingüístico de los mismos. Los trabajos suelen confinarse a una mera descripción donde se enfatizan las discordancias que se vienen atestiguando. Para compensar estas carencias, el trabajo que se propone tiene como finalidad recoger datos actuales sobre la nivelación de ustedes y de vocês, de acuerdo con el perfil social y geográfico de los hablantes, a través de una metodología innovadora basada en el no condicionamiento del informante. 



\section{Dialectología, corpus y metodología}

El presente trabajo se enmarca dentro del marco teórico variacionista, propuesto por Weinreich et al. (1968) y desarrollado por la sociolingüística. Esta teoría se asienta en el presupuesto de que la lengua se encuentra en continuo cambio y de que las motivaciones de los cambios que se producen en la misma se originan en el propio individuo, mientras que su difusión depende de factores extralingüísticos. Los cambios se rigen, pues, por dos patrones: uno lingüístico, que atiende a las reglas propias de la lengua en la génesis de las innovaciones; y otro extralingüístico, basado en que las características sociales de los hablantes condicionan la difusión, asentamiento o rechazo de las innovaciones.

Para medir los factores lingüísticos y extralingüísticos que influyen en el cambio estudiado, adoptaremos los conceptos de variantes y variable. En sociolingüística la variable dependiente hace referencia al aspecto lingüístico investigado, que se caracteriza por permitir varias alternativas o variantes de uso. La variable dependiente se pone en relación cuantitativa con variables independientes, lingüísticas o extralingüísticas, para poder determinar qué factores influyen en el uso investigado. Para que se produzca realmente un cambio lingüístico, una innovación tiene que haberse propagado socialmente, no basta solo con que aparezca. Hay innovaciones que no prosperan y otras que son evaluadas positivamente hasta esparcirse en la comunidad de habla.

En términos geográficos, las innovaciones pueden extenderse recurriendo, sobre todo, a dos procesos específicos. De acuerdo con Chambers \& Trudgill (1980), Chambers (1997), Hudson (2000) o Wolfram \& Schilling - Estes (2003), estos pueden atender a un modelo por ondas o contagio, basado en la idea de que una innovación surge en un punto geográfico. Este punto, también llamado foco o epicentro -ya que será el que propague con mayor ahínco las fases posteriores de la innovacióncontagia a su periferia el uso innovador, la cual, al adoptarlo, reproduce la fase inicial del foco, difundiéndolo a las zonas limítrofes que aún no comparten dicho uso. Al mismo tiempo, el foco irá transmitiendo fases posteriores del nuevo uso propuesto, tratando de contagiarlo del mismo modo. Este patrón de difusión prevé, por tanto, que en un proceso de cambio 
lingüístico, las soluciones más innovadoras dentro del mismo se hallen en el epicentro y, cuanto más nos alejemos de él, mayor probabilidad habrá de encontrar estadios anteriores o conservadores.

Mientras que el patrón por ondas solo tiene en cuenta el tiempo y el espacio como variables, los nuevos modelos de difusión lingüística incluyen además el peso demográfico de las poblaciones y las vías de comunicación (véase a este respecto también Britain 2010, 2012 o 2013). El patrón de difusión llamado jerárquico observa que la difusión de las innovaciones se produce entre núcleos de población que compartan las mismas características demográficas y que, a su vez, se hallen en cercanía. Es decir, una innovación surgida en una gran ciudad se propagará con anterioridad a otra gran ciudad o a otra que se asemeje en rasgos demográficos y que, a su vez, se halle relativamente próxima, antes que a los núcleos de población más pequeños, aunque estén menos alejados del foco que esas ciudades. Este patrón refleja, en gran medida, las vías de comunicación.

Por último, el patrón jerárquico tiene su contraejemplo en un patrón precisamente antijerárquico, cuyo funcionamiento vira en sentido contrario, extendiendo usos desde los núcleos de menor a mayor población. Este último tipo de difusión se produce cuando los hablantes más rurales rechazan fenómenos provenientes de áreas urbanas por un sentido de identidad muy arraigado, que trata de prevenir injerencias externas.

En términos sociales, las innovaciones y su generalización suelen obedecer a variables como el género, la edad, el nivel sociocultural, el origen geográfico o el área de residencia. Con respecto al primero, la teoría variacionista ha demostrado que las mujeres son el grupo más sensible a los usos prestigiosos (Labov 1966: 288, Labov 1978: 243), si bien también pueden representar un carácter algo más conservador, puesto que los usos tradicionales se suelen asociar al prestigio (Trudgill 1972; Labov 1995). Si observamos cómo influye el factor de la edad, hallamos muchos trabajos (célebres son los de Silva-Corvalán 1979 a propósito de la realización velar de /f/ en Chile o, en el caso del inglés, los de Macaulay 1977 con respecto a la pronunciación o elisión del fonema/t/ en Glasgow) que indican que los hablantes en la etapa mediana de la vida suelen ser más propensos a adoptar las soluciones de prestigio, ya que, para Bourdieu (1978), se encuentran ante la presión del mercado lingüístico.

Un factor clave suele ir aparejado al nivel educativo o la clase social, puesto que las soluciones de prestigio son adoptadas frecuentemente por 
aquellos hablantes que gozan de un estatus socioeconómico y educativo elevado, mientras que cuanto menos nivel cultural posee un hablante, mayor preponderancia a mantener particularidades vernáculas o estigmatizadas (véanse a modo de ejemplo los trabajos de Chambers 1997 o Blas Arroyo 2005). Asimismo, observamos que ciertos fenómenos, independientemente de su encuadre con la norma general, pueden gozar de aceptación en territorios específicos, por lo que el origen y residencia de los informantes son igualmente cruciales. Asimismo, la dicotomía que representa el mundo rural frente al ámbito urbano es clave para la evaluación de los fenómenos, así como de su extensión o rechazo. El hecho de que los centros urbanos se asocien con lugares donde se concentran los grupos de poder, aquellos que suelen sancionar lo prestigioso o lo estigmatizado, los ha dotado de una tendencia a propagar usos lingüísticos que se han considerado bien vistos, frente al rechazo de otros usos más característicos de entornos rurales (a este respecto, de nuevo es el voseo un claro ejemplo de dicha dicotomía, ya que, como muestra, el voseo que se atestigua en Cuba se da en zonas rurales con un gran rechazo en centros urbanos, Álvarez \& Freites 2010).

A todos estos condicionantes hay que agregar el factor del estilo, de cuya combinación se derivan cambios desde arriba o desde abajo (por encima o por debajo del nivel de consciencia) o la oposición de prestigio versus estigmatización. Ya que el concepto de prestigio no atañe a lo lingüístico, sino a lo social, una variante bien vista será aquella que la clase que ostente el poder político, económico o cultural decida. Por tanto, las innovaciones que se ajusten a este patrón serán las que más posibilidades tengan de triunfar y esparcirse. Sin embargo, el prestigio de una variante puede revertirse si el grupo poderoso que surja en otro momento de la historia deje de considerarlo como tal (Lass 1997: 364). En contraposición a esta idea surge la noción de prestigio encubierto (covert prestige), basada en el hecho de que los fenómenos dialectales y estigmatizados que perviven a pesar de la presión estandarizadora se mantienen por la voluntad de los hablantes a pertenecer a un grupo determinado. Esa pertenencia, que sobre todo se da en hombres, mujeres por debajo de los treinta años e individuos de clase baja, provoca el férreo uso de variantes estigmatizadas, aunque no se admita en público. Los casos de covert prestige pueden derivar en cambios from below, es decir, provenientes de las clases bajas, que se extienden hasta las clases altas (Trudgill 1972). 


\subsection{Extensión de fenómenos lingüísticos}

En el ámbito lingüístico, el surgimiento de una innovación lingüística no supone su aparición en todos los entornos en los que se puede dar. Está ampliamente documentado que las innovaciones se esparcen gradualmente hasta establecerse por completo (Labov 1995, Corbett 2006). Un ejemplo de ello en español resulta la asimilación, neutralización y pérdida de las consonantes en coda silábica. La caída de dichas consonantes empieza en la /d/ final, como en pared (Estrada 2012) y continúa en /s, $\theta$ / seguidos de consonante, como en asco, bizco $>$ asco, bisco, hasta que alcanza las $/ r$, $1 /$ en ese mismo contorno (arto 'alto', arma). La neutralización se extiende en una segunda fase a las consonantes finales ante pausa. Según Fernández - Ordóñez (2016), que se basa en los datos de Catalán (1971) y Estrada (2012), esta pérdida atiende a un continuum jerárquico. Una vez que la neutralización se ha establecido en una fase, puede saltar a la siguiente.

Otro ejemplo se encuentra en el sincretismo de los clíticos de objeto en plural. Esta nivelación empieza en la 2pl y, finalmente, alcanza la 1pl. Si el hablante produce el sincretismo en la 1pl, también lo expresa en la 2pl (Lara \& Díez del Corral 2015).

Sin duda, uno de los fenómenos que mejor ejemplifica la paulatina extensión de una concordancia es el voseo. Su implantación sobre el tuteo data de los siglos XVIII y XIX. Sin embargo, al menos en el caso de Argentina, este cambio se originó en el pronombre tónico que, al principio, inducía morfología tuteante en los demás elementos con referencia 2 sg. Poco a poco, la morfología de $2 \mathrm{pl}$ voseante pasó al imperativo, después al presente de indicativo y, por último, al presente de subjuntivo. Los clíticos, el posesivo y demás tiempos verbales aún concuerdan con morfología de tú (Fontanella de Weinberg 1979, Abadía de Quant 1992, Bertolotti \& Coll 2003).

\subsubsection{Sintaxis versus semántica}

Con el fin de analizar las razones de todas estas discordancias, hemos considerado distintas teorías para abordar la falta de concordancia. Una de estas defiende que las discordancias se dan en todos los idiomas y suelen estar producidas por una contradicción entre sintaxis y semántica. Corbett (2006) contrapone los conceptos de concordancia sintáctica y concordancia 
semántica para explicar la elección morfológica de los elementos concordantes (target) en relación a su referente o inductor (controller). Por concordancia sintáctica se entiende a aquella que se comporta atendiendo a las características gramaticales del elemento que induce dicha concordancia. Concordancia semántica será, pues, aquella que, independientemente de las características, se comporta primordialmente atendiendo a los rasgos semánticos que el inductor adquiere en la situación comunicativa.

Para que la concordancia, según Corbett, se decante por una de base sintáctica o semántica, hay que atender a varios parámetros. Primero a la lejanía que el elemento inductor de la concordancia tiene con respecto a su elemento controlado. Cuanto mayor es la proximidad entre el controller y el target, menor independencia tendrá el target y mayores probabilidades de concordancia sintáctica con el controller. Asimismo, la adopción de la concordancia por parte del target dependerá igualmente de la siguiente escala implicativa (ii):

(ii) Adjetivo adyacente $>$ predicado $>$ pronombre relativo $>$ pronombre personal

[...] semantic agreement is as likely or more likely in the predicate as compared with attributive position; and then semantic agreement is as likely or more likely in the relative pronoun as in the predicate and so on [...] (Corbett 2006: 207)

Es decir, cuanto más a la izquierda de la escala, mayor probabilidad de concordancia sintáctica. Por tanto, el pronombre personal es más susceptible de adquirir una morfología de base semántica que el pronombre relativo, el cual tendrá más posibilidades de concordarse según la semántica que el predicado y, así, sucesivamente. Si el target se concuerda semánticamente en el predicado, forzosamente lo hará en el pronombre relativo y en el pronombre personal, pero no en el adjetivo adyacente, que podrá concordarse sintácticamente. Sin embargo, el autor tan solo estudia las discordancias que se manifiestan en el número y el género, y mantiene aparte la categoría de persona.

\subsubsection{Index versus concord}

Por otro lado, Wechsler \& Zlatic (2003) en su obra The many faces of agreement radiografían las aparentes discordancias que se producen en 
diversas lenguas y, sobre todo, en serbocroata. Estos autores contraponen dos tipos de concordancias: index o agreement y concord. Aquellos elementos que reciben una concordancia index atienden a una estructura de sujeto - verbo y reciben información de género, número y persona. Los que recaen en concord se construyen sobre todo dentro del área de influencia de un sintagma nominal y reciben los rasgos de género, número y caso. Sin embargo, los mismos autores afirman que los pronombres de tratamiento se rigen por otros patrones que los sintagmas nominales, debido a su carácter pragmático, y repiten la idea de la recurrencia a la pluralidad como forma más usual para expresar honor, sensación de poder y distancia. Aun así, sus conclusiones muestran una tendencia interesante para la concordancia que los clíticos adoptan. En serbocroata, de acuerdo con Wechsler \& Zlatic $(2000,2003)$, las discordancias pronominales que oscilan entre dar preferencia a la sintaxis o a la semántica se suelen resolver en función del caso del pronombre. Así, los pronombres en nominativo o los clíticos ligados a sintagmas con referencia nominativa (i.e. los reflexivos) suelen adquirir concordancia index o sintáctica, mientras que los clíticos de objeto tienen más independencia para adoptar una concordancia semántica o pragmática en función del referente al que aludan.

\subsubsection{Relaciones de caso}

Ya hemos apuntado que las innovaciones suelen seguir un continuum a lo largo del cual se van estableciendo hasta completar su evolución. A este respecto se ha dedicado, entre otros, Blake (2004), quien analiza en su monográfico Case las relaciones gramaticales e implicativas que existen entre los diferentes casos y llega a la conclusión de que estos se rigen por la siguiente jerarquía (iii):

(iii) Sujeto $>$ objeto directo $>$ objeto indirecto $>$ oblicuos (locativo, instrumental, etc.) (Blake 2004: 87).

En el caso particular de la relativización, se puede postular que si una lengua es capaz de relativizar el objeto indirecto, lo hará obligatoriamente con el directo y el sujeto. En el caso del orden de palabras, el orden no marcado de numerosas lenguas sigue el patrón de izquierda a derecha. En latín, por ejemplo, la jerarquía de caso era la siguiente (iv): 
(iv) Nominativo $>$ acusativo $>$ dativo $>$ ablativo $>$ genitivo (Blake 2004: 89).

\subsection{Corpus}

Para alcanzar los objetivos perseguidos se ha contado con dos corpus, uno geolingüístico y otro sociolingüístico. En el primer corpus se han analizado los datos del Atlas Lingüístico de la Península Ibérica y otras fuentes originadas en los atlas, así como en el Corpus dialectal para o estudo da sintaxe (CORDIAL-SIN). Se trata, en todo caso, de informantes procedentes de ámbito rural, escasa escolarización y edad avanzada, y de encuestas de la primera mitad del siglo xx. En el segundo se ha diseñado ad hoc una recolecta de datos en Andalucía occidental y Portugal que ha contemplado diversos grupos de edad, género, niveles socioculturales y áreas rurales y urbanas.

La metodología, por tanto, persigue tan solo la variación en un contexto oral, sin que podamos contrastarlo con las ocurrencias que los mismos informantes tendrían para contextos escritos. A este respecto, Koch \& Oesterreicher (1990) han propuesto que la dicotomía oralidad / escritura resulta también relevante a la hora de seleccionar ciertos usos lingüísticos. Además, a esta distinción, hay que sumar el concepto inmediatez o distancia. La inmediatez se relaciona con el intercambio oral, mientras que la distancia se asocia a la escritura. No obstante, puede haber una mezcla de ambas categorías: una carta a un amigo o un discurso, en el que el plano escrito / oral se entremezcla con lo inmediato o lo distante. Nuestra hipótesis es que la falta de concordancia puede estar más promovida por la oralidad de la metodología y la inmediatez de la situación, ya que los hablantes tenían que dirigirse a personas conocidas o íntimas. Es muy probable que, en la distancia de un texto escrito y formal, las discordancias decrezcan, mientras que en una nota informal a un amigo, se mantengan. En la presente investigación, por tanto, atenderemos a las concordancias de acuerdo con la inmediatez que requería la metodología empleada y el alto número de interlocutores que se encuadran en dicha categoría. 


\subsubsection{Corpus geolingüistico}

Con el fin de dar más información sobre el ALPI, podemos decir que se trata de un trabajo pionero de corte dialectal elaborado en las lenguas romances de la Península Ibérica. Esta recopilación de datos dialectales, del que solo se publicó un tomo (1962) de los diez pensados en un principio, fue impulsada por Ramón Menéndez Pidal, quien encargó la dirección del atlas a su discípulo Tomás Navarro Tomás en los años 1920-1930, a imitación del entonces recién publicado Atlas lingüistico de Francia (1902-1912). Las encuestas se llevaron a cabo entre 1931 y 1936, año en el que estalló la Guerra Civil, y una pequeña parte se terminó de realizar entre finales de la década de 1940 y todo el decenio de 1950. Esto implica que los resultados que salgan de su estudio se refieren a realidades de esa época, que pueden haber cambiado. La realización de las encuestas estuvo a cargo de tres equipos repartidos por la zona castellana, la gallego-portuguesa y la catalano-valenciana, con dos investigadores nativos en cada grupo. Se encuestaron 527 enclaves (mapa 2), desechando puntos urbanos, ya que se pretendía recoger el habla rural de informantes con pocos niveles de estudio, que rondaran entre los cuarenta y sesenta años y que toda su vida hubieran vivido en el pueblo.

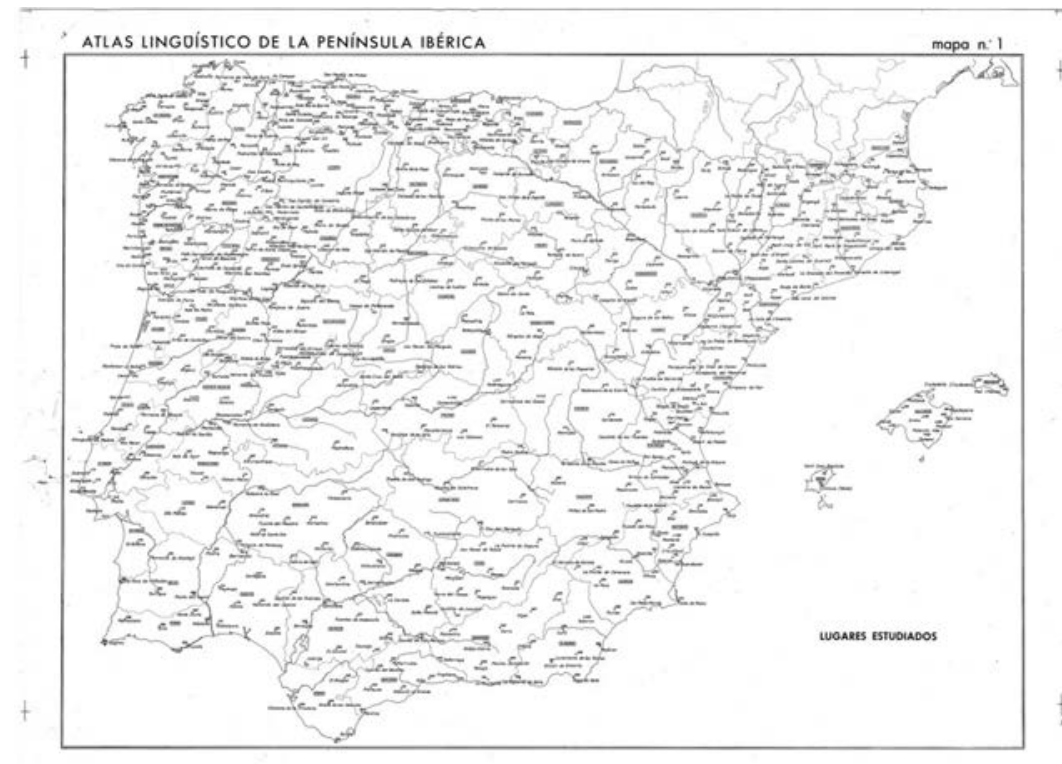

Mapa 2: Enclaves del ALPI (Navarro Tomás et al. 1962). 
Los resultados se recopilaron en cuadernos manuscritos en transcripción fonética y las preguntas abarcaban desde la pronunciación de palabras sueltas para el estudio de la fonética y el léxico, hasta la repetición de oraciones completas según el habla de cada zona, con el fin de estudiar la morfología y la sintaxis. Las transcripciones comportan un estudio pormenorizado de la fonética de acuerdo con el alfabeto de la RFE, incluyendo numerosas variantes en la pronunciación de los informantes. Después de la Guerra Civil, Navarro Tomás se llevó consigo al exilio los cuadernos de encuesta, que no se devolvieron al CSIC hasta 1951. Tras el elevado coste de la publicación del primer volumen, se retrasó la aparición de los nueve restantes y los cuadernos dejaron de estar localizados, quedando en manos privadas o en organismos públicos. Desde 1999, David Heap, profesor de la Universidad de Western Ontario, en Canadá, ha obtenido copias de los cuadernos y ha venido ofreciéndolos en red (2003-). Los datos inéditos del ALPI son, pues, una preciosa fuente de información para el estudio de la lenguas iberromances a principios del pasado siglo.

La metodología del cuestionario geolingüístico tiene ventajas e inconvenientes. En cuanto a los problemas que suscita, los datos pueden plantear dudas por la metodología seguida en su recolección: al tratarse de preguntas cerradas, los encuestadores pedían a los informantes que repitieran la palabra o la frase incluida en el cuestionario, por lo que esto pudo haber condicionado la respuesta del informante y la espontaneidad de su discurso. A pesar de los fallos que el planteamiento del cuestionario de un atlas lingüístico pueda plantear, sus resultados sirven como punto de partida para describir los rasgos en estudio y tratar de postular un patrón que se ajuste al comportamiento de dichos rasgos.

Las 14 preguntas del cuestionario analizadas para estudiar la $2 \mathrm{pl}$ fueron: ¿Cuándo salís de viaje? (n. ${ }^{\circ} 315$ del cuestionario); Id aprisa (n. $\left.{ }^{\circ} 321\right)$; Volved pronto (n. $\left.{ }^{\circ} 324\right) ;$ Cantad una jota (n. $\left.{ }^{\circ} 323\right)$; Decid lo que queráis (n. $\left.{ }^{\circ} 325\right) ;$ ¿Sois parientes del alcalde? (n. $\left.{ }^{\circ} 336\right)$; Os vais a caer (n. $\left.{ }^{\circ} 341\right)$; Os han engañado (n. $\left.{ }^{\circ} 342\right)$; Os queréis callar (n. ${ }^{\circ} 343$ ); Arrodillaos (n. $\left.{ }^{\circ} 344\right)$; Bebeos este vaso de aguardiente (n. $\left.{ }^{\circ} 345\right)$; Siéntense ustedes (n. $\left.{ }^{\circ} 364\right) ; ~ ¿ A d o ́ n d e ~ c a m i n a ́ i s ? ~\left(n . ~{ }^{\circ} 410\right)$ y Lo queréis para vosotros (n. $\left.{ }^{\circ} 411\right)$.

A los datos del ALPI hay que sumar, en el caso del portugués, el CORDIAL-SIN (Corpus dialectal para o estudo da sintaxe) (elaborado a finales de la década de 1990), proyecto del Centro de Lingüística de la Universidad de Lisboa, cuyo objetivo principal es el estudio de la 
variación sintáctica del portugués europeo, tanto continental como insular. Su corpus está constituido por pasajes de discurso espontáneo y semi-dirigido de 200 enclaves portugueses recolectados para el Atlas Lingüístico de Portugal (mapa 3). Sus muestran provienen de distintas fuentes, cuyos datos se llevan recogiendo desde hace 30 años, con un total de 4.500 horas de grabaciones. Los extractos proceden de los siguientes corpus: Atlas Linguístico e Etnográfico de Portugal e da Galiza (ALEPG), Atlas Linguístico do Litoral Português (ALLP), Atlas Linguístico e Etnográfico dos Açores (ALEAç) y Fronteira Dialectal do Barlavento Algarvio (BA).

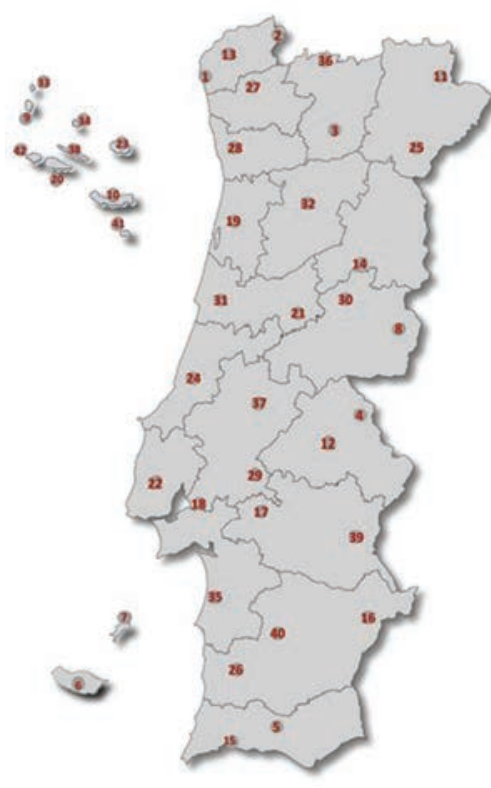

1. VPA Vila Praia de Âncora (Viana do Castelo.)

24. MTM Mota do Martinho

2. CTL Castro Laboreiro (Viana do Castelo)

3. PFT Perafta (Vila Real)

4. AAL Cast. Vide, Porto da Esp., S. Salv.

Aramenha, Sapeira, Alpalhão, Nisa

(Portalegre)

5. PAL Porches, Alte (Faro)

6. CLC Càmara de Lobos, Caniçal (Funchai)

7. PST Camacha, Tanque (Funchal)

8. MST Monsanto (Castelo Branco)

9. FLF Fajäzinha (Horta)

10. MIG Ponta Garça (Ponta Delgada)

11. OUT Outeiro (Bragança)

12. CBV Cabeço de Vide (Portalegre)

13. Min Arcos de Valdevez, Bade, S.

Lourenço da Montaria (Viana do Castelo)

14. FIG Figueiró da Serra (Guarda)

15. ALV Alvor (Faro)

16. SRP Serpa (Beja)

17. LVR Lavre (Évora)

18. ALC Alcochete (Setúbal)

19. Cov Covo (Aveiro)

20. PIC Bandeiras, Cais do Pico (Horta)

21. PVC Porto de Vacas (Coimbra)

22. EXB Enxara do Bispo (Lisboa) (Leiria)

25. LAR Larinho (Bragança)

26. LUZ Luzianes (Beja)

27. Fis Fiscal (Braga)

28. GIA Gião (Porto)

29. STJ Santa Justa (Santarém) 30. UNS Unhais da Serra

(Castelo Branco)

31. VPC Vila Pouca do Campo

(Coimbra)

32. GRJ Granjal (Viseu)

33, CRV Corvo (Horta)

34. GRC Graciosa (Angra do

Heroismo)

35. MLD Melides (Setúbal)

36. STA Santo André (Vila Real)

37. MTV Montalvo (Santarém)

38. CLH Calheta (Angra do

Heroismo)

39. CPT Carrapatelo (Évora)

40. A.T Afustrel (Beja)

41. STE Santo Espirito (Ponta

Delgada)

42. CDR Cedros (Horta)

23. TRC Fontinhas (Angra-do-Heroismo)

Mapa 3: Enclaves del CORDIAL-SIN.

A estos datos habrá que sumar los recogidos del corpus sociolingüístico (que se detalla a continuación) en lo que respecta al enclave encuestado y su perfil demográfico. Los mapas se elaborarán en el programa Gabmap (Nerbonne et al. 2011). 


\subsubsection{Corpus sociolingüistico}

En lo que atañe al ámbito sociolingüístico, la variable en estudio ha contado con informantes de tres tramos de edad, dos sexos, dos niveles socioculturales y procedentes tanto de áreas rurales como urbanas.

Para la obtención de los datos, se diseñó un protocolo específico aplicado a menores de treinta años (jóvenes), informantes entre treinta y sesenta (mediana edad) y mayores de sesenta. Con el fin de asegurarnos la aparición de todos los datos por parte del hablante, creamos un protocolo basado en el doblaje de escenas de series de televisión. Recopilamos una sucesión de escenas al efecto donde se favoreciera el uso de la segunda persona del plural y que, además, tuviera todo tipo de contextos simétricos y asimétricos. Para cada escena, se inventaba una sinopsis y una pequeña descripción con frases tipo, de tal manera que el informante supiera de dónde partir a la hora de doblar la imagen. Cada resumen se orientaba a provocar el uso de algún elemento sintáctico en cuestión (clíticos, imperativo, posesivo, etc.) que dependen del elemento ustedes / vocês. Las frases tipo se enunciaban en tercera persona y el informante las repetía en segunda persona, ya que su cometido era interpretar lo que en la serie se decía.

El resultado de este protocolo resultó ser un éxito, ya que las dos series seleccionadas, de gran popularidad en las pantallas española y portuguesa, fueron un aliciente para que el entrevistado cumpliera de buena gana las instrucciones de la actividad.

Los enclaves en que se puso en práctica este método de encuesta son los siguientes (tabla 9 y mapa 4):

Tabla 9: Enclaves encuestados.

\begin{tabular}{|l|l|l|}
\hline MUNICIPIO & PROVINCIA & POBLACIÓN \\
\hline Abrantes & Santarém & 42.235 \\
\hline Alcácer do Sal & Setúbal & 14.287 \\
\hline Alcalá de los Gazules & Cádiz & 5.439 \\
\hline Algeciras & Cádiz & 114.277 \\
\hline Alhaurín El Grande & Málaga & 24.249 \\
\hline Alosno & Huelva & 4.152 \\
\hline Antequera & Málaga & 41.620 \\
\hline Arahal & Sevilla & 19.536 \\
\hline Arraiolos & Évora & 7.616 \\
\hline Ayamonte & Huelva & 20.406 \\
\hline
\end{tabular}




\begin{tabular}{|l|l|l|}
\hline MUNICIPIO & PROVINCIA & POBLACIÓN \\
\hline Bollullos del Condado & Huelva & 14.394 \\
\hline Bujalance & Córdoba & 7.792 \\
\hline Cabezas Rubias & Huelva & 781 \\
\hline Cádiz & Cádiz & 122.990 \\
\hline Camas & Sevilla & 26.535 \\
\hline Carmona & Sevilla & 28.793 \\
\hline Cártama & Málaga & 24.242 \\
\hline Cartaya & Huelva & 19.323 \\
\hline Casariche & Sevilla & 5.619 \\
\hline Castilleja de la Cuesta & Sevilla & 17.474 \\
\hline Castro del Río & Córdoba & 8.108 \\
\hline Cazalla de la Sierra & Sevilla & 5.054 \\
\hline Conil de la Frontera & Cádiz & 22.116 \\
\hline Constantina & Sevilla & 6.337 \\
\hline Córdoba & Córdoba & 328.704 \\
\hline Cortegana & Huelva & 4.898 \\
\hline Covilhã & Castelo Branco & 54.506 \\
\hline Cumbres Mayores & Huelva & 1.888 \\
\hline Dos Hermanas & Sevilla & 129.719 \\
\hline Dos Torres & Córdoba & 2.494 \\
\hline Écija & Sevilla & 40.880 \\
\hline El Castillo de las Guardas & Sevilla & 1.545 \\
\hline El Pedroso & Sevilla & 2.194 \\
\hline El Ronquillo & Sevilla & 1.429 \\
\hline Elvas & Portalegre & 28.279 \\
\hline Encinasola & Huelva & 1.353 \\
\hline Espiel & Córdoba & 2.459 \\
\hline Estepona & Málaga & 67.986 \\
\hline Fuentes de Andalucía & Sevilla & 7.257 \\
\hline Fundão & Castelo Branco & 29.213 \\
\hline Hinojales & Huelva & 298 \\
\hline Hinojosa del Duque & Córdoba & 7.172 \\
\hline Huelva & Huelva & 148.101 \\
\hline Isla Cristina & Huelva & 21.443 \\
\hline Jerez de la Frontera & Cádiz & 211.670 \\
\hline La Línea de la Concepción & Cádiz & 62.697 \\
\hline & & \\
\hline
\end{tabular}




\begin{tabular}{|l|l|l|}
\hline MUNICIPIO & PROVINCIA & POBLACIÓN \\
\hline La Nava de la Concepción & Sevilla & 1.704 \\
\hline Lebrija & Sevilla & 27.395 \\
\hline Lepe & Huelva & 27.406 \\
\hline Lisboa & Lisboa & 545.245 \\
\hline Lora del Río & Sevilla & 19.403 \\
\hline Los Barrios & Cádiz & 22.948 \\
\hline Lucena & Córdoba & 42.754 \\
\hline Málaga & Málaga & 568.479 \\
\hline Marbella & Málaga & 142.018 \\
\hline Montoro & Córdoba & 9.801 \\
\hline Morón de la Frontera & Sevilla & 28.334 \\
\hline Nerja & Málaga & 22.918 \\
\hline Odemira & Beja & 26.106 \\
\hline Osuna & Sevilla & 17.820 \\
\hline Pedrera & Sevilla & 5.352 \\
\hline Peniche & Leiria & 27.315 \\
\hline Pombal & Leiria & 56.300 \\
\hline Pozoblanco & Córdoba & 17.519 \\
\hline Puebla de Guzmán & Huelva & 3.127 \\
\hline Puerto Real & Cádiz & 41.537 \\
\hline Ronda & Málaga & 36.665 \\
\hline Serpa & Beja & 16.178 \\
\hline Sevilla & Sevilla & 700.169 \\
\hline Tarifa & Cádiz & 18.085 \\
\hline Tavira & Faro & 24.995 \\
\hline Tocina & Sevilla & 9.640 \\
\hline Tondela & Viseu & 31.152 \\
\hline Ubrique & Cádiz & 16.877 \\
\hline Utrera & Sevilla & 52.013 \\
\hline Valdelarco & Huelva & 223 \\
\hline Valverde del Camino & Huelva & 12.766 \\
\hline Vejer de la Frontera & Cádiz & 12.882 \\
\hline Vélez-Málaga & Málaga & 76.911 \\
\hline Villa del Río & Córdoba & 7.473 \\
\hline Villanueva de Córdoba & Córdoba & 1.5826 \\
\hline Villanueva del Duque & Córdoba & \\
\hline & & \\
\hline
\end{tabular}




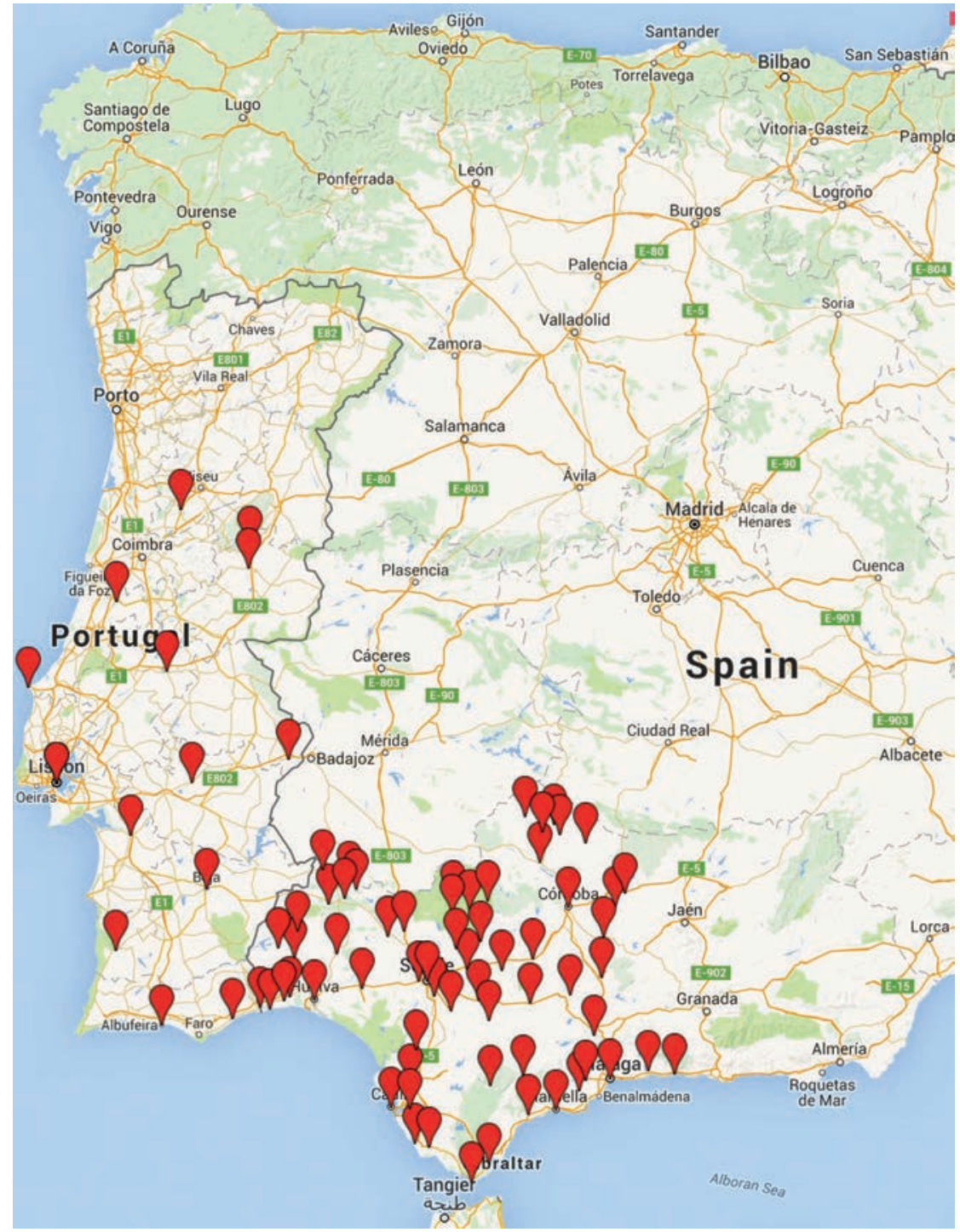

Mapa 4: Enclaves encuestados. 


\subsection{Metodología}

Las dos series de televisión que se escogieron fueron la estadounidense Friends y la española Aquí no hay quien viva. El motivo que condujo a seleccionar estos dos programas reside en que la dinámica del guión genera, casi siempre, diálogos múltiples en los que uno o dos personajes han de dirigirse a más de una persona al mismo tiempo. Además, tanto en una como en otra son recurrentes los interlocutores de todo tipo, es decir, personas con una relación asimétrica descendente con respecto al personaje que hay que doblar; personas con una relación asimétrica ascendente con respecto al personaje que hay que doblar, y personas con una relación simétrica y también de intimidad con respecto al personaje al que se dobla. Gracias a esto, obtuvimos el siguiente resultado global, representado en la tabla 10 .

Tabla 10: Informantes y ocurrencias del corpus sociolingüístico.

\begin{tabular}{|l|l|}
\hline INFORMANTES & OCURRENCIAS \\
\hline 242 & 4.491 \\
\hline
\end{tabular}

De entre todas las sitcoms que encontramos actualmente, son dos las que pueden representar (por su audiencia e internacionalización) un buen comienzo para que el informante enseguida comprenda el material y pueda incluso sentirse identificado. Un de ellas fue Friends, comedia de situación emitida entre los años 1994 y 2004, que versa sobre las relaciones personales y sociales de un grupo de amigos cercanos a los treinta años, algunos de los cuales comparten piso. Son frecuentes los diálogos entre varios de ellos, entre los padres de un personaje con el mismo, compañeros de trabajo o jefes.

Las secuencias extraídas de dicha serie se presentaron a los informantes de la siguiente manera. Se mostraba el vídeo y se enunciaban las frases-guía enumeradas (algunas de las cuales se ejemplifican a continuación), que servían de guía para aquellos informantes que se quedaban en blanco y necesitaban algún estímulo con el que empezar. Asimismo, se proponían estas oraciones, siempre en estilo indirecto y tercera persona, en el caso de que el hablante no hubiera expresado los contextos sintácticos esperados: 
a) La protagonista de la escena se encuentra con sus amigas celebrando que se va a casar, pero ella no está tan contenta y empieza a decirles lo que ellas sí pueden hacer por seguir solteras.

a. Frase-guía: Les dice que ellas pueden hacer lo que quieran $>$ Dato perseguido: Podéis hacer lo que queráis.

b. Frase-guía: Les dice que se pueden ir de viaje > Dato perseguido: Os podéis ir de viaje.

c. Frase-guía: Les dice que no tienen que dar explicaciones a nadie $>$ Dato perseguido: No tenéis que dar explicaciones a nadie.

d. Frase-guía: Les dice que son libres > Dato perseguido: Vosotras / ustedes sois libres.

e. Frase-guía: Les dice que no se casen > Dato perseguido: No os caséis / no casarse / no casaros.

f. Frase-guía: Les recomienda que no se casen > Dato perseguido: Os recomiendo que no os caséis.

b) El grupo de hombres protagonistas planea una partida de póker, a la que se quiere sumar el grupo de mujeres, pero estos las rechazan por motivos machistas y ellas responden con argumentos feministas.

a. Frase-guía: Les dice que son machistas $>$ Dato perseguido: Vosotros / ustedes sois machistas.

b. Frase-guía: Les dice que ellas no saben jugar > Dato perseguido: Vosotras / ustedes no sabéis jugar.

c. Frase-guía: Les dice que ellos son mejores que ellas $>$ Dato perseguido: Somos mejores que vosotras / ustedes.

d. Frase-guía: Les pregunta qué se creen > Dato perseguido: ¿Qué os creéis?

La otra serie exhibida fue la española Aquí no hay quien viva, emitida entre los años 2003 y 2006, cuyo guión presenta la vida en una comunidad de vecinos del centro de Madrid, donde conviven familias, personas mayores, jóvenes de alquiler, el portero y parejas recién casadas. Al igual que Friends, sus secuencias entre varios personajes que hablan a otros tantos a la vez son constantes, ya que no solo se muestra el día a día de cada núcleo familiar, sino cómo interactúan entre todos los vecinos.

Algunas de las escenas recopiladas de esta serie que se presentaron a los informantes, junto con las frases-guía, son las siguientes: 
a) Las tres ancianas protagonistas llaman a la puerta de su vecino para preguntarle por su vida y este, harto de ellas, les pide que se vayan y que lo dejen en paz.

a. Frase-guía: Les dice que está harto de ellas > Dato perseguido: Estoy harto de vosotras / ustedes.

b. Frase-guía: Les pide que lo dejen en paz > Dato perseguido: Dejadme en paz / Dejarme en paz / Déjenme en paz.

c. Frase-guía: Les recrimina que siempre están cotilleando $>$ Dato perseguido: Siempre estáis / están cotilleando.

d. Frase-guía: Les dice que siempre se están metiendo en su vida $>$ Dato perseguido: Os estáis / Se están / Se estáis metiendo en mi vida.

e. Frase-guía: Les pide que se metan en su vida > Dato perseguido: Meteos / Meteros / Métanse en la vuestra / suya / en vuestros / sus asuntos.

b) El personaje protagonista ha pedido a dos conocidos que le hagan una obra en casa, pero cuando vuelve, le han hecho una chapuza y les amenaza con no pagarles si no se la hacen adecuadamente.

a. Frase-guía: Les pregunta qué han hecho > Dato perseguido: ¿Qué habéis hecho?

b. Frase-guía: Les dice que eso no fue lo que les pidió > Dato perseguido: Esto no fue lo que os pedí.

c. Frase-guía: Les pide que se lo vuelvan a hacer $>$ Dato perseguido: Me lo volvéis a hacer.

d. Frase-guía: Les amenaza con no pagarles > Dato perseguido: No os pago.

c) El director de una sucursal bancaria comenta al matrimonio protagonista por qué no pueden recibir el préstamo que solicitaron.

a. Frase-guía: Les dice que no les puede conceder el préstamo > Dato perseguido: No les podemos conceder el préstamo.

b. Frase-guía: Les dice que lo siente por ellos $>$ Dato perseguido: Lo sentimos por ustedes.

c. Frase-guía: Les informa de que no son solventes $>$ Dato perseguido: No son solventes.

d. Frase-guía: Les dice que no tienen aval > Dato perseguido: No tienen aval.

e. Frase-guía: Les recomienda ir a otro banco si lo desean $>$ Dato perseguido: Pueden ir a otro banco, si lo desean. 


\subsection{Análisis estadístico}

Lo datos extraídos se han analizado estadísticamente, de acuerdo con las fórmulas del chi cuadrado y la regresión logística. Asimismo, las variables lingüísticas que hemos previsto para el español han sido el pronombre tónico; pronombre átono; posesivo; tiempo verbal; modo verbal; modalidad; situación comunicativa; tipo de oración subordinada; morfología pronominal de 2 pl. En cuanto a los parámetros extralingüísticos que hemos previsto para el análisis del fenómeno español, han sido los siguientes: sexo; edad; estudios; provincia; zona del ALPI; tamaño de población. Los parámetros lingüísticos que hemos previsto para el análisis de vocês por vós han sido los siguientes: pronombre tónico; pronombre átono; posesivo; verbo; situación comunicativa; morfología pronominal. Los parámetros extralingüísticos que hemos previsto para el análisis de estos fenómenos en portugués han sido los siguientes: sexo; provincia; zona del ALPI; tamaño de población.

Tras el procesamiento de los datos, nuestro método de análisis ha previsto la realización de un análisis estadístico del corpus sociolingüístico. Para ello, en Andalucía se ha considerado la variable dependiente (elección de ustedes o vosotros) en relación con las variables sociales independientes sexo, edad, nivel educativo, origen, zona del ALPI, y población del enclave, y se han aplicado dos pruebas de significatividad estadística (chi cuadrado y regresión logística). Si bien este análisis solo lo hemos aplicado a la elección del pronombre tónico, realizaremos un análisis estadístico descriptivo del resto de elementos sintácticos con referencia a ustedes.

En el caso del portugués, debido a la escasez de datos del corpus de control, nos limitaremos a un análisis estadístico descriptivo, tanto del pronombre tónico como de los elementos sintácticos, y estableceremos la correlación solo con las variables extralingüísticas siguientes: el género del informante, su origen y la zona del ALPI.

Dicha metodología ha dado como resultado, en el caso de los datos españoles, dos análisis del cambio: uno en tiempo real, que se desprende del contraste de los resultados actuales con los obtenidos del ALPI; y otro, en tiempo aparente, llevado a cabo gracias a la comparación de los tres grupos de edad previstos en el corpus (Bailey 2003). Para el portugués, el análisis se ha restringido al cambio en tiempo real, al confrontar los resultados actuales con los obtenidos en el ALPI y el CORDIAL-SIN. 


\section{Geografía de la cortesía en el suroccidente peninsular}

El primer objetivo que nos habíamos marcado era el de cartografiar la evolución del fenómeno, desde el ALPI hasta los datos que la metodología empleada diera como resultado. Si empezamos por el atlas lingüístico, observamos que solo previó 14 preguntas distintas. Estas incluyen formas de 2pl en diferentes situaciones sintácticas. Así, ¿Cuándo salís de viaje? (n. ${ }^{\circ} 315$ del cuestionario) ha podido dilucidar el comportamiento de la concordancia en el predicado, sin un pronombre expreso; Id aprisa (n. $\left.{ }^{\circ} 321\right)$, Volved pronto (n. $\left.{ }^{\circ} 324\right)$, Cantad una jota (n. $\left.{ }^{\circ} 323\right)$ y Decid lo que queráis (n. $\left.{ }^{\circ} 325\right)$ han dado cuenta del comportamiento de los imperativos y, en el último caso, de un verbo en la oración subordinada. En ¿Sois parientes del alcalde? (n. ${ }^{\circ} 336$ ) hemos averiguado si había diferencias entre verbos copulativos y los que no lo son. Os vais a caer (n. $\left.{ }^{\circ} 341\right)$, Os han engañado (n. $\left.{ }^{\circ} 342\right)$, Os queréis callar (n. $\left.{ }^{\circ} 343\right)$, Arrodillaos (n. $\left.{ }^{0} 344\right)$ y Bebeos este vaso de aguardiente (n. $\left.{ }^{\circ} 345\right)$ nos han proporcionado información sobre el se aspectual, medio, el clítico en función de complemento directo y su posición enclítica o proclítica. Siéntense ustedes (n. ${ }^{\circ}$ 364) ha podido informar si influye la especificación del sujeto o el tipo de interlocutor y, una vez más, hemos observado el comportamiento del clítico. Y, por último, las frases ¿Adónde camináis? (n. $\left.{ }^{\circ} 410\right)$ y Lo queréis para vosotros $\left(\mathrm{n}^{\circ}{ }^{\circ} 411\right)$, preguntadas en el cuestionario en función del interlocutor (niños y amigos vs. desconocidos y ancianos) nos han guiado para el comportamiento del fenómeno según a quién iba dirigida la pregunta y según el pronombre explícito.

Los resultados muestran que, en el pronombre tónico, el único alocutivo posible, independientemente de la formalidad de la situación comunicativa, recae en ustedes o vocês en Andalucía occidental y en el centro-sur de Portugal, respectivamente (mapas 5 y 6). Aunque la explicitación del sujeto es menor, la expresión del pronombre en el término del sintagma preposicional nos asegura esa opción como la única para Andalucía occidental y el centro-sur de Portugal. El resultado de la investigación conjunta de todos los mapas andaluces (Lara 2010,2012) puede visualizarse en el mapa 5. 


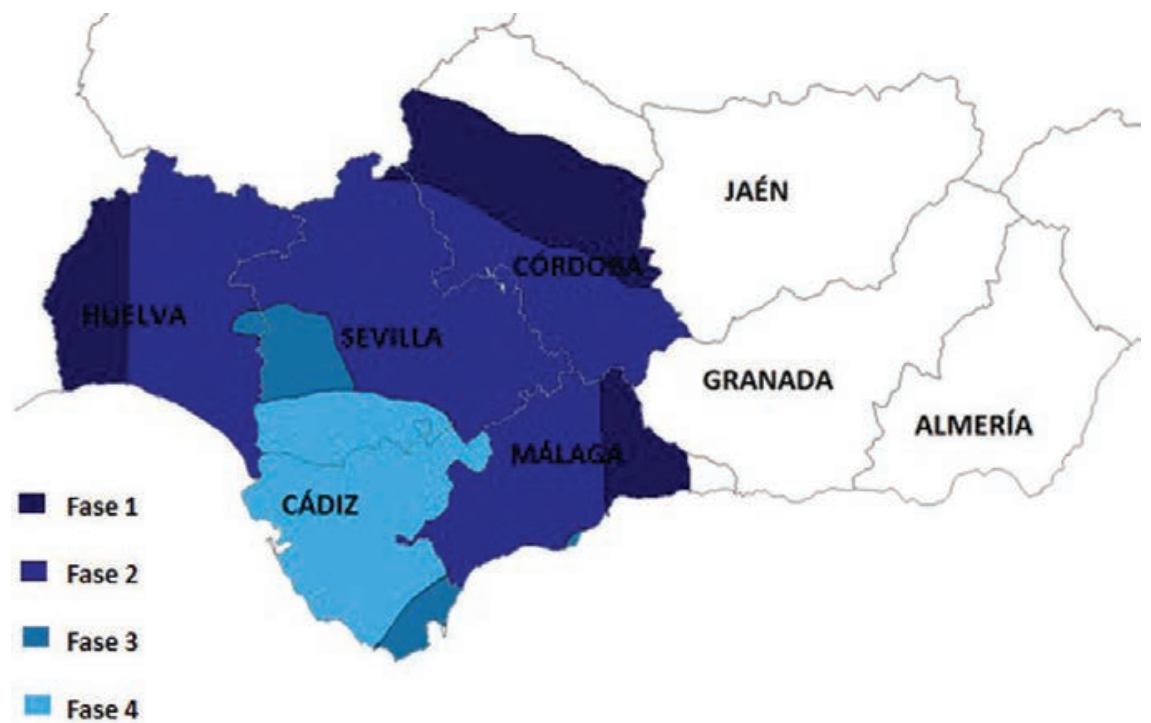

Mapa 5: Extensión geográfica de la nivelación de ustedes en el ALPI.

Toda el área coloreada indica la zona donde no existe vosotros y se ha neutralizado el tratamiento de plural en ustedes. El fenómeno se divide en fases que revelan el avance implicativo de la concordancia en $3 \mathrm{pl}$. La $3 \mathrm{pl}$ aparece primero en el pronombre sujeto (fase 1), se extiende más tarde al reflexivo (fase 2), quizá al objeto (los) (fase 3) y, por último, al verbo (fase 4). Como puede observarse, las fases se disponen como áreas concéntricas respecto del estadio más avanzado, representado por la fase 4.

Tabla 11: Fases de la extensión de la 3pl en Andalucía occidental.

\begin{tabular}{|l|l|l|l|l|}
\hline & SUJETO & REFLEXIVO & OBJETO & VERBO \\
\hline FASE 1 & $3 \mathrm{PL}$ & $2 \mathrm{PL}$ & $2 \mathrm{PL}$ & $2 \mathrm{PL}$ \\
\hline FASE 2 & $3 \mathrm{PL}$ & $3 \mathrm{PL}$ & $2 \mathrm{PL}$ & $2 \mathrm{PL}$ \\
\hline FASE 3 & $3 \mathrm{PL}$ & $3 \mathrm{PL}$ & $2 \mathrm{PL} / 3 \mathrm{PL}$ & $2 \mathrm{PL}$ \\
\hline FASE 4 & $3 \mathrm{PL}$ & $3 \mathrm{PL}$ & $2 \mathrm{PL} / 3 \mathrm{PL}$ & $2 \mathrm{PL} / 3 \mathrm{PL}$ \\
\hline
\end{tabular}

Estos datos parecen revelar una escala implicativa (tabla 11) en los elementos sintácticos dependientes de ustedes, de acuerdo con la cual, la concordancia de $3 \mathrm{pl}$ se extiende progresivamente siguiendo la escala de (v): 
(v) Pronombre tónico $>$ reflexivo $>$ objeto $>$ verbo

Es decir, si encontramos 3pl en el verbo, forzosamente hallaremos $3 \mathrm{pl}$ en el reflexivo y, por supuesto, en el pronombre tónico (sujeto y término de sintagma preposicional). La tercera persona en un estadio presupone la tercera persona en los de su izquierda, pero no en los de su derecha. Solo cuando la 3 pl está asentada en un elemento, puede pasar y atestiguarse en el siguiente de su derecha y así sucesivamente.

Sin embargo, la nueva lectura de los datos gracias a la investigación de Lara \& Díez del Corral (2015) permite matizar este análisis si entendemos que los es, en realidad, no un pronombre de objeto de $3 \mathrm{pl}$, sino de 2pl. Así, sería posible estimar una sola las fases 2 y 3 de la tabla 11. Ello obligaría a una reformulación del continuum implicativo de la extensión de la $3 \mathrm{pl}$, como en (vi).

(vi) Pronombre tónico $>$ reflexivo $>$ verbo

Esta reformulación resulta totalmente pertinente a la luz de los datos del ALPI para la extensión de vocês y las concordancias de 3pl, como muestra el mapa 6. 


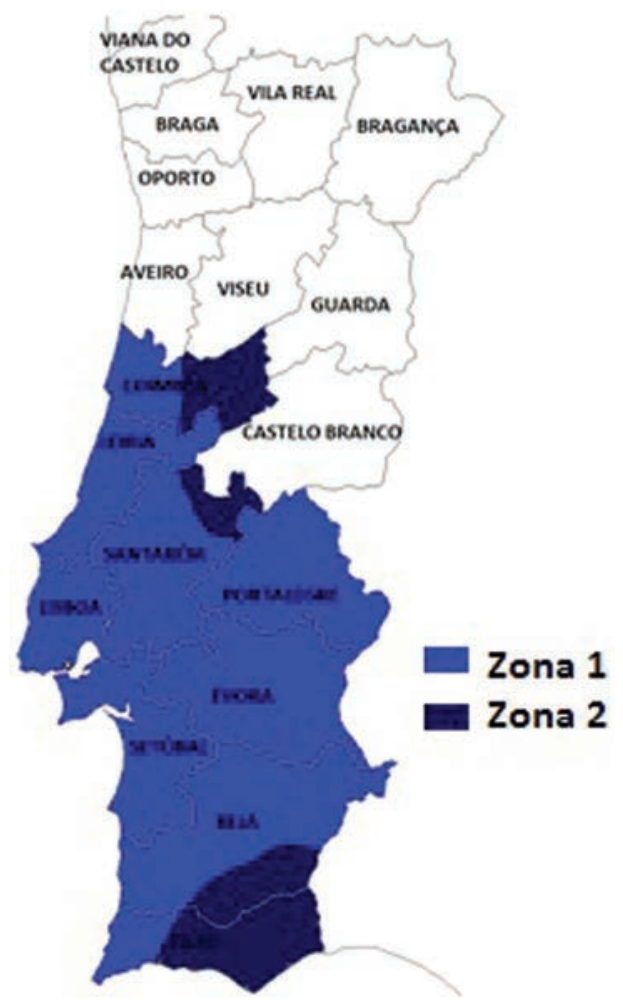

Mapa 6: Extensión geográfica de la nivelación en vocês en el ALPI.

En Portugal, la extensión gramatical surge en el pronombre tónico, si bien los datos de los que se dispone no permiten aclarar qué pasos se da hasta que el reflexivo y el verbo adoptan la 3 pl, por lo que la jerarquía queda de la siguiente manera:

(vii) Pronombre tónico / reflexivo / verbo > acusativo

Los datos del ALPI no ofrecen datos del dativo ni del posesivo que, en el caso del portugués, debería adoptar morfología de $2 \mathrm{pl}$ de acuerdo con la presión estándar: vos y vosso. Falta por averiguar si en la misma zona donde el acusativo es de $3 \mathrm{pl}$, a pesar de las prescripciones normativas, el dativo adquiere dicha persona gramatical o si, como prevemos, se rige por un continuum implicativo.

Por último, para el caso del español, es necesario indicar que ciertos elementos y contornos lingüísticos no se han podido analizar por falta de 
datos en el cuestionario del ALPI. Lapesa (2000), Cano (2004) o Menéndez Pidal (2005) han apuntado al hecho de que el verbo en perfecto adoptaba por sistema la tercera persona del plural, con contraste con los demás tiempos, que se construyen en segunda. Además, afirman que el posesivo referido a ustedes prescinde de la forma $2 \mathrm{pl}$ (vuestro) y se expresa mediante un sintagma preposicional (de ustedes), entre otras cosas, para evitar el fuerte sincretismo de $s u$. A continuación, pasaremos a pormenorizar la evolución geográfica del fenómeno andaluz, comparando los datos que el ALPI ha proporcionado con los resultantes de la nueva metodología, y trataremos de extraer observaciones sobre su desarrollo a lo largo del último siglo.

Por un lado, el análisis de los resultados del ALPI ha arrojado un mapa con un patrón de difusión por ondas, en el que se perciben tres innovaciones: la eliminación de vosotros, la adopción de la $3 \mathrm{pl}$ en el reflexivo y la penetración de la $3 \mathrm{pl}$ en el verbo en imperativo y, al menos, de la subordinada. Este fenómeno se esparce en su fase 1 (adopción de ustedes como pronombre tónico) por toda la provincia de Cádiz, Huelva y Sevilla y comprende toda el área de Málaga hasta su extremo oriental y Córdoba, hasta la parte nororiental. La fase 2 ( $3 \mathrm{pl}$ en el reflexivo) se atestigua prácticamente en la misma área, a excepción del centro de Córdoba, el centro-oriente de Málaga y el extremo occidental de Huelva. Por último, la fase 3 más innovadora (con afectación del verbo subordinado) solo se atestigua en el extremo sur de Sevilla y casi la totalidad de Cádiz, con excepción del sureste. Aunque el imperativo solo se expresa como un infinitivo y es generalizado en todas las provincias (sentarse), este hecho también es mayoritario en el área andaluza donde existe la distinción estándar ustedes / vosotros, por lo que no se ha contemplado como una posible innovación hacia la 3 pl.

Con el fin de confrontar esos datos con los actuales, hemos optado por representar el nivel de incidencia de la particularidad vernácula de acuerdo con el porcentaje de aparición de la misma. De esta manera, el mapa que representa la situación actual se divide en zonas donde el uso vernáculo es inexistente o en una proporción mínima $(<33 \%)$; zonas en las que el uso alcanza una incidencia media (entre 33\% y 66\%); y, por último, zonas en las que el fenómeno se documenta acérrimamente $(>66 \%)$. Debido a la alta volatilidad de las concordancias, en función de los factores sociales que detallaremos más adelante y a su mayor oscilación en los elementos sintácticos concordantes con el pronombre tónico, cartografiaremos tan solo la incidencia geográfica del pronombre tónico con valor de sujeto. 


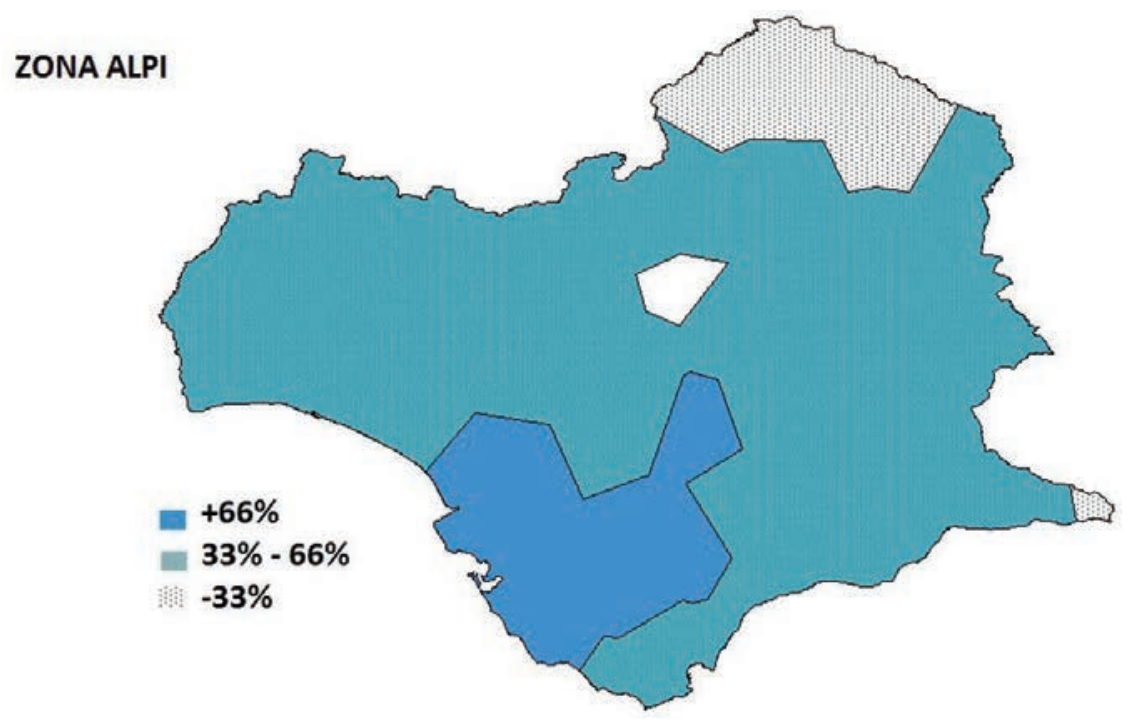

Mapa 7: El uso de ustedes según la zona del ALPI.

\section{ENCLAVES}

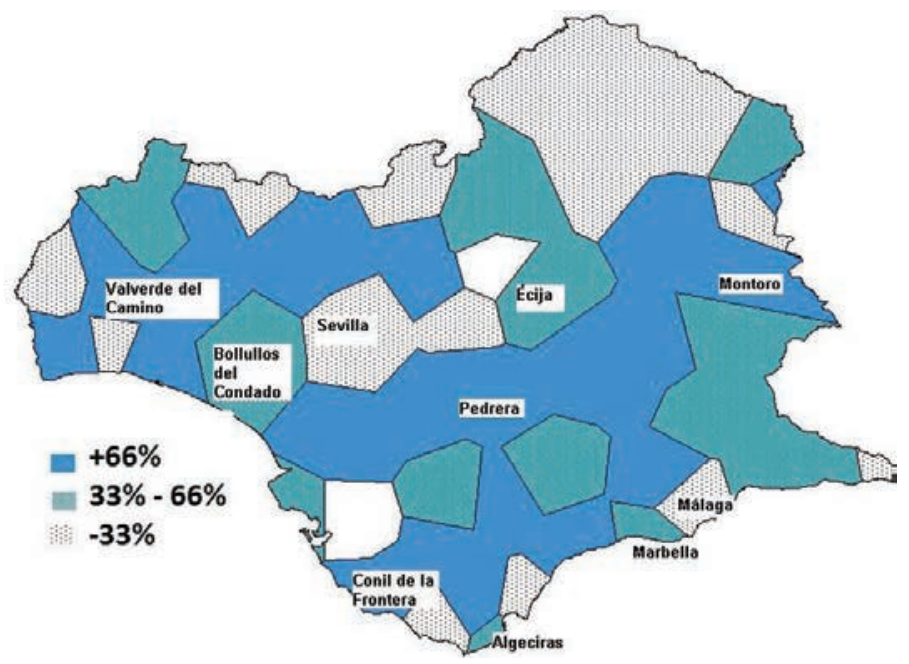

Mapa 8: El uso de ustedes según los enclaves encuestados.

Los dos mapas representados arriba contrastan los datos agrupándolos por las zonas del ALPI (mapa 7) y manteniéndolos independientes en cada uno de los enclaves encuestados individualmente (mapa 8). Por un lado, el 
mapa basado en las zonas del ALPI muestra que el fenómeno conserva el mismo estado de localización que hace 100 años, por lo que no ha sufrido grandes cambios geográficos. Es más, como en los datos del ALPI, es la zona 3, el foco, el área de mayor uso de la particularidad, seguida por las zonas 1 y 2 , que igualan el porcentaje de uso, y, por último, la zona 0 (norte de Córdoba y extremo oriental de Málaga), que sigue sin presentar ocurrencias del fenómeno o ha producido escasos ejemplos.

Por otro lado, la nivelación de ustedes produce una ilustración muy desigual si atendemos a su preponderancia de uso enclave por enclave. El mapa 8 revela que el empleo de la particularidad dialectal es mayor cuanto menor es el número de habitantes de la población, como puede observarse en el mismo. Así, enclaves menores como Valverde del Camino, Montoro, Pedrera o Conil de la Frontera tienen un alto porcentaje del fenómeno, mientras que en Marbella, Bollullos del Condado, Algeciras o Écija, la nivelación en ustedes empieza a perder fuerza. Es, sobre todo, en Sevilla y Málaga donde la distinción del estándar se impone con mayor vehemencia, ya que el porcentaje de uso de ustedes como único pronombre oscila entre el $0 \%$ y el $33 \%$.

De este análisis se desprenden dos conclusiones en relación a la extensión geográfica de la variable dialectal en estudio. La primera se correlaciona con el mantenimiento del fenómeno y postula que se va esparciendo por ondas, ya que el foco es el área de mayor incidencia del fenómeno. Su periferia recibe un uso medio y, por último, se va difuminando allende la zona intermedia. Este patrón ha sido descrito por Chambers \& Trudgill (1980). En resumen, el patrón de difusión geográfico coincide con el del ALPI y, además, vuelve a reproducir las mismas áreas, siendo el sur de Sevilla y casi toda la provincia de Cádiz, excepto la zona suroriental, las zonas más innovadoras y dialectales, el resto de Andalucía occidental la zona de transición y los límites con Castilla y Andalucía oriental el área de desaparición. Todo esto concuerda con lo estudiado por Wolfram \& Schilling - Estes (2003), quienes postulan que, en un fenómeno en el que se produzcan tres innovaciones asociadas a un cambio R, R1 surgirá en un punto específico a partir del cual se difundirá hacia su periferia. Cuando R1 se extienda a la periferia, R2 habrá aparecido en el mismo punto donde nació R1 previamente. En una evolución ulterior, R2 habrá alcanzado la periferia del foco, mientras que R1 habrá saltado a una zona aun más lejana y, al mismo tiempo, R3 habrá surgido de nuevo en el foco o epicentro. 
Por tanto, si medimos las innovaciones de acuerdo con su nivel de incidencia, $<33 \%$ se corresponde con R1, entre $33 \%$ y $66 \%$ con $\mathrm{R} 2$ y, por último, $>66 \%$ con R3. R1 se documenta en el área más distante, seguida de R2 que cubre la periferia del foco, el cual presenta una incidencia superior al 66\%. La segunda conclusión tiene que ver con el patrón de difusión de las formas aceptadas en la lengua estándar. En este caso, la tendencia hacia la norma peninsular de distinguir mediante dos pronombres la formalidad de la situación, asociando vosotros $+2 \mathrm{pl}$ a la informalidad y ustedes $+3 \mathrm{pl}$ a la formalidad, se promueve en los núcleos más urbanos y se va esparciendo de modo jerárquico o en cascada a otros núcleos de la misma proporción demográfica, los cuales, a su vez, la difunden a otros de características similares hasta que llega a las zonas más rurales en última instancia. Este modelo de difusión se denomina modelo de gravedad. En palabras de Wolfram \& Schilling - Estes:

Changes are most likely to begin in large, heavily populated cities, which have historically been cultural centres. From there, they radiate outward, but not in a simple wave pattern. Rather, innovations first reach moderately seized cities, which fall under the area of influence of some large, focal city, leaving nearby sparsely populated areas unaffected. Gradually, innovations filter down from more populous areas to those of lesser population, affecting rural areas last, even if such areas are quite close to the original focal area of the change (Wolfram \& Schilling-Estes 2003: 724).

Este modelo de gravedad o jerárquico debe subordinarse a la teoría de las ondas en este caso, puesto que la incidencia del uso vernáculo también depende de la zona del ALPI donde se halle el municipio: por ejemplo, hay mayor número de enclaves con bajo uso en Córdoba que en la provincia de Cádiz. Sin embargo, el modelo de gravedad permite entender que las ciudades de Sevilla y Málaga hayan producido muy pocos empleos dialectales, favoreciendo en gran medida la distinción entre ustedes y vosotros. Seguidamente, hallamos los núcleos de Cádiz, Algeciras o Écija, que presentan una distribución media y, por último, pueblos más modestos como Conil de la Frontera, Lebrija, Lucena, Antequera o Ayamonte, por citar algunos, donde el fenómeno aún está muy arraigado. El análisis geolingüístico actual, que ha incluido ciudades y hablantes con estudios, permite, pues, confirmar, de un lado, y matizar, de otro, la distribución reflejada por los atlas. 
En el caso del portugués, la extensión de vocês y sus concordancias pueden sintetizarse en el mapa 9:

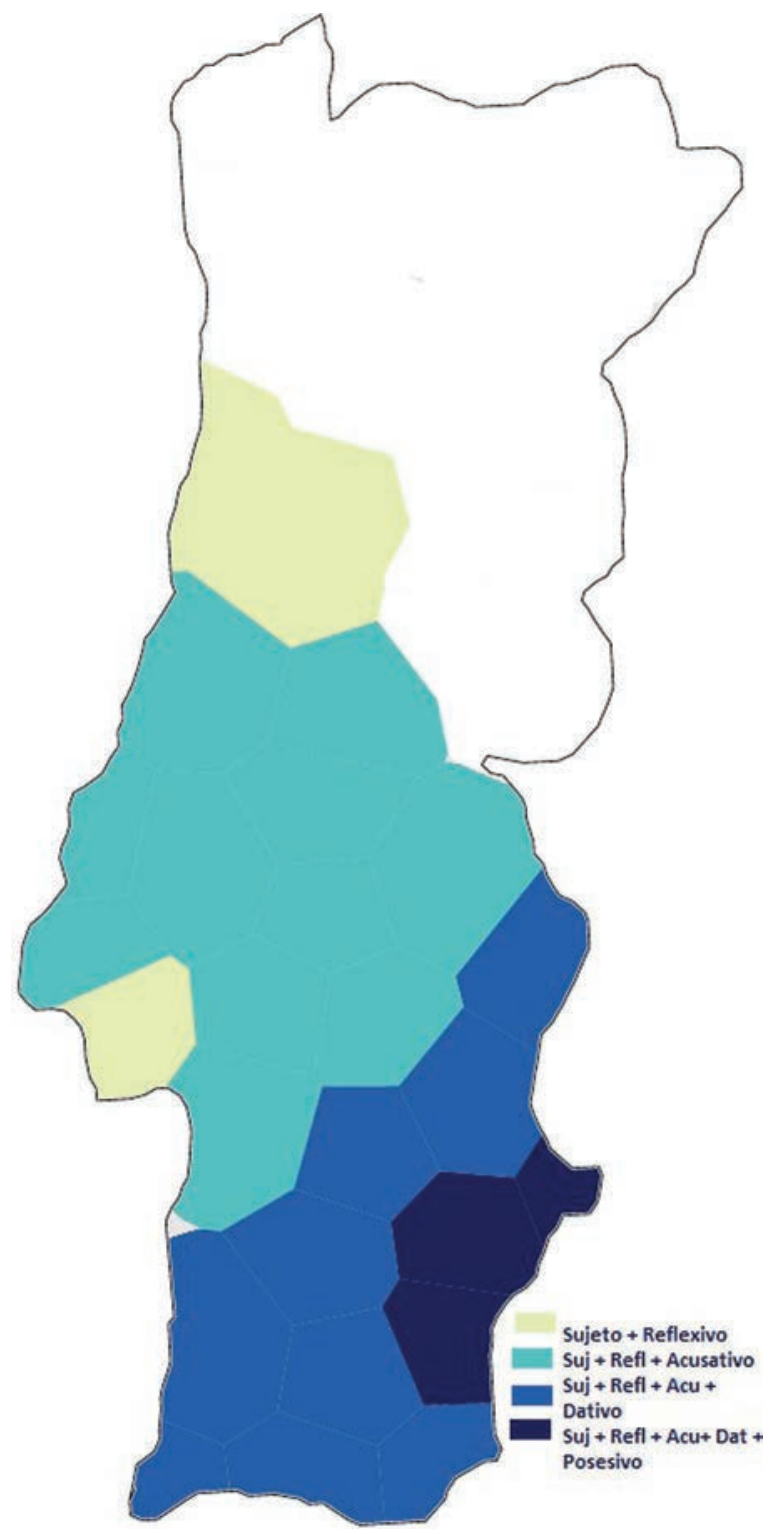

Mapa 9: Extensión del tratamiento vocês y formas concordantes en Portugal. 
El mapa 9 muestra claramente que el fenómeno ha progresado de acuerdo con el modelo de ondas o por contagio. Si atendemos al mismo, observamos que la primera oleada coincide con la nivelación del sujeto con el reflexivo y el verbo en 3 pl. Seguidamente, en una zona que comprende casi toda el área del fenómeno, excepto en las nuevas provincias afectadas y en la capital, el acusativo adopta la $3 \mathrm{pl}$. La innovación posterior recae en la flexión en $3 \mathrm{pl}$ del dativo, cuya área de incidencia es menor, ya que tan solo cubre el extremo oriental del país. La innovación ulterior es el sintagma de vocês para el posesivo, tan solo atestiguado en la provincia de Beja, en su zona más limítrofe con España. Claramente, esta última innovación parece indicar que el foco o epicentro del uso de vocês se halla en el distrito de Beja, en las inmediaciones de Serpa y Barrancos, justo en la frontera con el fenómeno andaluz. Los materiales del CORDIAL-SIN, no obstante, no dan apenas cuenta de ocurrencias, pero muestran una ligera influencia de la nivelación en vocês en las provincias de Aveiro y Viseu.

Una cuestión extremadamente interesante es que el mapa que ha resultado de nuestra investigación coincide con las isoglosas clásicas trazadas para el portugués europeo continental por Manuel de Paiva Boléo (1950), cuyo límite se difumina alrededor de Viseu y Aveiro pero apenas alcanza Castelo Branco. Esta división se basa sobre todo en la pronunciación de dos fonemas: [ $\left.\mathrm{t} \int\right]$ y $[\mathrm{g}]$. Al norte se mantiene la pronunciación africada [t $\widehat{\tau}]$ mientras que al sur se ha generalizado la fricativa [S]. El mapa 10 muestra la frontera del primer fenómeno, cuya división es pareja a la expresión de [k] por [g]. 


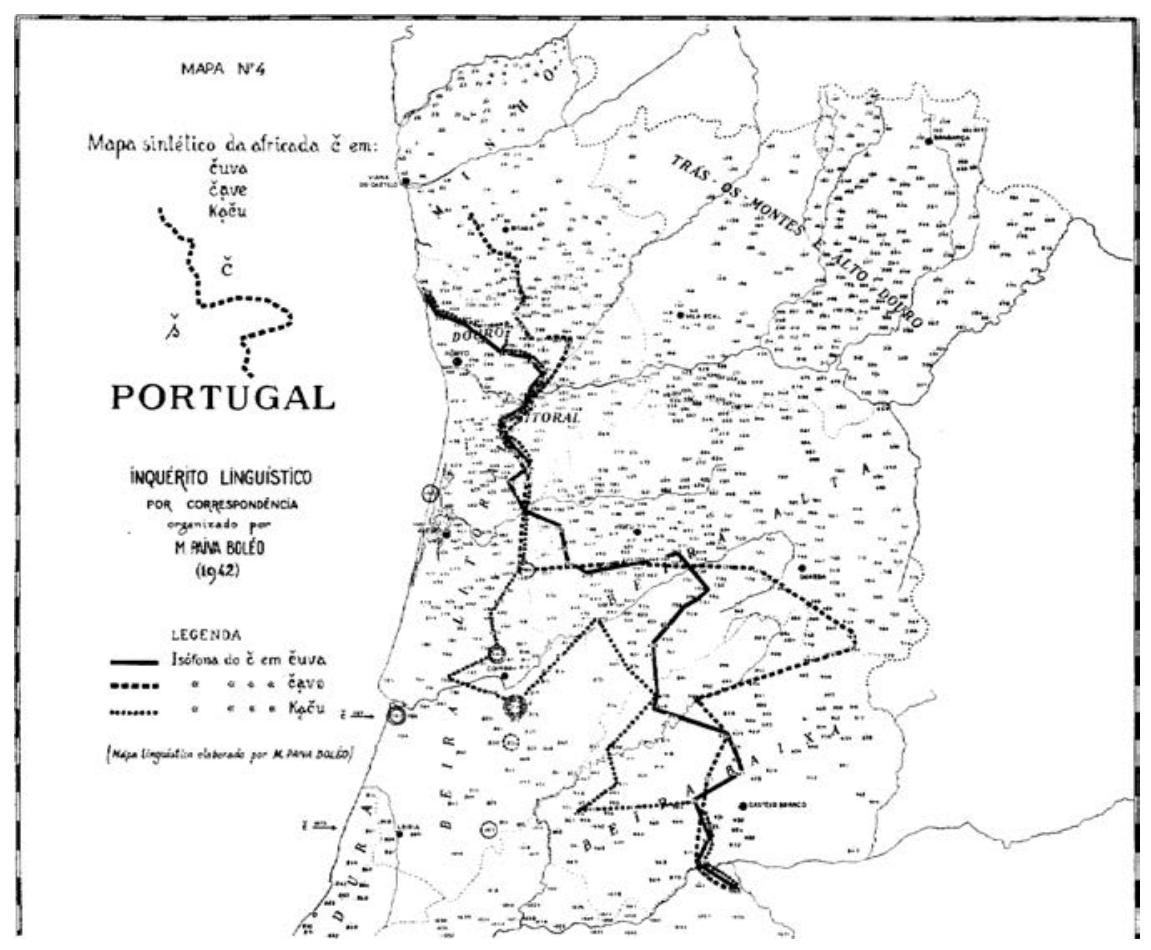

Mapa 10: Principales isoglosas de Portugal I (Boléo 1950: 48).

La misma área en la que vocês se ha extendido es en la que se documenta una pronunciación de ch como [S].

La propuesta de Paiva Boléo se asemeja a la de Luís F. Lindley Cintra (1970), que dibuja en dirección diagonal, desde Aveiro hasta Castelo Branco, la frontera entre los dialectos norteños y sureños y la pronunciación distinta de ambos fonemas $/ \mathrm{t} \widehat{\int} / \mathrm{y} / \mathrm{g} /$. El siguiente mapa muestra la división en dos áreas compactas: norte y sur. La línea roja representa la isoglosa entre las dos zonas lingüísticas del portugués europeo continental. 


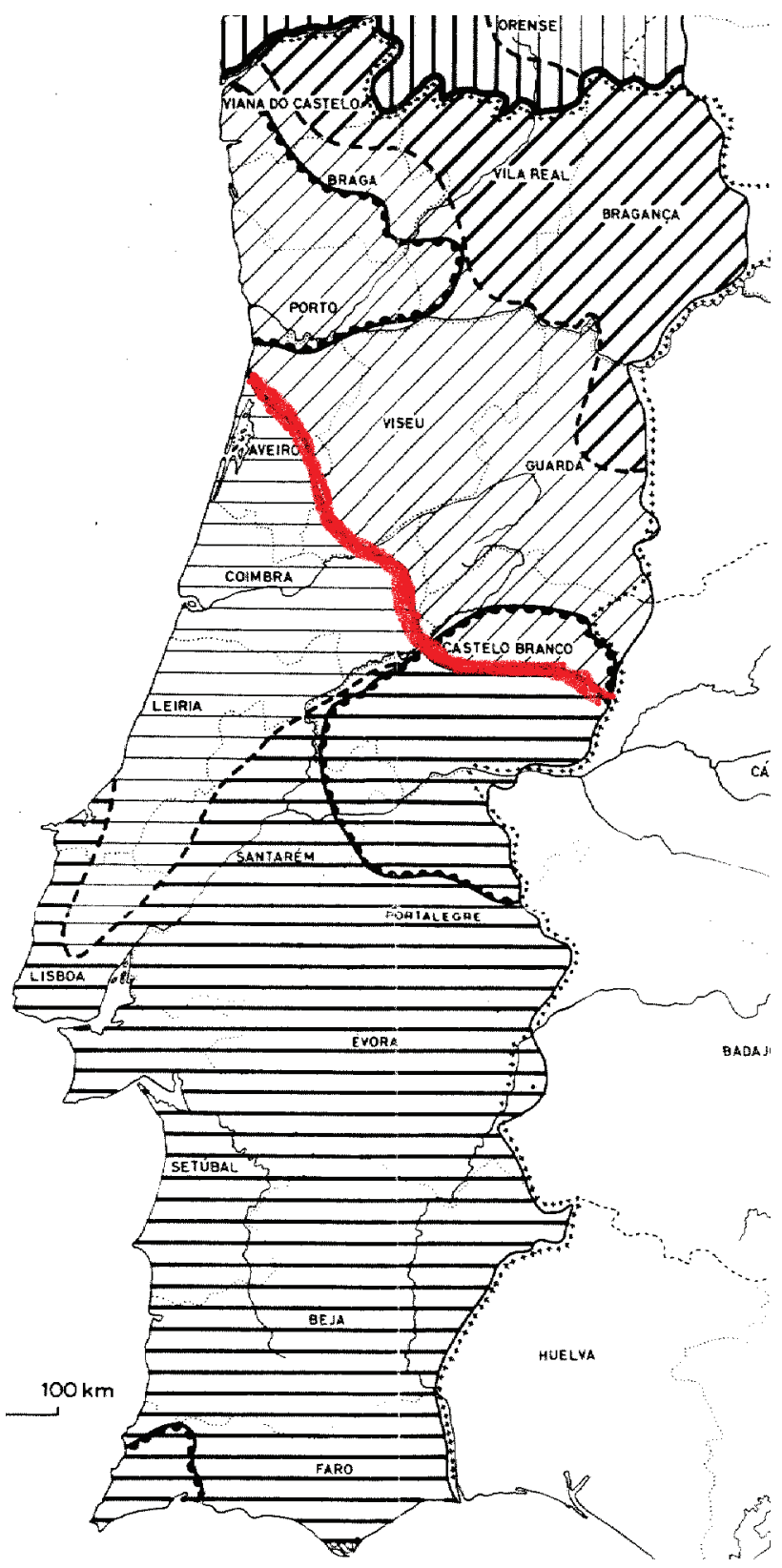

Mapa 11: Principales isoglosas de Portugal II (Cintra 1970: 118). 
En conclusión, la gramática también puede ayudar a constituir o corroborar áreas dialectales, aunque pocas veces se recurrió a ella en la dialectología tradicional, tan apegada a la fonética y el léxico. Sin embargo, nuestra visión de los dos fenómenos se ve modificada en parte cuando los cotejamos en conjunto y no por separado. Si se ilustran ambos fenómenos en un mismo mapa, observamos un área común (mapa 12).

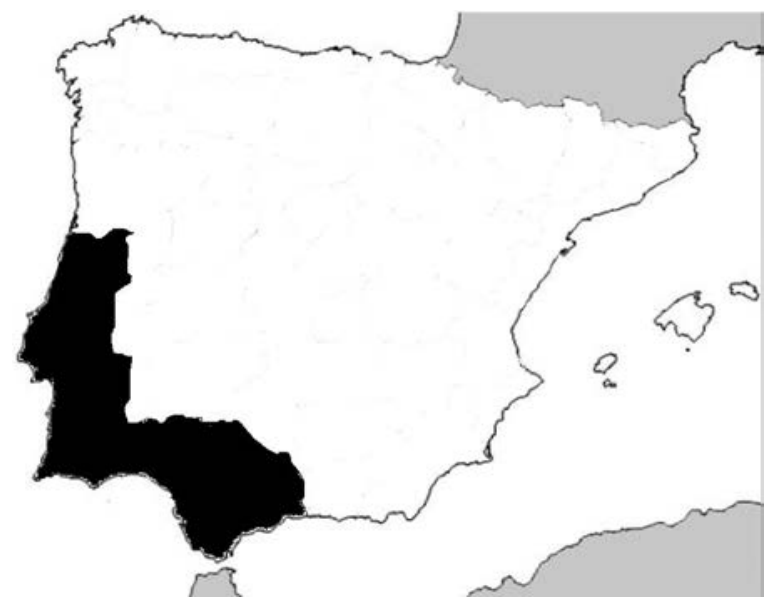

Mapa 12: Extensión geográfica de las nivelaciones en ustedes y vocês en la Península Ibérica.

El mapa 12 refleja una tendencia interesante, puesto que la nivelación se esparce por todo el suroeste de la Península Ibérica, evidenciando la cercanía lingüística entre Andalucía occidental y el centro-sur de Portugal. Esta proximidad también se ha atestiguado en otros fenómenos de corte léxico y fonético. Según Fernández-Ordóñez (2011), la palabra borrego para denominar a la cría de la oveja se difunde por toda la zona suroccidental del español peninsular y penetra en el centro-sur portugués, en detrimento del vocablo cordeiro. Además, la palabra chivo también se manifiesta de forma ininterrumpida por la misma área del español peninsular y el centro-sur de Portugal (chibo), o el término mazorca - maçaroca que comparte una distribución cartográfica similar. Resulta pertinente subrayar el hecho de que estas palabras no solo hacen referencia a variación léxica, sino que pertenecen al campo de la agricultura y los animales domésticos, por lo que reflejan una proximidad cultural muy estrecha. Cintra (1961, 1962) divide el centro-norte y el centro-sur, de acuerdo con las diferencias 
entre las palabras ordeñar o ubre, entre otras, y da cuenta de que la parte meridional posee cierta tendencia a difundir innovaciones aunque no de manera sistemática.

En cuanto a la fonética, hemos indicado que Cintra (1970) estableció la distinción entre centro-norte y centro-sur al comparar varias pronunciaciones, pero la producción de la sibilante correspondiente a las grafías /s/ y /ss/ el criterio que más consenso ha suscitado a la hora de partir geográficamente el portugués europeo. A tenor de sus descubrimientos, la pronunciación septentrional es ápico-alveolar mientras que la del sur es predorsodental. Y es precisamente la pronunciación del sur la que coincide con la pronunciación del seseo en Andalucía occidental. Todas estas coincidencias han llevado a postular la creación de un área de convergencia lingüística o Sprachbund (como es conocido más comúnmente), cuya prueba más visible se materializa en lo que se refiere a la cortesía. Los datos que han resultado del trabajo de campo sugieren que el desarrollo de las nivelaciones portuguesa y española han ido por caminos idénticos en lo que se refiere a su evolución gramatical (cuestión en la que profundizaremos en los capítulos siguientes) y a su establecimiento definitivo en la parte suroccidental de la Península Ibérica. No obstante, esta no es la única vez que han terminado desarrollando una misma estrategia para la cortesía.

El surgimiento de varios sintagmas nominales en la Edad Media ocurrió simultáneamente y ambas lenguas evolucionaron hacia un mismo sistema: vuestra merced / a vossa mercê se convirtió en la estrategia menos marcada de cortesía, vuestra majestad / a vossa majestade se empleó para dirigirse al monarca, vuestra excelencia / a vossa excelência se reservó para la aristocracia y el clero (Menon 2006, Menéndez Pidal 2005). En el primer caso (vuestra merced / a vossa mercê), ambos sintagmas desarrollaron el mismo proceso de gramaticalización. Es más, Lara (2012) muestra ocurrencias de estadios antiguos en la gramaticalización de a vossa mercê a você, ya que los datos del ALPI proporcionan ejemplos de vossemecê o vomecê. Estas dos alternativas coinciden con fases intermedias en la evolución de vuestra merced a usted en español, como vuested o vuesasted (Menon 2006, Pla Cárceles 1923). Desde un punto de vista gramatical, el proceso se ha repetido en diferentes ocasiones. Como veremos y defenderemos en el capítulo 5, hace cien años, ustedes era un tópico que se iba tornando en sujeto y, según Hammermüller (2010), la imposición de vuestra merced sobre vós siguió el mismo proceso. Primero 
se expresó como vocativo y, por consiguiente, su posición era extraoracional. El verbo se conjugaba en $2 \mathrm{pl}$ debido a que la concordancia la inducía el pronombre vós. Como el español es una lengua pro drop, la producción de vós tenía que ser baja en comparación con la probabilidad de aparición del vocativo o el tópico (vuestra merced). Una vez que la construcción se hizo cada vez más frecuente, vuestra merced se reinterpretó como sujeto y, en consecuencia, el verbo comenzó a concordar en 3 sg. De hecho, según Menon (2006), Menéndez Pidal (2005) y Cano (2008), los primeros usos de vuestra merced / a vossa mercê alternaban entre concordancia de $2 \mathrm{pl}$ y $3 \mathrm{sg}$.

Llama la atención que el desarrollo autónomo en el sistema de tratamientos en ambos idiomas tenga lugar en el Sprachbund suroccidental o, dicho de otro modo, que las nivelaciones se restrinjan al suroeste de la Península Ibérica (aunque en el caso de Portugal, empieza a extenderse al norte por representar el estándar). Si bien los Sprachbünde más célebres son los que se atestiguan en los Balcanes o el área de convergencia lingüística del sudeste asiático (e incluso uno mayor en toda Europa, según Haspelmath 2001), la región ibérica en la que estas nivelaciones se manifiestan se caracteriza por compartir un desarrollo común, independientemente del período histórico. A modo de ejemplo, la lengua tartesia, hablada antes de la conquista de la Península Ibérica por el imperio romano, se extendía prácticamente por la zona en la que, actualmente, la nivelación en ustedes está más arraigada No obstante, el período en el que dicha zona geográfica compartió más intercambio fue justo después del descubrimiento de América y la división del mundo que llevaron a cabo las coronas de España y Portugal.

Durante los siglos posteriores hasta la independencia de las colonias españolas y portuguesas de América, la región suroccidental de la Península Ibérica era la zona de la que partían numerosas expediciones y desde donde se llevaba a cabo el comercio con el continente americano. Y, como en el portugués europeo y en Andalucía occidental, vemos las mismas nivelaciones en las variedades americanas de ambas lenguas. La influencia entre ambos lados del Atlántico a este respecto no ha sido estudiada a fondo. No vamos a entrar en el debate sobre la influencia andaluza en las variedades americanas, ya que representa un tema bastante controvertido, pero de alguna manera se han tenido que condicionar las unas a las otras en una época poscolonial. Ya hemos comentado que la eliminación de vosotros en Andalucía se inició en el siglo XVIII, cuando España aún 
era metrópoli y, en el siglo XIX, ustedes ya se había generalizado en dicha zona (Fernández 2012, García Godoy 2012). Asimismo, se suele datar la desaparición completa de vosotros de las variedades de América a finales del siglo XIX (Bertolotti 2015, en prensa). El portugués exhibe este mismo patrón. Al igual que con el español, no entraremos en detalle sobre la influencia del sur de Portugal sobre la variedad brasileña, pero la nivelación en vocês, que también comenzó en el siglo XVIII (Cintra 1972, Faraco 1996), se ha extendido por todo Brasil y lleva siendo el único pronombre informal durante más de dos siglos (Menon 2006).

De igual manera, en singular, podemos atestiguar desarrollos análogos a ambos lados del Atlántico. A día de hoy, el pronombre formal usted en español se percibe como informal e incluso afectivo en ciertas regiones americanas, sobre todo en América Central y el Caribe (Hummel et al. 2010). Su empleo es compartido con los pronombres informales tradicionales tú y vos, ya que se puede recurrir a los tres en contextos tanto informales como íntimos. García Godoy (2012) y Calderón Campos (2010) afirman que usted como informal o afectivo se podía usar en el español andaluz durante la última etapa colonial, es decir, en un momento en que América Latina empezaba a adoptarlo también para la informalidad. De nuevo, la nivelación en singular de usted a expensas de tú se origina en el español peninsular del suroeste y se exporta posteriormente a las variedades americanas. El caso del plural parece seguir el mismo modelo.

La situación del portugués está mejor documentada. En el plural, Brasil no posee el pronombre vós para la informalidad de $2 \mathrm{pl}$, al igual que el portugués europeo meridional, sino que emplea vocês como informal y os senhores como la estrategia de formalidad más común. En singular, você ha desplazado a $t u$ en casi todo el país latinoamericano (Lopes \& Cavalcante 2011) y en el portugués europeo del sur, aún aparece como pronombre informal (Lara \& Guilherme 2015, 2018). Además, las similitudes también surgen en la 1pl: el brasileño ha difundido la innovación a gente en lugar del canónico nós para la 1pl, la cual también se atestigua geográficamente en el sur de Portugal y no en el norte (Lara \& Díez del Corral 2015). Ya sea en español o en portugués, todos estos fenómenos se originan en el Sprachbund de la Península Ibérica y luego se empiezan a manifestar también en las variedades americanas.

Las similitudes en fonética, morfosintaxis y los sistemas de tratamiento en América y en la región suroccidental de la Península Ibérica tienen explicación por el intercambio comercial que se concentraba en ciertos 
puertos. Las relaciones entre Sevilla, Cádiz, Lisboa y el Algarve con las colonias americanas produjeron nivelaciones que se mantienen hoy día, en comparación con otros grandes puertos peninsulares (como Oporto o Bilbao), que mantuvieron unos rasgos lingüísticos distintos. Sin embargo, Oporto y Bilbao recibían mercancías de otros lugares y no promovieron el intercambio con las colonias americanas (O'Flanagan 2008). Su independencia hizo que las oposiciones vós - vocês y vosotros - ustedes sobrevivieran; por el contrario, la interdependencia de los puertos suroccidentales (Pike 1972) con sus sucursales en América provocaron un desarrollo propio que puede contemplarse en los rasgos fonéticos y léxicos a los que nos hemos referido anteriormente, pero sobre todo, condujeron a un sistema de formas de tratamiento propio, cuya evolución ha sido pareja. 



\section{Sociolingüística de la cortesía en el suroccidente peninsular}

Todo trabajo de campo que se precie necesita de un apoyo empírico que elimine cualquier prejuicio o idea preconcebida que se haya adquirido durante el mismo. Aunque en la realización de las encuestas, el investigador adquiere de facto una serie de conclusiones, a la vista de lo que ha ido recogiendo, estas impresiones pueden jugarle una mala pasada a la hora de analizar los datos, ya que puede estar influenciado por un juicio previo. Con el fin de evitar estos peligros, hemos decidido aplicar un análisis estadístico a nuestra muestra.

Basándonos en todo lo que se ha dicho hasta ahora (Cano 2004, Menéndez Pidal 2005, Lara 2012, Lapesa 1981 y 2000, Mondéjar 1970, Penny 2004, Alvar, Llorente \& Salvador 1961-1965, Alvar 1996, Carrasco Santana 2002, Fernández 2012), así como en los datos extraídos del ALPI (Lara 2011, 2012), hemos optado por considerar el pronombre tónico (ustedes / vosotros) la variable dependiente primordial, ya que el fenómeno, a la luz de los mismos datos históricos, surge en esa forma.

Como toda cuantificación estadística, esta no ha estado exenta de problemas. En nuestro caso, a pesar de contar con 242 informantes y 4.491 ocurrencias, la muestra resulta demasiado pequeña para un análisis de tanta envergadura. A diferencia de una selección aleatoria, en la que se estudia a un número importante de personas escogidas al azar, nuestro corpus se ha confeccionado de acuerdo con una selección por cuotas, es decir, se ha decidido de antemano el perfil sociológico del encuestado y se ha procurado expresamente ese tipo de informantes en detrimento de otros, que no eran de interés en nuestra investigación. Asimismo, el sistema de selección de la muestra utilizado establece limitaciones a la validez inferencial de los contrastes estadísticos en relación con los que habrían resultado de una selección aleatoria, por otro lado imposible en nuestro caso, aunque siguen teniendo, no obstante, un valor indicativo. Los resultados, por tanto, han de juzgarse atendiendo a estas restricciones.

En todo estudio sociolingüístico de corte variacionista se pretende averiguar qué factor lingüístico o sociológico incide en mayor medida 
en el desarrollo lingüístico de un fenómeno dado. Estos factores se suelen denominar como variables independientes, porque de ellas depende, en gran medida el comportamiento gramatical de dicho fenómeno. Para nuestra investigación, como ya se explicó en el capítulo 2, hemos elegido como factores extralingüísticos el sexo, la edad, el nivel de estudios, el tamaño del municipio de residencia, la provincia y la zona del ALPI. Como variables dependientes, el pronombre tónico en función de sujeto y de término de sintagma preposicional. Para la estadística descriptiva, hemos manejado además las variables referidas al clítico, el posesivo, el tiempo y modo verbales, la modalidad y la situación comunicativa. En el caso del verbo subordinado, también mediremos la incidencia del tipo de subordinada.

A tenor de la bibliografía especificada en este trabajo, el uso de $u s$ tedes a costa de vosotros respondía a hablantes iletrados, de entorno rural y circunscritos a las provincias de Cádiz, Córdoba, Huelva, Málaga y Sevilla. Debido a que el ALPI tan solo recogió respuestas de informantes mayores, decidimos en la confección del corpus, incluir todas las franjas etarias (menores de 30 años, de mediana edad y ancianos), ya que las distintas fases vitales de cada uno son cruciales en nuestro comportamiento lingüístico. Asimismo, introdujimos el factor sexo, puesto que se ha demostrado que las mujeres suelen ser más sensibles a las formas de prestigio por diversos motivos a los que ya aludimos anteriormente. Hemos recogido en el tamaño de la población de residencia la idea de entorno rural o urbano, ya que resulta muy arbitrario decidir a partir de qué número de habitantes se considera que un municipio es rural o urbano. Además, en la actualidad, dicha dicotomía no se encuentra tan marcada como antes, puesto que es habitual que una persona que viva en lo que, hasta ahora, se ha denominado enclave rural, se desplace diariamente a un entorno urbano, por motivos de trabajo, familiares, de ocio o de la índole que sea. Es más, desde la década de 1960, las encuestas que el Instituto Nacional de Estadística (INE) realiza a los hogares sobre las condiciones de vida vienen recogiendo la convergencia que existe entre los modelos de vida de núcleos pequeños y amplios; entre otro motivos, la cesta de la compra (un indicador que siempre ha proporcionado una diferencia entre el concepto rural y urbano) se ha igualado en ambos núcleos, el porcentaje de población universitaria es pareja, debido a las mejoras de las comunicaciones, y los hábitos en el ocio también se han igualado. Por tanto, hemos optado por dividir la muestra en cinco clases: mayor y menor de 5.000 habitantes; 
mayor o menor de 10.000 habitantes; mayor o menor de 20.000 habitantes; mayor o menor de 100.000 habitantes; mayor o menor de 500.000 habitantes. Por último, hemos resuelto incluir la zona ALPI (de acuerdo con la clasificación en áreas que se desprende de los datos de dicho atlas y de la que ya hemos hablado a lo largo del libro) por una razón, aparentemente, obvia: los límites lingüísticos no tienen por qué coincidir con los administrativos.

\subsection{Estudio estadístico}

Una vez explicada la composición del análisis, nos disponemos a describir la muestra. La variable dependiente (pronombre tónico) se ha correlacionado con cada una de las independientes de dos maneras: atendiendo al número de informantes que han dado una solución u otra y al número de ejemplos producidos para cada categoría. Igualmente, hemos aplicado la prueba del contraste chi cuadrado de Pearson para cada caso, con el fin de establecer la significatividad de los datos analizados. La prueba del chi cuadrado contrasta la hipótesis de independencia entre las variables consideradas. Si el contraste resulta significativo, esto supone que hay base empírica suficiente para rechazar esta hipótesis y, por consiguiente, para aceptar la alternativa: que existe relación entre ambas variables. La decisión puede tomarse con distintos niveles de significación, siendo el más frecuente el del 5\%. El umbral de significatividad del contraste viene dado, en cada caso, en función del nivel de significación fijado y de los grados de libertad, que dependen, a su vez, del número de variables y de categorías consideradas.

Debido a que la muestra nos ha proporcionado un gran número de informantes que se caracterizaban por la variación en el pronombre tónico, hemos optado por hacer dos clasificaciones: informantes que usan sistemáticamente o en gran mayoría el pronombre ustedes (a la que hemos abreviado con la letra $U$ ) e informantes que usan sistemáticamente o en gran mayoría el sistema peninsular (clasificación que hemos abreviado con la letra $V$ ). Esta decisión responde al hecho que ya apuntábamos con anterioridad: el corpus resulta demasiado escaso para un análisis estadístico que pretende contemplar un gran número de variables. A mayor división, 
menor muestra y, por consiguiente, más dificultad a la hora del análisis estadístico y de su utilidad para nuestro caso. Con el fin de sintetizar la gran información estadística que se obtuvo en el análisis, ofreceremos los resultados de las variables que resultaron significativas: el nivel educativo (tabla 12), la edad (tabla 13) y la demografía del enclave (tabla 14).

Tabla 12: Significatividad del nivel de estudios.

Tabla de contingencia SUJETO U / V * Estudios

Recuento

\begin{tabular}{|ll|r|r|r|}
\hline \multirow{2}{*}{} & & \multicolumn{2}{|c|}{ Estudios } & \multirow{2}{*}{ Total } \\
\cline { 3 - 4 } & & $\mathrm{N}$ & $\mathrm{S}$ & \\
\hline SUJETO U / V & $\mathrm{U}$ & 116 & 16 & 132 \\
& $\mathrm{~V}$ & 53 & 44 & 97 \\
Total & 169 & 60 & 229 \\
\hline
\end{tabular}

Pruebas de chi-cuadrado

\begin{tabular}{|l|c|c|c|c|c|}
\hline & Valor & gl & $\begin{array}{c}\text { Sig. asintótica } \\
\text { (bilateral) }\end{array}$ & $\begin{array}{c}\text { Sig. exacta } \\
\text { (bilateral) }\end{array}$ & $\begin{array}{c}\text { Sig. exacta } \\
\text { (unilateral) }\end{array}$ \\
\hline Chi-cuadrado de Pearson & $31,949^{\mathrm{a}}$ & 1 &, 000 & & \\
Corrección por continuidad & 30,253 & 1 &, 000 & & \\
Razón de verosimilitudes & 32,279 & 1 &, 000 &, 000 &, 000 \\
Estadístico exacto de Fisher & 229 & & &, & \\
N de casos válidos & 229 & & & \\
\hline
\end{tabular}

a. 0 casillas $(0,0 \%)$ tienen una frecuencia esperada inferior a 5 . La frecuencia mínima esperada es 25,41 .

b. Calculado sólo para una tabla de $2 \times 2$. 


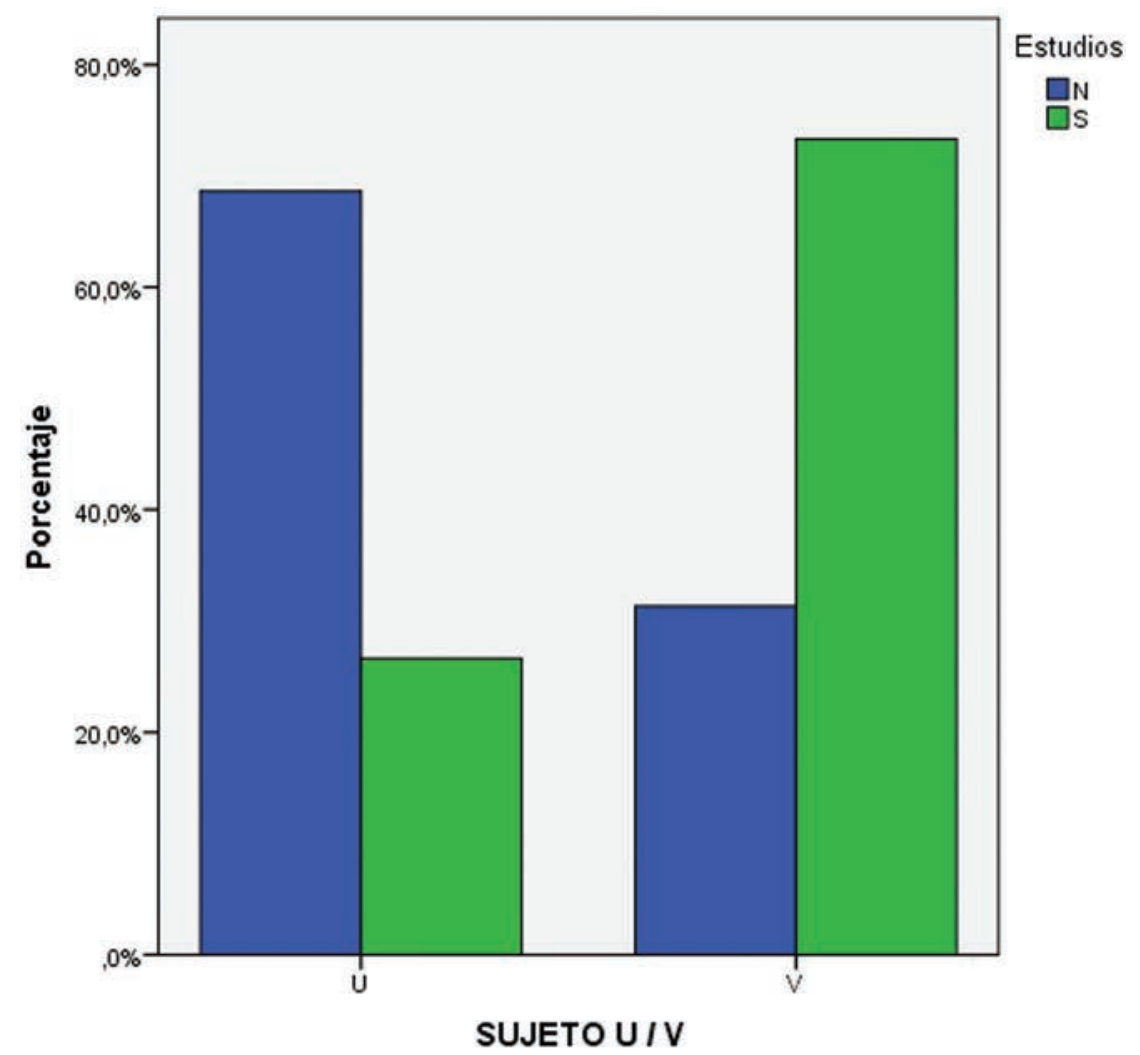

Gráfico 1: Nivel de estudios en el uso de ustedes.

El nivel educativo parece incidir fuertemente también a la hora de elegir ustedes o comportarse en el tratamiento de $2 \mathrm{pl}$ como el resto de la Península. De acuerdo con el gráfico, la probabilidad de imitar las formas de prestigio es directamente proporcional al nivel de estudios. Los informantes que han cursado la educación superior prefieren en un 75\% la distinción ustedes / vosotros, mientras que los que no han alcanzado el ámbito universitario son altamente propensos a mantener actitudes lingüísticas vernáculas en este caso. Si atendemos a la tabla, los datos se cruzan claramente, dando a entender una gran relevancia de esta variable en el comportamiento lingüístico del hablante. El resultado del chi cuadrado de Pearson nos confirma el análisis, ya que, para un grado de libertad, ha dado 31, 949, muy por encima del valor de referencia. 
Tabla 13: Significatividad de la edad

Tabla de contingencia SUJETO U / V * Edad.

Recuento

\begin{tabular}{|lc|c|c|r|r|}
\hline \multirow{2}{*}{} & & \multicolumn{3}{|c|}{ Edad } & \multirow{2}{*}{ Total } \\
\cline { 3 - 5 } & & -30, & $30-60$ & $60-$ & \\
\hline \multirow{2}{*}{ SUJETO U / V } & U & 55 & 48 & 29 & 132 \\
& $\mathrm{~V}$ & 37 & 55 & 5 & 97 \\
Total & & 92 & 103 & 34 & 229 \\
\hline
\end{tabular}

Pruebas de chi-cuadrado

\begin{tabular}{|l|c|c|c|}
\hline & Valor & gl & $\begin{array}{c}\text { Sig. asintótica } \\
\text { (bilateral) }\end{array}$ \\
\hline Chi-cuadrado de Pearson & $15,962^{\mathrm{a}}$ & 2 &, 000 \\
Razón de verosimilitudes & 17,389 & 2 &, 000 \\
$\mathrm{~N}$ de casos válidos & 229 & & \\
\hline
\end{tabular}

a. 0 casillas $(0,0 \%)$ tienen una frecuencia esperada inferior a 5 . La frecuencia mínima esperada es 14,40 .

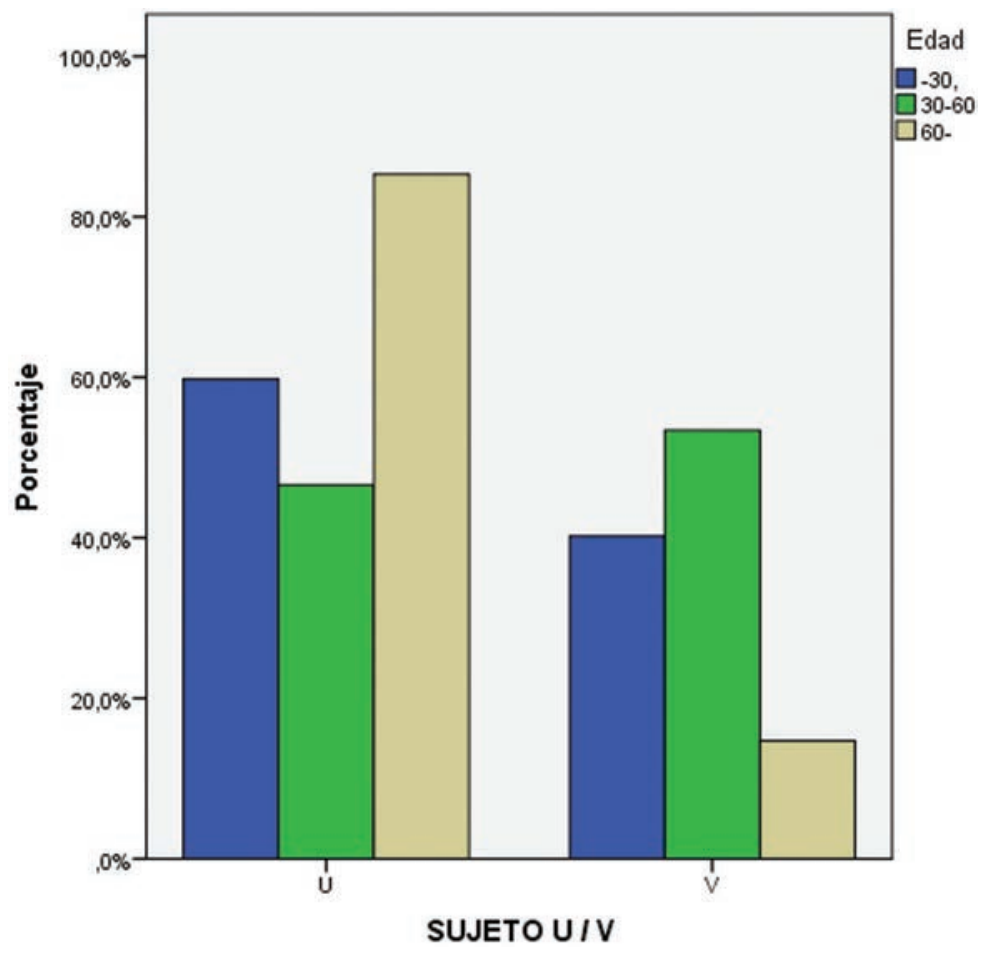

Gráfico 2: Edad en el uso de ustedes. 
La edad parece ser definitoria en el uso vernáculo o estándar de los pronombres de segunda persona del plural. Para dos grados de libertad, cuyo número de significatividad estadística es 5,991, el resultado obtenido corresponde a 15,962, muy por encima del umbral de relevancia. Al observar el gráfico de barras, se advierte claramente que los informantes mayores de 60 años prefieren con una amplia mayoría el uso exclusivo de ustedes, mientras que los otros dos grupos se reparten casi a partes iguales el comportamiento dialectal o estándar, siendo los hablantes de mediana edad los más sensibles (casi un 60\%) a la forma prestigiosa.

Por último, pretendemos averiguar cómo influye el número de habitantes y las características demográficas de los enclaves encuestados, con el fin de saber si los hablantes que pertenecen a entornos más poblados se comportan de distinta manera que aquellos que habitan en municipios más reducidos. De todos los cortes que se propusieron, ha sido la barrera del medio millón de habitantes ha sido crucial para el comportamiento lingüístico de la variable en estudio.

Tabla 14: Significatividad del tamaño de población.

Tabla de contingencia SUJETO U / V * POB 500.000

Recuento

\begin{tabular}{|ll|c|c|c|}
\hline \multirow{2}{*}{} & & \multicolumn{2}{|c|}{ POB 500.000 } & \multirow{2}{*}{ Total } \\
\cline { 3 - 4 } & & -500000 & 500000 & \\
\hline \multirow{2}{*}{ SUJETO U / V } & U & 124 & 8 & 132 \\
& $\mathrm{~V}$ & 81 & 16 & 97 \\
Total & 205 & 24 & 229 \\
\hline
\end{tabular}

Pruebas de chi-cuadrado

\begin{tabular}{|l|c|c|c|c|c|}
\hline & Valor & gl & $\begin{array}{c}\text { Sig. asintótica } \\
\text { (bilateral) }\end{array}$ & $\begin{array}{c}\text { Sig. exacta } \\
\text { (bilateral) }\end{array}$ & $\begin{array}{c}\text { Sig. exacta } \\
\text { (unilateral) }\end{array}$ \\
\hline $\begin{array}{l}\text { Chi-cuadrado de Pearson } \\
\text { Corrección por continuidad }\end{array}$ & $6,488^{\mathrm{a}}$ & 1 &, 011 & & \\
$\begin{array}{l}\text { Razón de verosimilitudes } \\
\text { Estadístico exacto de Fisher }\end{array}$ & 6,435 & 1 &, 020 & & \\
N de casos válidos & 229 & & &, 011 &, 010 \\
\hline
\end{tabular}

a. 0 casillas $(0,0 \%)$ tienen una frecuencia esperada inferior a 5 . La frecuencia mínima esperada es 10,17 .

b. Calculado sólo para una tabla de $2 \times 2$. 


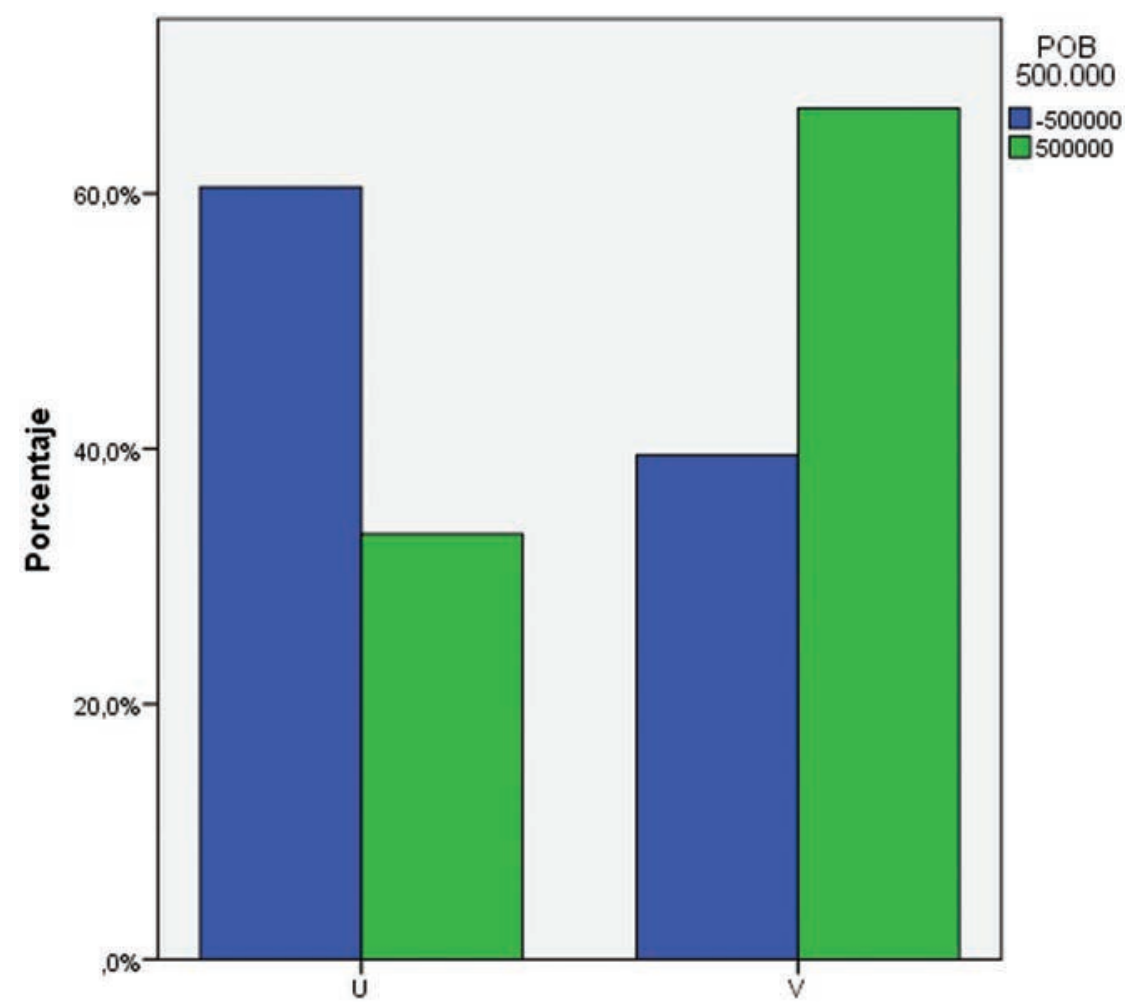

SUJETO UIV

Gráfico 3: Tamaño de población en el uso de ustedes.

En este corte, no obstante, el chi cuadrado sale relevante para un grado de libertad $(6,488)$. De acuerdo con el gráfico, hay una tendencia clara de los informantes que viven en entornos completamente urbanos (de más de medio millón de habitantes) por las formas estándares (70\%), frente al $60 \%$ de informantes procedentes de municipios menores que optan por el uso único de ustedes.

En otro orden de cosas, la prueba de la regresión logística ha dado como resultado el orden de impacto de los factores significativos que inciden en el fenómeno. En este caso, el rasgo extralingüístico más importante ha sido el nivel de estudios, seguido de la edad del informante. Por último, su adscripción a una densidad e población específica $(+500.000$ hab. o -500.000hab.) es el último aspecto que incide dentro de los tres más relevantes. Simplificando, los hablantes con estudios superiores, de entre 
30 y 60 años y/u oriundos de las zonas más urbanas son los que más se decantan por actitudes prestigiosas, en nuestro caso, la distinción entre vosotros y ustedes, de acuerdo con el canon peninsular. El procesamiento estadístico de los datos produjo significatividad tan solo en las variables de estudios, edad y tamaño de población. Puesto que esta última más el comportamiento geográfico ya han sido evaluados en el apartado anterior, pasemos a analizar de forma pormenorizada las otras dos variables independientes.

\subsection{Nivel de estudio}

El nivel educativo ha sido el que mayor relevancia ha proporcionado en el análisis estadístico, tanto del chi cuadrado de Pearson como de la regresión logística. Si comparamos los dos mapas donde se cartografía la incidencia de la particularidad dialectal, de acuerdo con este parámetro, observamos lo siguiente.

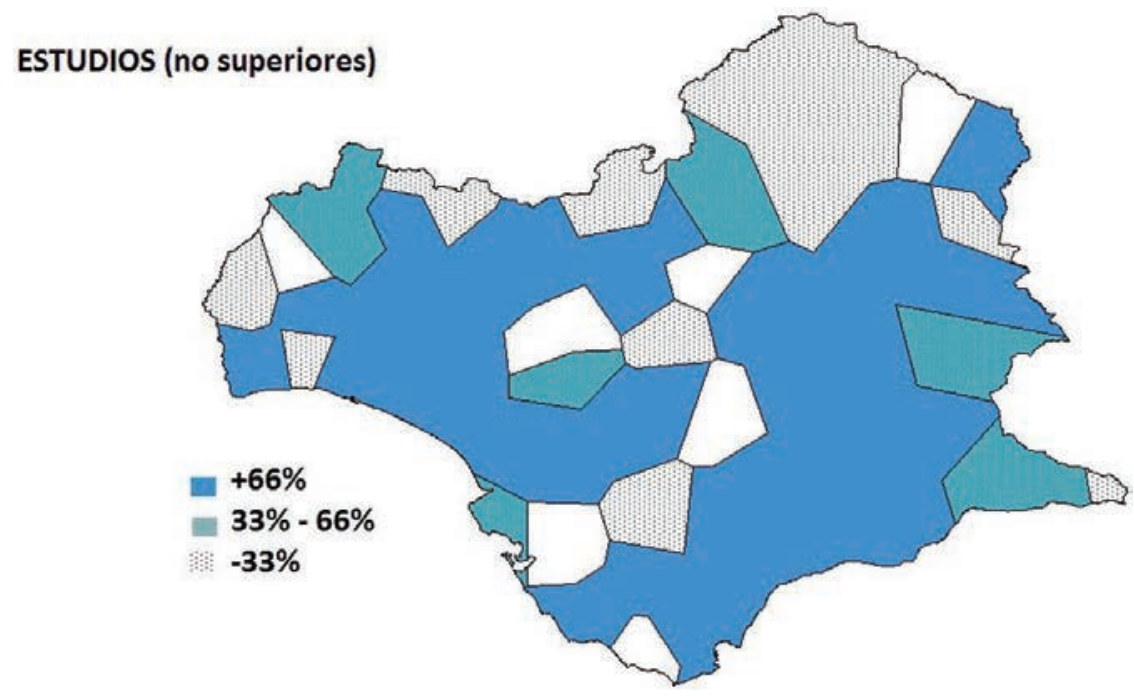

Mapa 13: Uso de ustedes en los informantes sin estudios superiores. 


\section{ESTUDIOS (superiores)}

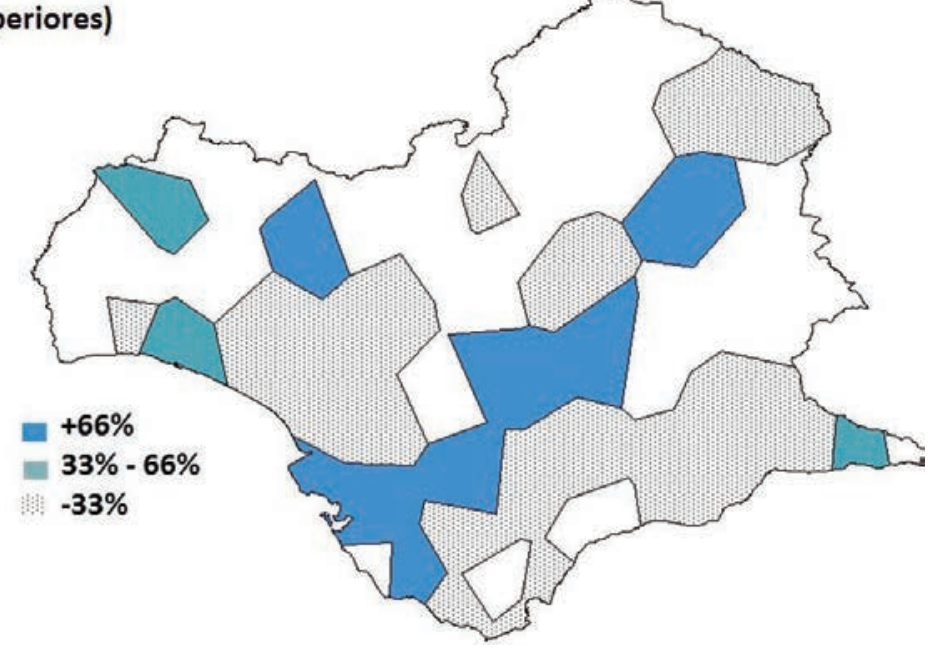

Mapa 14: Uso de ustedes en los informantes con estudios superiores.

El nivel $>66 \%$ decae de forma abrupta en los informantes cultos, cuyos individuos más vernáculos suelen pertenecer a enclaves gaditanos y sevillanos donde el fenómeno se mantiene con más vehemencia. En contraste, el uso del fenómeno es alto en hablantes con estudios no superiores por toda el área afectada. Solo en las zonas fronterizas con la zona 0 (sobre todo en Córdoba), el uso decrece hasta el nivel porcentual más bajo. Los casos de empleo intermedio, no obstante, son esporádicos, contra lo que cabría esperar a la vista de los mapas vinculados a las zonas del ALPI.

\subsection{Edad}

Si atendemos al factor edad (correlacionado con el nivel de estudios), enseguida observamos su importancia, como se cartografía en los mapas 15, $16,17,18$ y 19. 


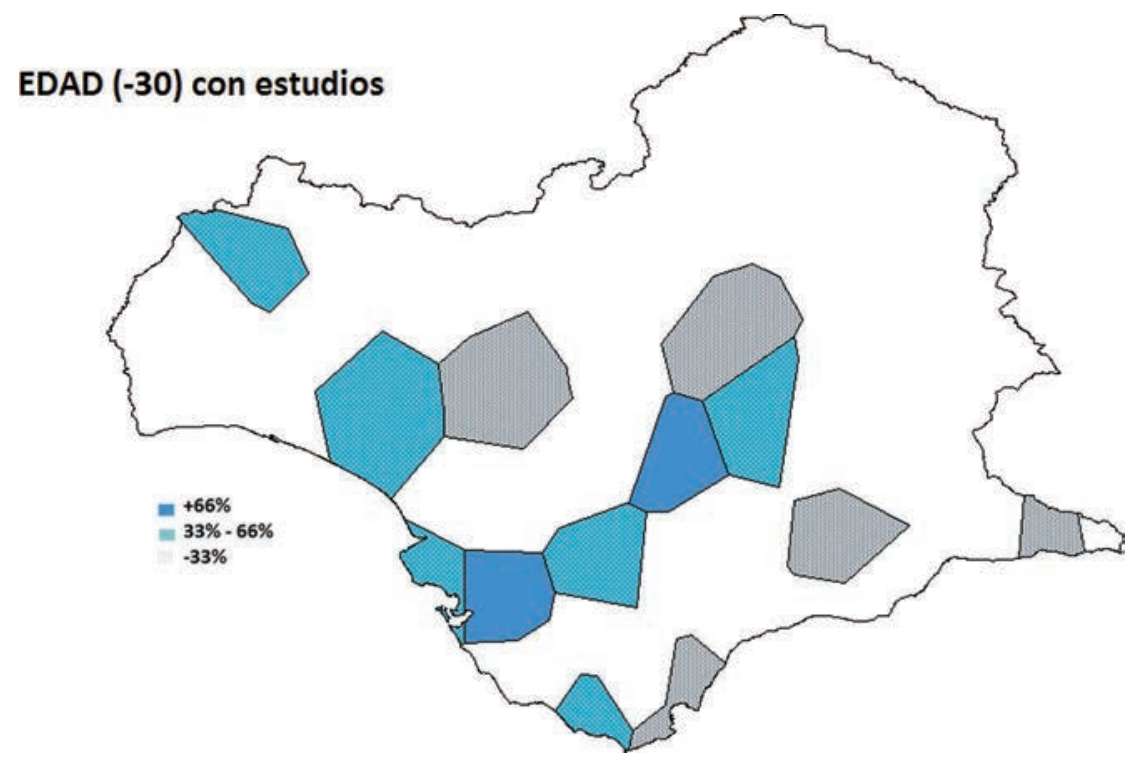

Mapa 15: Uso de ustedes en los informantes menores de 30 años (con estudios).

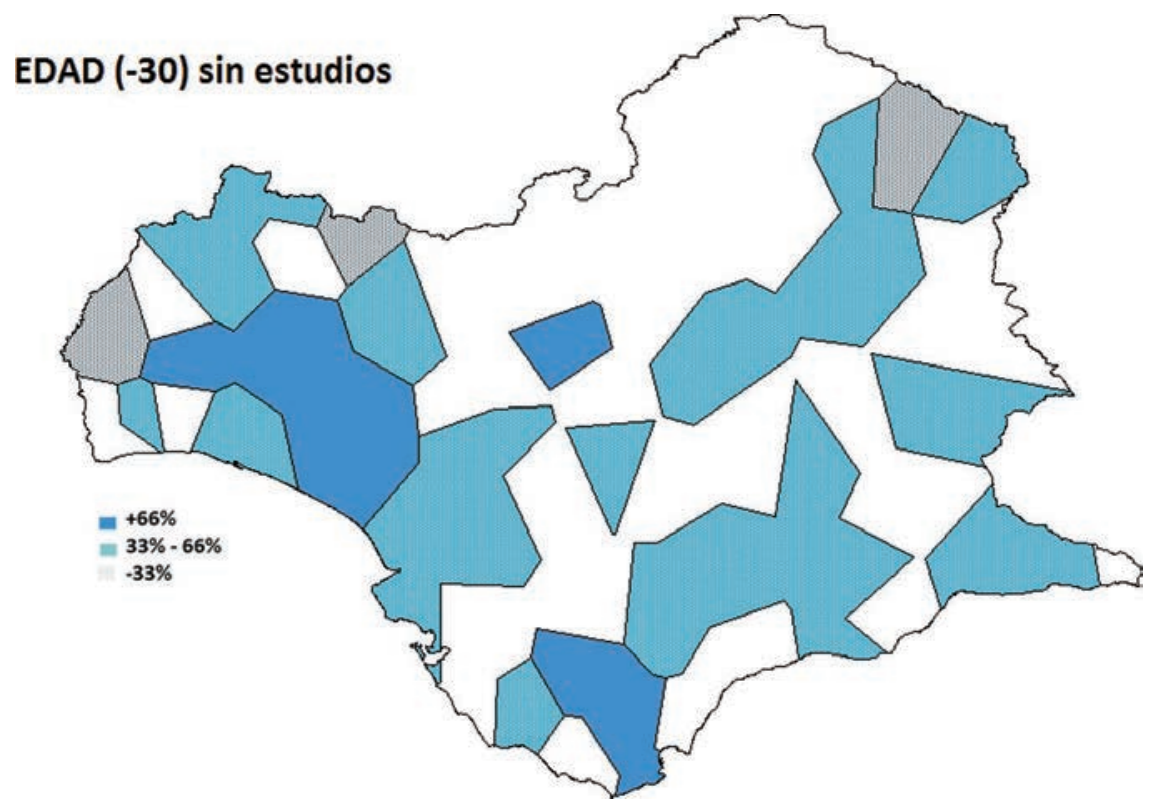

Mapa 16: Uso de ustedes en los informantes menores de 30 años (sin estudios). 
Los mapas 15 y 16 demuestran que, aunque la edad es un factor clave, el nivel de estudios asociado a la misma es tan importante como dicha variable. Aunque hay menos informantes con estudios superiores encuestados en la franja de edad menor de 30 años, la comparación nos permite observar que los hablantes más cultos tienden en mayor proporción al estándar incluso en aquellas zonas donde el fenómeno en estudio está más arraigado, mientras que la escasez de estudios superiores provoca un mayor conservadurismo, si bien no tan pronunciado como en las personas mayores, ya que los informantes menores de 30 años suelen permanecer en un grado intermedio de dialectalismo.

\section{$\operatorname{EDAD}(30-60)$ con estudios}

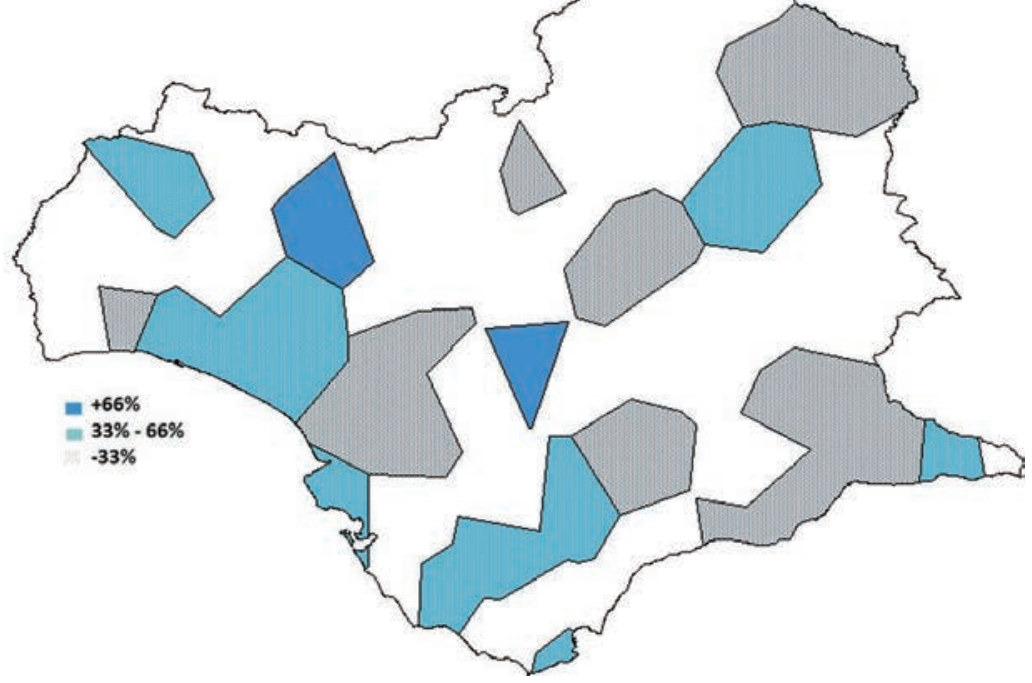

Mapa 17: Uso de ustedes en los informantes de entre 30 y 60 años (con estudios). 


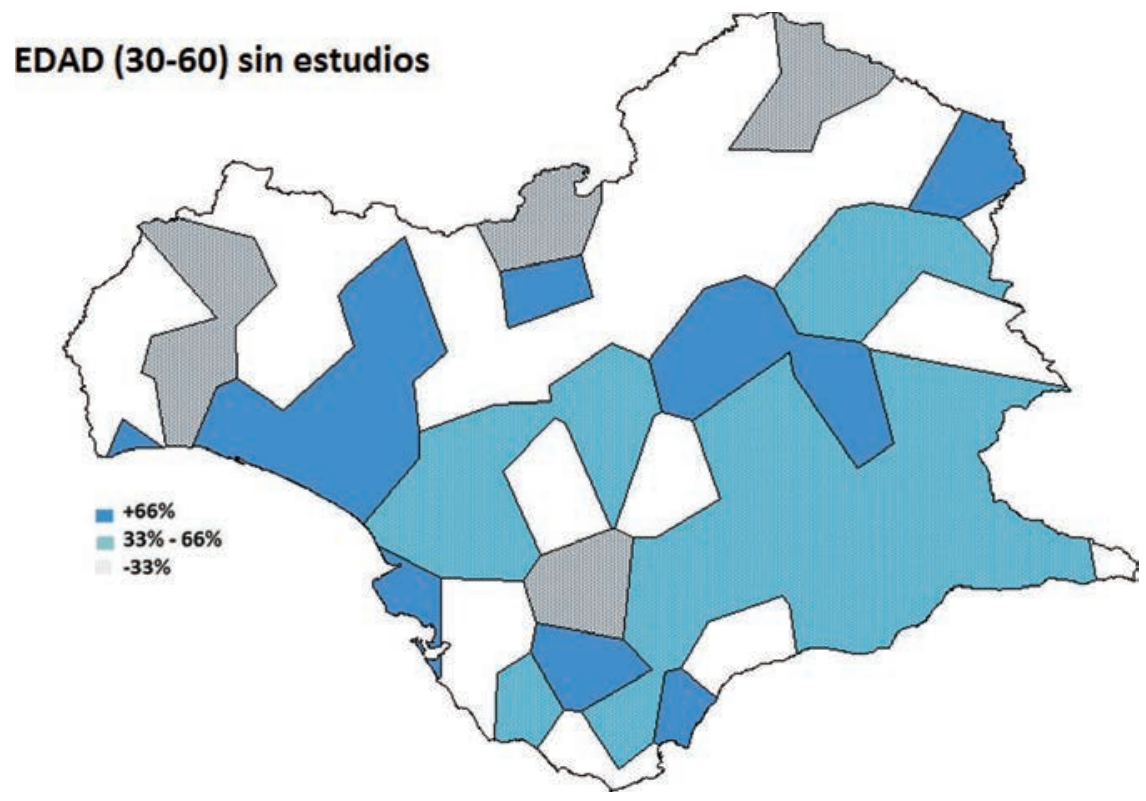

Mapa 18: Uso de ustedes en los informantes de entre 30 y 60 años (sin estudios).

El cotejo de los mapas 17 y 18 confirman la tendencia que ya se vislumbraba en el grupo etario inferior. Cuanto mayor sea el nivel educativo, menor rigidez a la hora de adoptar el modelo estándar. Mientras que los adultos cultos de la zona más focal del fenómeno prefieren en gran medida el estándar, la baja proporción del uso único de ustedes tan solo se manifiesta en zonas muy periféricas en el caso de los adultos con bajo nivel educativo. Es por ello que en el mapa 18 hallamos un grado intermedio y, a veces, grande de dialectalismo. 


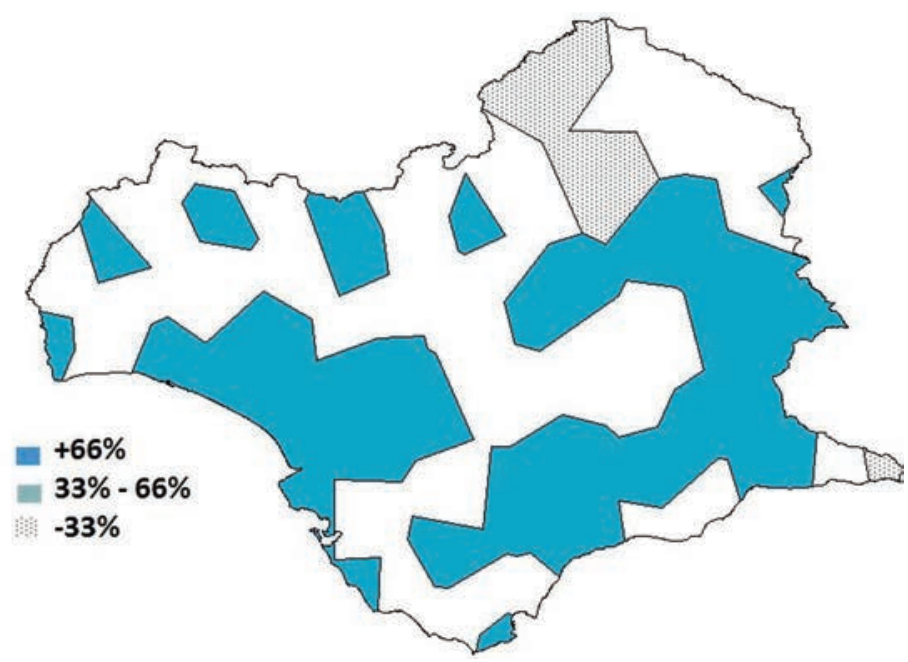

Mapa 19: Uso de ustedes en los informantes mayores de 60 años.

Como ya adelantábamos, el uso elevado y/o hegemónico del fenómeno pertenece a hablantes de edad más avanzada. Tan solo en la zona 0 o fronteriza con la misma, hemos hallado distinción entre ustedes y vosotros, sin que haya término medio entre las dos alternativas. En este resultado puede haber influido también el hecho de que, por razones metodológicas, solo pudo entrevistarse en este grupo de edad a personas sin estudios superiores.

En cambio, los informantes más jóvenes y de edad media se debaten entre el uso vernáculo y la tendencia al patrón estándar con leves diferencias. Aunque encontramos pocos puntos donde la incidencia es escasa o nula, los hablantes con edades comprendidas entre 30 y 60 suelen oscilar en mayor proporción a favor de la norma. Hay muchos más enclaves de uso medio en informantes de estas generaciones que en jóvenes, que producen en mayor proporción la variante dialectal. Esta aparente incongruencia no resulta tal si observamos la realidad de otros fenómenos lingüísticos.

El hecho de que los jóvenes se comporten de forma más conservadora del uso dialectal puede achacarse a lo que se ha denominado el mercado lingüístico, estrechamente relacionado con el mercado laboral (Bourdieu 1978). Esta tesis sostiene que los hablantes que han de desempeñar un trabajo remunerado tratan de adaptarse a la norma prestigiosa incluso en el aspecto lingüístico si desean tener éxito en su trayectoria profesional. 
Mientras los jóvenes asisten al instituto o la universidad, la mayoría de los individuos de mediana edad ya trabaja y, por tanto, son más sensibles a los patrones que la sociedad espera de ellos. Esta realidad ha sido documentada por Macaulay (1977) a propósito de la elisión de la /t/ en el área de influencia de Glasgow, pero también se ha registrado en el uso de a gente por nós, de acuerdo con las investigaciones de Seara (2000). En nuestro caso, ya que el uso de ustedes se halla muy estigmatizado incluso en la región donde se produce, los hablantes de mediana edad, en el ejercicio de su trabajo y presionados por los usos más prestigiosos, recuperan la norma para adecuarse a lo que se espera de ellos. Los jóvenes, en cambio, se ven aún con mayor independencia respecto a las normas sociales y pueden no atenerse al canon.

\subsubsection{Cambio en tiempo real y aparente}

Como adelantamos previamente, nuestro objetivo era, por un lado, llevar a cabo un análisis del cambio en tiempo real, confrontando los datos actuales de personas de edad avanzada con los resultantes del ALPI, ya que el perfil del informante era el mismo; y, por otro, un análisis del cambio en tiempo aparente, comparando los datos de todas las franjas etarias de nuestro corpus sociolingüístico.

De acuerdo con el primer parámetro, no se ha producido ninguna evolución destacable en el fenómeno, ya que los hablantes ancianos sin estudios de la segunda mitad del siglo xx producen la misma particularidad, con la misma virulencia y en la misma zona geográfica que sus coetáneos de ahora. Sin embargo, el segundo parámetro arroja una lectura contraria. 


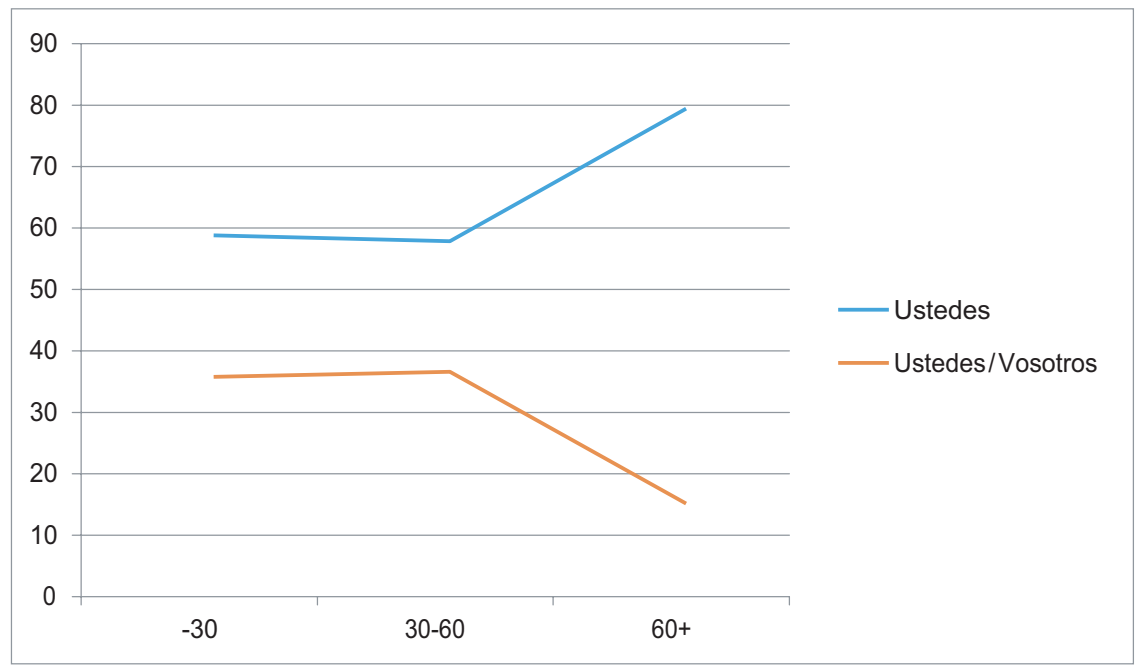

Gráfico 4: Porcentaje de uso estándar y vernáculo, según la edad, en hablantes no cultos.

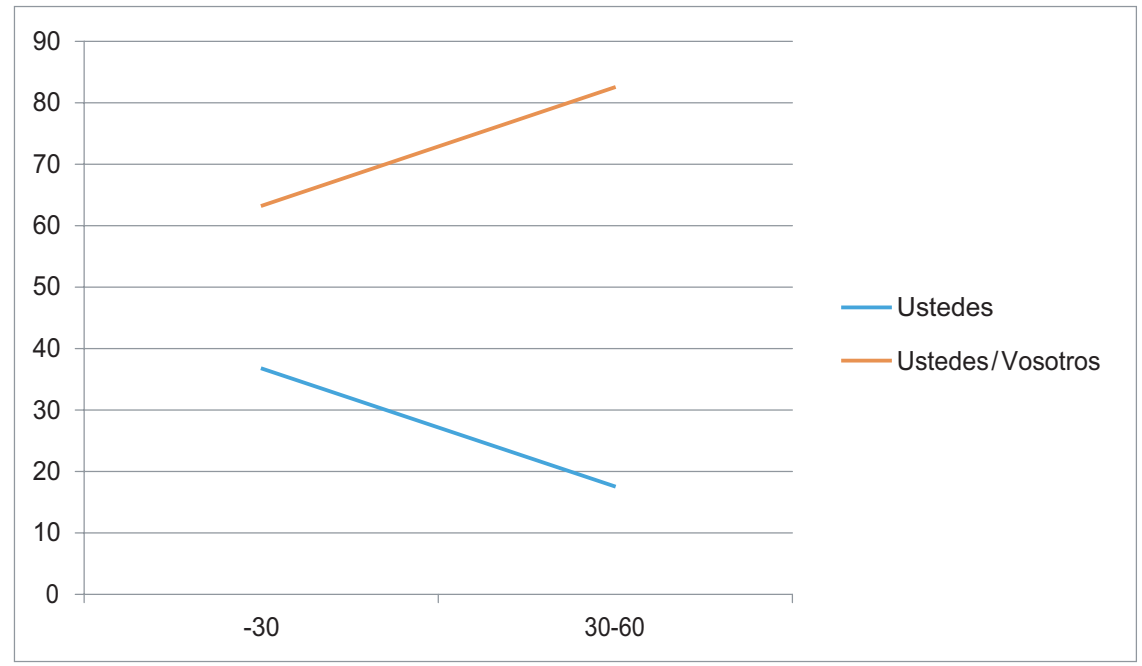

Gráfico 5: Porcentaje de uso estándar y vernáculo, según la edad en hablantes cultos.

Los gráficos 4 y 5 muestran una ligera tendencia por parte de los hablantes cuya edad comprende la franja entre 30 y 60 años al uso más estándar. Aunque la diferencia es ínfima en el caso de los informantes con un bajo nivel educativo, la disimilitud se acentúa más al comparar los hablantes 
cultos. En este caso, los jóvenes han preferido de forma intermedia el uso estándar, aunque el uso vernáculo alcanza el 40\%, mientras que los adultos presentan una abrumadora proporción de usos estándares. En el lado opuesto se encuentran los informantes de edad avanzada, cuya sensibilidad al estándar resulta mínima, tan solo alcanzada por aquellos oriundos de zonas limítrofes del fenómeno.

De acuerdo con Chambers \& Trudgill (1980), una situación como la descrita se debe al hecho de que los jóvenes están menos presionados por el estándar y sus usos lingüísticos responden en mayor medida a lo que su red social valora positivamente. Los ancianos también se rigen por este patrón, ya que han dejado de estar fuera del ámbito laboral, si bien es cierto que no se ha encuestado a ningún hablante de ese grupo de edad que tuviera estudios superiores. En cambio, los adultos asumen un comportamiento desigual al de los anteriores grupos de edad. Su inserción en la población activa conlleva una presión mucho más beligerante a la hora de adoptar el prestigio, lo que puede revelarse en el gráfico. Según estos autores, ante un resultado como este, no podemos afirmar que se esté fraguando un cambio.

Los resultados sociales, por tanto, han revelado que el uso de $u s-$ tedes resulta ser actualmente un marcador, que se emplea con mayor vehemencia cuanto menores son los estudios y se rechaza a favor del uso estándar cuanto mayores son los estudios. En el caso del portugués, compararemos de manera descriptiva el comportamiento lingüístico de acuerdo con el género, ya que la ubicación geográfica fue descrita en apartados anteriores.

\subsection{Análisis de las variables sociales en el portugués}

Como ya expusimos, la investigación que atañe al fenómeno portugués nos daría cuenta de los posibles cambios de acuerdo con el sexo del hablante y su localización geográfica, así como de un análisis en cambio real al comparar el segmento de población de tercera edad encuestado con el que se entrevistó en época del ALPI y el CORDIAL-SIN. 


\subsubsection{Sexo}

Los resultados de la estadística descriptiva para el portugués muestran que las mujeres producen menos ocurrencias de $2 \mathrm{pl}$ en el pronombre tónico, es decir, se adaptan más al patrón prestigioso. El hecho de que las mujeres suelan ofrecer más sensibilidad hacia los usos mejor vistos no tiene una justificación universalmente aceptada, pero, para Chambers \& Trudgill (1980), hay varios factores que ayudan a explicarlo. Por una parte, las mujeres han tenido tradicionalmente menos oportunidades de éxito que los hombres y, por ello, tratan de ganar posibilidades imitando y comportándose de la manera que mejor considera una sociedad, también en lo lingüístico. Por este motivo, participan menos en redes sociales muy compactas y, por tanto, están menos presionadas por lo que se valora en las mismas y más por los valores compartidos en el conjunto de la sociedad. Suelen tener más movilidad social que los hombres e, históricamente, se han ocupado de la educación de sus hijos, tratando de ser más sensibles a lo que está mejor visto para inculcarlo a la progenie.

Para este caso, observamos que, en los distritos encuestados que han producido el patrón estándar, aunque algunos aún vacilen entre este y la situación anterior, las mujeres presentan un porcentaje bajísimo de 2pl, a diferencia de los hombres, mucho más conservadores o menos presionados. Podemos observar este acercamiento al modelo estándar en el comportamiento con respecto a la elección de la concordancia del pronombre tónico. Como se ve en los gráficos 6 y 7, las mujeres han sido más proclives al estándar, ya que apenas han producido sujetos en $2 \mathrm{pl}$, aunque sí han elegido mayoritariamente esta persona para el sintagma preposicional de compañía (como indica la norma). Los hombres, en cambio, aumentan algo el porcentaje de vós para el sujeto en alguno de los enclaves de las nuevas provincias encuestadas, excepto en Covilhã. Son las mujeres de estas mismas provincias las que antes se acoplan a la presión normativa. 


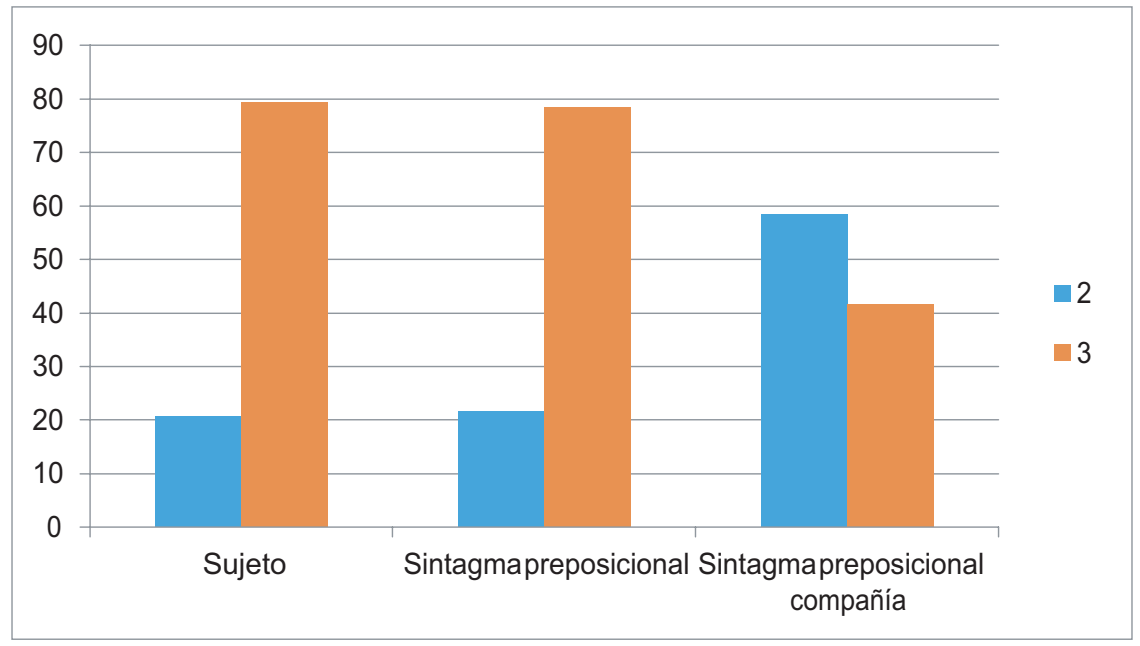

Gráfico 6: Pronombre tónico en hombres.

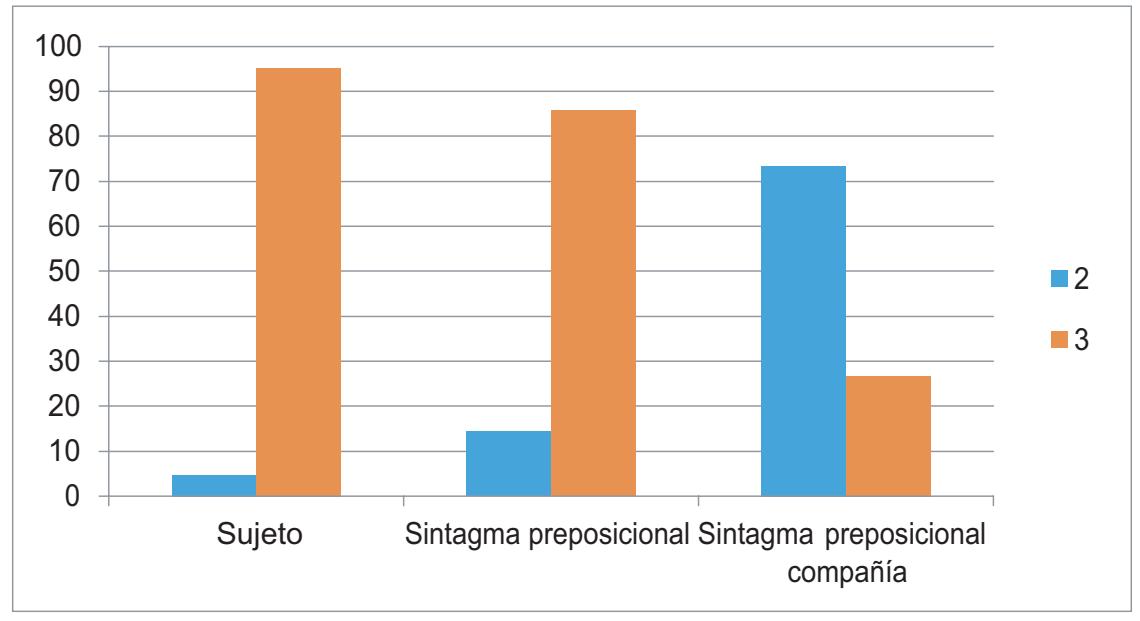

Gráfico 7: Pronombre tónico en mujeres.

\subsubsection{Edad}

La comparación de los tres corpus manejados, con informantes de un perfil prácticamente idéntico, permite postular que este fenómeno no solo se mantiene, sino que se impone en las zonas donde ya se documentaba y 
penetra con fuerza en Aveiro y Viseu (tendencia que ya se observaba en el CORDIAL-SIN, si bien los datos que mostraba eran escasos) y, con mucha mayor discreción, en Castelo Branco. Lejos de retroceder, la universalización de vocês sigue desplazando los usos de vós en aquellas zonas en las que aún existía dicha diferenciación, por lo que el cambio se mantiene y se amplía geográficamente.

\subsubsection{Zona ALPI}

En el caso de la importancia geográfica, nos damos cuenta de que, cuanto más cercanos al foco, mayor posibilidad de hallar $3 \mathrm{pl}$.

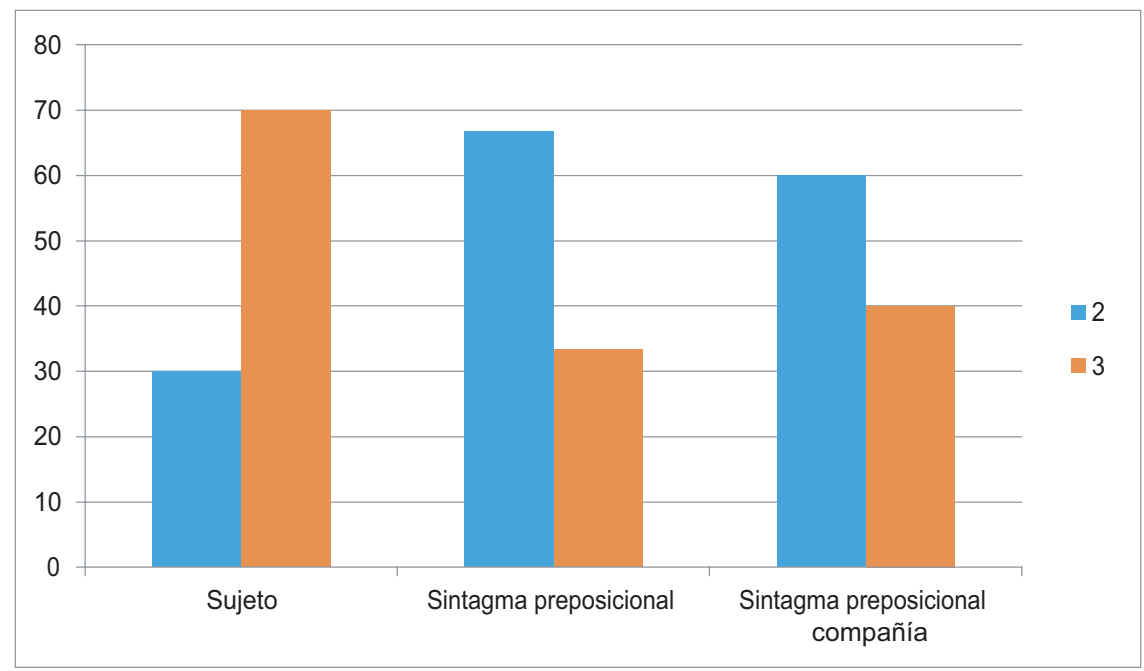

Gráfico 8: Pronombre tónico según la zona 0 del ALPI. 


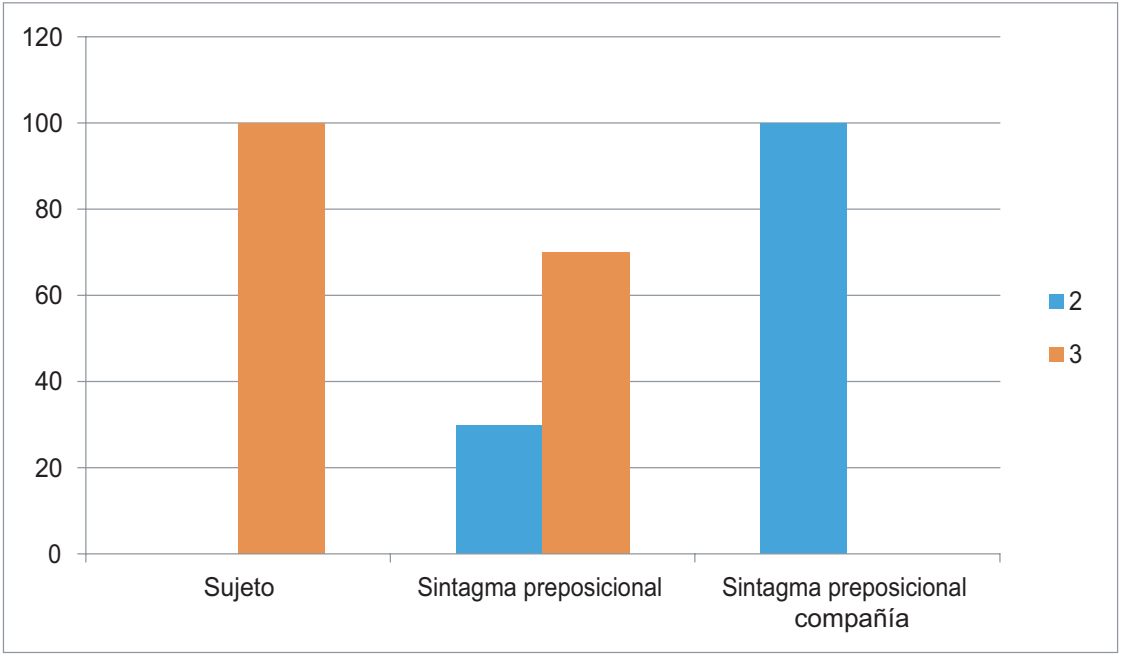

Gráfico 9: Pronombre tónico según la zona 1 del ALPI.

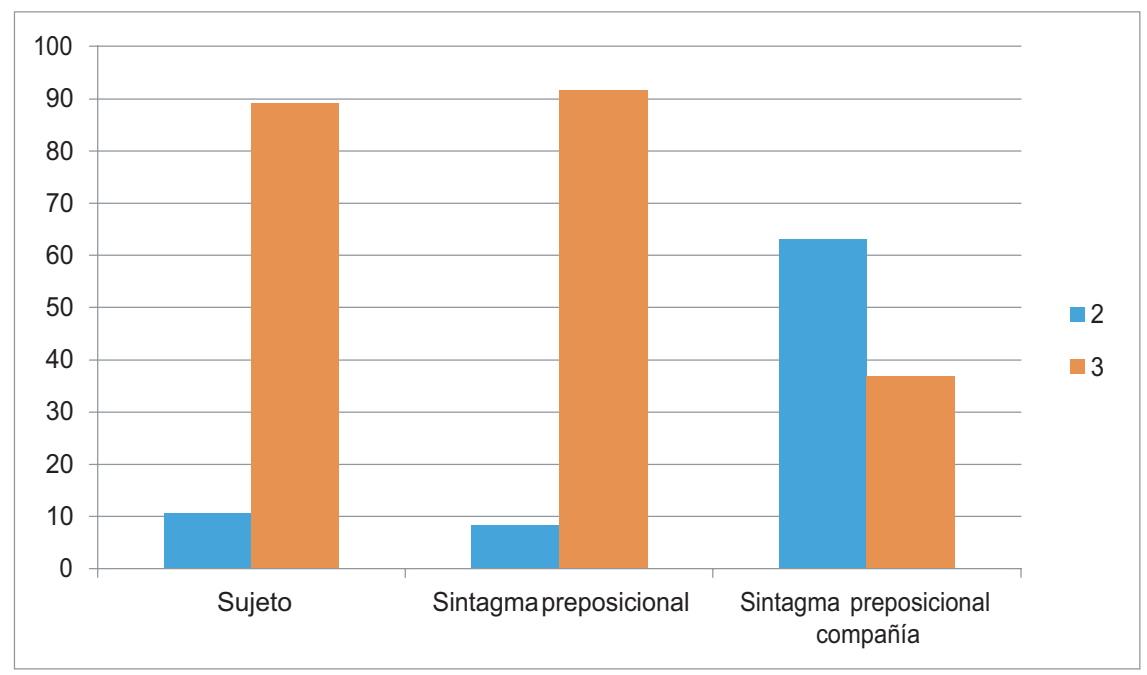

Gráfico 10: Pronombre tónico según la zona 2 del ALPI.

Los gráficos 8, 9 y 10 revelan claramente que en la zona 0, donde el ALPI desconocía la presencia de vocês, el estándar está ya penetrando, en concreto, en Viseu, y posiblemente en Castelo Branco, aunque con menos fuerza, ya que tan solo se ha documentado una ocurrencia en Covilhã. La zona 1 arroja un resultado favorable a vocês, tanto en posición de sujeto 
como regido por preposición, si bien el porcentaje alcanzado en esta posición es menor que el de la zona 2. Es también muy significativo que la zona 1 desconozca el empleo de vocês en los sintagmas preposicionales encabezados por com. Es la zona de Pombal, en la zona 2, en la antigua frontera dialectal, donde aún se han documentado soluciones de $2 \mathrm{pl}$, por lo que se configura como un área de transición. Independientemente de estas apreciaciones, resulta claro que es en el sujeto donde primero aparece el fenómeno, seguido del sintagma preposicional y, en última instancia, del sintagma preposicional de compañía, que opta mayoritariamente por la 2 pl. 


\section{Lingüística de la cortesía en el suroccidente peninsular}

Pasemos a continuación a analizar el comportamiento lingüístico del fenómeno de la nivelación de ustedes y vocês. Si bien en la primera parte se tratarán las discordancias entre sujeto y verbo, al no haber hallado tales en el caso del portugués, nos ceñiremos a la casuística del español a ese respecto. Antes, observemos algunos ejemplos de la falta de discordancia en el caso de vocês ${ }^{1}$ :

(4) Onde é que vocês se conheceram? (Alcácer do Sal / H)

(5) Vocês estão a falar mal de alguém (Alcácer do Sal / H)

(6) Onde se conheceram vocês? (Odemira / M)

(7) Vocês não venham tarde para casa (Odemira / M)

Incluso el empleo de vocês se da en término de sintagma preposicional, aunque el de compañía posee una gran proliferación de $2 \mathrm{pl}$, frente a las ocurrencias esporádicas de com vocês:

(8) Têm de estudar alguma coisa que seja de interesse para vocês (Ode$\operatorname{mira} / \mathrm{H})$

(9) Eu ligo para vocês (Peniche / H)

(10) Dou-lhes um beijo a vocês (Tavira / M)

(11) Contou a vocês uma história (Lisboa / H)

(12) Eu quero falar com vocês (Peniche / M)

(13) Eu vou com vocês (Tavira / H)

El hecho de que convosco sea muy prolífico (frente a com vocês) ha sido explicado por Rini (1999). De acuerdo con el autor, a diferencia del español, donde la forma convusco desapareció de la lengua ya a finales de la

1 Los ejemplos del corpus estarán localizados de acuerdo con los rasgos sociales del informante. Para ello, utilizaremos una serie de abreviaciones que desglosamos a continuación. Para el sexo: H (hombre), M (mujer); para la edad: $<30$ (menores de 30), 30-60 y >60 (mayores de 60); para los estudios: E (con estudios), NE (sin estudios). Ante la gran cantidad de enclaves encuestados, mantenemos el nombre completo de los mismos para mayor claridad. 
Edad Media, el portugués prefirió mantener convosco (y connosco en la 1pl) con resultado fonético en /o/ que representaba el paso intermedio entre el pronombre tónico vós / nós y el pronombre átono vos / nos. Debido a que los pronombres tónicos de $1 \mathrm{pl}$ y $2 \mathrm{pl}$ se pronuncian con una $/ \mathrm{J} / \mathrm{abierta}$ y los clíticos con /u/, la pronunciación de este sintagma preposicional se lleva a cabo mediante una /o/ cerrada o, lo que es lo mismo, el paso intermedio. La morfología de convosco es coherente con el sintagma preposicional de compañía para las demás personas, comigo, contigo, consigo, lo que sin duda puede haber influido en la adopción tardía del modelo com vocês, que significaba también la escisión paradigmática.

\subsection{La concordancia sujeto - verbo}

El hecho de que hallemos discordancias de persona entre el sujeto y el verbo podría deberse a la posibilidad de que nos encontremos ante un caso de topicalización. En español oraciones como Los estudiantes somos trabajadores o Los trabajadores sois responsables, en donde un sintagma nominal (tercera persona por defecto) concuerda sin ningún tipo de agramaticalidad o de violación del estándar con el verbo en $1 \mathrm{pl}$ o $2 \mathrm{pl}$, suelen explicarse como un caso típico de topicalización. Entre el sintagma nominal y el verbo existiría un pronombre nulo o una aposición especificativa encubierta: Los estudiantes, [nosotros] somos trabajadores y Los trabajadores, [vosotros] sois responsables (RAE 2009: 2563).

No obstante, hay autores, como Fábregas (2008), que estiman que estas oraciones no se explican como una dislocación a la izquierda, puesto que, de acuerdo con su argumentación, solo se manifiesta en el plural y no en el singular, tal y como ejemplifica con la oración *El estudiante quiero aprobar el examen. La falta de concordancia en oraciones con indefinidos en singular, como Ninguno queremos suspender, se justificaría en que, en realidad, el pronombre ninguno lleva aparejado de manera encubierta el genitivo de nosotros, es decir, sería Ninguno [de nosotros] queremos suspender. Asimismo, el autor alega que no es posible una discordancia de persona en pronombres en singular, como en *Usted quieres aprobar el examen.

Sin embargo, existen ejemplos que contravienen esa imposibilidad en el singular. Por una parte, los datos del ALPI muestran que sí hay 
discordancias con usted, que alterna con verbos de concordancia tuteante y ustedeante. Estas frases son Póngase usted el sombrero y Deme usted un pañuelo (preguntas 346 y 347 del cuestionario). Las respuestas ejemplificadas en (14), (15) y (16) se atestiguan en toda el área del español peninsular occidental y en la mayor parte de Andalucía y dan fe del empleo del verbo (e incluso del reflexivo) de 2 sg acompañando a un tratamiento de 3sg (Lara 2018):

(14) Ponte usted el sombrero.

(15) Ponse usted el sombrero.

(16) Dame usted un pañuelo.

Por otro lado, debe tenerse en cuenta el fenómeno del voseo, cuyo pronombre vos - originariamente plural- no induce en todas las formas verbales morfología voseante: vos tuviste frente a vos tenés. Aunque la persona es siempre la $2^{\mathrm{a}}$, desde el punto de vista histórico vos [Pronombre $2 \mathrm{pl}$ - referencia 2sg] puede concordar con verbos de [Morfología 2pl] o de [Morfología 2sg].

En recapitulación, los tópicos parecen admitir la falta de concordancia de persona en la $1 \mathrm{pl}$ y la $2 \mathrm{pl}$ con constituyentes dislocados de $3 \mathrm{pl}$. Ello no parece ser posible en el singular cuando el elemento dislocado es un sintagma nominal, pero sí existen ejemplos en que usted [Pronombre $3 \mathrm{sg}$ - referencia 2sg] puede concordar no solo con verbos de [Morfología de $3 \mathrm{sg}$ ] sino de [Morfología de 2sg]. El conflicto entre los rasgos gramaticales de la forma pronominal y su referencia semántica parece avalar esta dúplice concordancia, tal como en el voseo.

Como se ha indicado, las discordancias de persona suelen deberse a cuestiones de estructura informativa. Givón (1975) estudia el cambio sintáctico que produce una dislocación a la izquierda o derecha de la oración. La topicalización de un elemento a la izquierda denota que ese elemento es demasiado débil desde el punto de vista informativo dentro de la oración y, por ello, se resalta extraoracionalmente. No obstante, la frecuencia del tópico a la izquierda provoca que el hablante lo reinterprete como el sujeto, ya que ocupa la posición no marcada del mismo. Este reanálisis fija la nueva construcción, hasta que el tópico deja de serlo y se convierte también en sujeto.

El autor incluso expone que los sujetos tienen mayor probabilidad de desarrollar una concordancia gramatical que otros argumentos. Según él, variedades no estándares del inglés empiezan a presentar construcciones 
en las que el sujeto tiene que estar reforzado por un pronombre anafórico que proyecta la concordancia del sujeto. El ejemplo que expone del inglés es el siguiente:

(17) The man, he came

El hombre él venir.3sG.PST

('El hombre vino')

En esta fase, el referente del sujeto se halla fuera de la oración siendo la opción marcada. La frecuencia de esta construcción se reanaliza y se fija en (18).

(18) The man he came

El hombre él venir.3sG.PST

('El hombre vino')

En el primer contexto, the man se revela como el tópico y he como el sujeto; mientras que en el segundo ejemplo, the man ya es el sujeto y he se comporta como una concordancia con el sujeto. En última instancia, el tópico termina siendo completamente reanalizado como sujeto y su anáfora desaparece (19).

(19) The man came

El hombre venir.3sG.PST

('El hombre vino')

Incluso en variedades del francés acontece el proceso intermedio, ya que el tópico, reinterpretado como sujeto, necesita ser repetido mediante un pronombre que recoja sus rasgos de persona, caso y número. Un ejemplo de ello se puede encontrar en una variedad criolla de base francesa:

(20) Lé dié

El diosél

sont

malin

('Dios es listo')

(21) Lé démon

El demonio él pensar-PCP.MASC.SING.

('El demonio ha pensado')

(Givón 1975: 155). 
Para Givón, la topicalización sirve de prerrequisito para un reanálisis de un sujeto nuevo y, por tanto, de un nuevo pronombre y una concordancia gramatical innovadora. En otro trabajo de 1990, Givón apunta que los pronombres permiten la identificación del tópico y la continuidad topical en el discurso. Esta tesis es compartida por Elvira (1996), quien, además, sostiene que los tópicos tienen repercusiones sobre la sintaxis. Como veremos a continuación, los tópicos pueden provocar una reestructuración del orden no marcado de constituyentes en una lengua o incluso pueden ser el paso previo para el surgimiento de una nueva concordancia.

De hecho, Hopper \& Traugott (2003) afirman que los tópicos son la clave para la gramaticalización de los mismos como sujeto. El proceso de reanálisis que experimentan por su tendencia a ubicarse al principio de la oración (ya que introducen el tema del que se va a tratar) los confiere de una propensión continua para convertirse en sujetos. A diferencia de estos, los tópicos no tienen por qué experimentar concordancia verbal y solo los sujetos pueden proyectar un reflexivo que marque de nuevo su referencia dentro de la oración. Siguiendo los postulados de Li (1975), los sujetos son, esencialmente, tópicos gramaticalizados.

Lehmann (1975) va más allá y afirma que las lenguas indoeuropeas han evolucionado de un patrón de prominencia topical a uno de prominencia del sujeto. Es decir, los estadios más tempranos del indoeuropeo, así como de las lenguas clásicas (latín, griego, Basile 2001), presentaban una estructura en la que se resaltaba en primera posición el tópico de la oración, independientemente del sujeto gramatical. El hecho de que el tópico sea generalmente el agente de la oración lleva al reanálisis de ese elemento como el sujeto. El autor afirma que la realización de sujetos expresos era más frecuente en el latín y griego clásicos que en sus variedades arcaicas, y mucho más numerosa en sus épocas tardías. La evolución posterior, en las lenguas derivadas del indoeuropeo, es la expresión del sujeto obligatorio y del germen de los expletivos (it, there, es) para construcciones existenciales e impersonales y, por último, la pérdida de las marcas de persona en la flexión verbal en detrimento del recurso pro drop. Para Lehmann, la cada vez mayor frecuencia de sujetos en lugar de tópicos en la evolución lingüística del latín y el griego hizo posibles las construcciones con infinitivo. Para el autor, la cronología sería la siguiente: Él prometió: "Voy" $>E$ El prometió que iría $>$ Él prometió ir.

Como ya se ha mencionado, una de las características de los tópicos es su referencia posterior en la oración, si bien esta anáfora no está 
obligada a recibir todos los rasgos de concordancia del elemento extraoracional al que hace referencia. Un caso bastante ejemplificador lo encontramos en bretón. Borsley \& Stephens (1989) argumentan que en una lengua VSO, como el bretón, las oraciones afirmativas con sujeto precediendo el resto de la oración solo pueden deberse a un caso de topicalización de este. Es por ello que en este tipo de frases el verbo no recoge los rasgos del referente, por lo que un sintagma nominal plural (22) o con dos núcleos coordinados en posición de tópico no obligan a un verbo en plural.
(22) Ar
Ar vugale a lenn
(*lennont)
levrioù
Los niños leer-3SG.PRES.IND.
(*leer-3PL.PRES.IND.) libros
('Los niños leen libros')

Es más, la 3pl en estas circunstancias es agramatical e imposible, siendo la concordancia verbal la menos marcada y por defecto, esto es, la de tercera persona del singular.

Otros ejemplos de falta aparente de concordancia entre sujeto y verbo pueden explicarse asimismo por la existencia de un tópico encubierto. Así, para Kayne (2009), las aparentes discordancias en el francés actual entre nous y on se explican por un pronombre implícito. La frase On a tous ri ('Nos hemos reído todos'), en la que, a pesar de tener un on que puede ser genérico, la presencia de tous implica una lectura de 1pl, se explica por el hecho de tener en realidad un pronombre encubierto nous que no se expresa, por lo que, en realidad, la frase es [Nous,] on a tous ri. La presencia de nous (que al ser tónico puede ser el tópico, posición imposible para on) permitiría la correferencia con tous y la concordancia en $3 \mathrm{sg}$ se explicaría por la explicitación del innovador on. Esta tesis se refuerza por el comportamiento del imperativo, donde no puede haber una tercera persona del singular que se interprete como nous (*Part!) y solo se construye con la morfología propia de nous (Partons!). Este hecho se relaciona con lo acaecido en Andalucía, ya que las oraciones imperativas son las que favorecen la concordancia plena en primera instancia, por lo que el sujeto de esa modalidad solo puede ser ustedes. En estas frases, en las que también habría un pronombre encubierto, los rasgos de concordancia de la $3 \mathrm{sg}$ no casan con nous, mientras que los de 1pl, sí.

Para el autor, estas $1 \mathrm{pl}$ encubiertas del francés se comportan de forma análoga a otros fenómenos del italiano. En el estándar de esta lengua, podemos tener frases con lectura 1pl, a pesar de que la oración reflexiva esté construida en 3sg: Si è stati invitati tutti, donde tutti se interpreta 
como 1pl. Es más, si se topicaliza el sujeto, este solo puede ser noi: Noi, si è stati invitati tutti, pero resulta agramatical con cualquier pronombre de otra persona. Los pronombres de tercera persona normativos en el italiano actual son el resultado de un proceso de topicalización de la Alta Edad Media. Rohlfs (1968) y Ernst et al. (2008) recogen que lui, lei y loro empezaron a coexistir con las formas egli, ella, essi, esse que eran los pronombres de sujeto normativos.

$\begin{array}{lll}\text { Lui, egli sa } & \text { ogni } & \text { cosa } \\ \text { Él.obL. él.NOM. saber.3sg.PrS. } & \text { cada } & \text { cosa } \\ \text { ('Él lo sabe todo') } & & \end{array}$

Con el tiempo, esta construcción se fue hacienda común y el antiguo sujeto se clitizó.

$\begin{array}{lll}\text { Lui e' sa } & \text { ogni } & \text { cosa } \\ \text { Él.obL. él.NOM. saber.3sG.PRS. } & \text { cada } & \text { cosa } \\ \text { ('Él lo sabe todo') } & & \end{array}$

Finalmente, el clítico desapareció y el pronombre oblicuo terminó siendo el sujeto, tal y como lo conocemos hoy.

$\begin{array}{llll}\text { Lui } & \text { sa } & \text { ogni } & \text { cosa } \\ \text { Él.NOM. } & \text { saber.3sG.PRS. } & \text { cada } & \text { cosa } \\ \text { ('Él lo sabe todo') } & & \end{array}$

La falta de concordancia entre el elemento topicalizado y el verbo puede afectar al número (bretón), la persona (francés, italiano, español) y, por supuesto, también al caso o papel sintáctico. Elvira (1993), por ejemplo, analiza la disposición de los textos alfonsíes en español medieval, en los que, aparentemente, se ven anacolutos, cuando, en realidad, un elemento topicalizado se ha dislocado a la izquierda, y su referencia se recupera mediante un pronombre durante la oración. Asimismo, presenta el término nominativus pendens ('nominativo cero'), el cual aparece de forma anticipada y no participa en la frase, en términos estrictamente sintácticos, si bien se recupera anafóricamente dentro de ella. Estos casos, que surgen en la prosa alfonsí, ya eran posibles en los textos clásicos latinos y griegos. Ejemplo de este uso es la frase Tú, si los dioses te aman, es el momento de realizar tus asuntos (Elvira 1993: 247). Aun más, estos casos también se documentan en otras lenguas romances y de distintas familias. En su 
análisis de textos medievales alfonsíes, Elvira añade la proliferación de sujetos antepuestos que, narrativamente, señalan cambios alternativos de protagonismo de la acción, como ya sucedía en textos de César, Salustio o Tito Livio.

Los reánalisis de los tópicos en sujeto, como anunciamos, pueden derivar incluso en un cambio estructural del orden de palabras de una lengua dada. Prueba de ello nos la da Adams (1987), quien analiza la evolución del francés antiguo al actual, ya que, antes del siglo xv, dicha lengua era pro-drop y se comportaba como V2, al igual que el alemán (26).

$\begin{array}{llll}\mathrm{Si} & \text { firent } & \text { grant } & \text { joie la nuit } \\ \text { Así } & \text { hacer-3PL.PAST.IND. } & \text { gran } & \text { alegría la noche } \\ \text { ('Así se alegraron mucho esa noche') } & & \end{array}$

Sin embargo, la clitización de los pronombres de sujeto, la caída de la fórmula V2 y la pérdida de rasgos de concordancia supusieron el cambio a una lengua de sujeto obligatorio. Según la autora, fue la topicalización del sujeto la que llevó al reanálisis del patrón V2, ya que el sujeto era la función que con mayor frecuencia se movía hacia una posición de tópico. Las oraciones declarativas podían no explicitar el pronombre (26), a diferencia de las subordinadas (27), pero esa topicalización tan frecuente del sujeto llevó a explicitarlo por sistema. Por desgracia, nuestro corpus no presenta un número elevado de ejemplos que permitan contrastar las subordinadas con sujeto explícito o nulo, ya que la proporción es similar.

(27) Einsi corurent

Por eso correr-3PL-PAST.IND. vindrent

venir- 3PL.PAST.IND. par mer tant que il

por mar hasta que 3PL.NOM.

('Por eso corrieron por mar hasta que llegaron a Cadmée')

Según Adams, los nuevos hablantes, al escuchar la alta frecuencia de frases con sujeto en primera posición, interpretaron que el orden canónico era SVO, como el actual, en lugar de una estructura V2.

En el caso del español, Fernández-Ordóñez (2009) analiza el orden de palabras de varias obras pertenecientes al reinado de Alfonso x, el Sabio, y describe su ordenación, indicando que cualquier elemento oracional (sujeto, objeto, adverbio, subordinada, complemento regido...) podía ser susceptible de colocarse en una posición extraoracional. Los tópicos eran, posteriormente, rescatados en la oración con un pronombre o un elemento deíctico 
que devolvía o marcaba la referencialidad del elemento topicalizado. Además de la excesiva topicalización, los textos alfonsíes presentaban un alto grado de focalización, puesto que eran recurrentes la proclisis y la inversión predicativa. Si el orden de palabras no marcado en la era alfonsí se correspondía con la estructura VSO, la continua topicalización, más frecuente en los sujetos, y la focalización de los mismos por carácter enfático o contrastivo produjo un reanálisis a la actual estructura SVO.

También en inglés se ha detectado un cambio sintáctico producido por la topicalización. Allen (1995) ha investigado la estructura sintáctica actual en inglés de verbos como like, en las que hay un sujeto experimentante y un objeto tema. En inglés medieval, este tipo de verbos se construía mediante el tema en nominativo y el experimentante en dativo. Sin embargo, el orden no marcado era expresar el experimentante en primer lugar, seguido del tema y, por último, el verbo: dativo - nominativo - verbo. Esta topicalización del dativo motivó su reanálisis. Ya que siempre se colocaba en primer lugar, se le consideró el sujeto, por lo que el antiguo dativo devino el nuevo nominativo y, por tanto el sujeto. El antiguo nominativo se convirtió en el nuevo dativo y, por ende, el objeto.

En español, el experimentante también ha motivado su dislocación. Elvira (2014) investiga la relación entre la topicalización y el doblado de clíticos del español actual, obligatorio en las oraciones con objetos antepuestos. Según el autor, el doblado surgió ya en época medieval con la topicalización de los sintagmas objeto, cuya referencia se recuperaba en la frase mediante el pronombre átono ( $A$ María le doy un libro / A ella la $v e o$ ). Sin embargo, en el español antiguo, este doblado era más usual con los verbos con un argumento en dativo experimentante ( $A$ mí me gusta). Para Elvira, existen dos tipos de dativo: de objeto indirecto y de sujeto (también llamados sujetos no canónicos). Estos últimos son los que se corresponden con los argumentos cuyo papel temático recae en un experimentante (A mí, me gusta / A Pedro le inquieta tu actitud). Por tanto, el doblado de clítico surgió en ese tipo de construcción con verbos con un dativo experimentante, ya que, tipológicamente, son argumentos con alta frecuencia de topicalización. Su extensión fue progresiva al resto de casos en los que se antepone el objeto, excepto en una lectura causativa ( $E l$ humo molesta a mi padre). De hecho, los datos de doblado de clíticos para dativos de objeto indirecto son menores que para los de dativo de sujeto. Este doblado con dativos de sujeto, para Elvira, es un ejemplo de concordancia de sujeto y no de objeto, como aparentemente se podría concluir. 
Asimismo, tipológicamente, la concordancia con elementos del discurso tiene lugar siempre antes con el sujeto que con el objeto. La lengua que mantenga concordancia de objeto, obligatoriamente la posee con el sujeto.

En conclusión, la topicalización subyace como mecanismo de emergencia de una nueva estructura sintáctica SVO y del reanálisis del tópico en el sujeto. Mientras que ese proceso de gramaticalización avanza, en distintas lenguas se documentan estados intermedios en que el tópico puede no concordar en número, persona o caso con los elementos correferentes situados en la oración, quizá por la existencia en esta de un pronombre nulo con rasgos no idénticos a los del tópico.

$\mathrm{Si}$ es verdad que los sujetos son tópicos gramaticalizados, ustedes, originalmente empleado como tópico adjunto, tendería a reanalizarse en sujeto y, con ello, debería transferir sus rasgos a los demás elementos puesto que se hallaría ya dentro de la oración. Ello explicaría que, poco a poco, aparezcan concordancias verbales de $3 \mathrm{pl}$. Sin embargo, otra de las razones por las que se pueden presentar anomalías aparentes en la concordancia se debe a la posible existencia de un pronombre o un rasgo encubierto (covert / silent) que no está fonológicamente realizado. Asimismo, la estructura informativa del discurso también es crucial para explicar aparentes discordancias. Por ello, diferenciaremos entre tópico, foco y sujeto como posibles posiciones sintácticas e informativas del pronombre ustedes para determinar si el carácter de una u otra importa a la hora de desencadenar la concordancia de $2 \mathrm{pl}$ o de $3 \mathrm{pl}$.

De acuerdo con la teoría que describimos, los tópicos o temas pueden subdividirse en dos: vinculantes y dislocados. Los primeros solo pueden aparecer en la periferia izquierda, ha de tener un correferente dentro de la oración y no es necesario que la tematización presente rasgos idénticos a los del constituyente de la oración, ya sea de número, género, persona o de caso. Un ejemplo extraído de Bosque \& Gutiérrez Rexach (2009: 686) es En cuanto al ordenador, yo odio esas máquinas infernales. Asimismo, estos temas vinculados pueden introducirse por locuciones como en cuanto $a /$ con respecto $a$. A diferencia de estos, los tópicos dislocados presentan un tema idéntico al de la oración, hacen más prominente la entidad temática y, además, pueden estar ocupados por cualquier sintagma, como se ejemplifica a continuación:

(28) A Pepe, no lo vi ayer

(29) En la mesa, no he puesto nada 
(30) Contento, no te diré que lo estoy mucho (Bosque \& Gutiérrez Rexach 2009: 687).

Todos los temas tienen que recuperarse en el discurso mediante un pronombre. Así sucede en los ejemplos (28) a (30). Aunque (29) no produce en español una anáfora visible dentro de la oración, en francés o italiano en / ci recuperan el tema dislocado. En español, habría un pronombre covert o silent.

Por otro lado, los focos introducen constituyentes que se anteponen por motivos informativos. Presentan una prosodia propia, ya que contienen la cima melódica de la oración. Así contrastan con los demás elementos de la oración, que también pueden ser susceptibles de focalizarse. Este tipo de estructuras provoca una inversión del verbo y el sujeto (siempre y cuando no sea el sujeto el focalizado), de tal manera que es imposible una oración como (31) y es obligado el orden de (32):

(31) *VEINTE EUROS yo pagué

(32) VEINTE EUROS pagué yo

Aunque en algunos idiomas como el húngaro (Puskas 1997), la focalización obliga a la anteposición en la oración del elemento focalizado, el español permite un orden libre, siendo solo la prosodia la que marca el foco.

Analizaremos a continuación los datos en que ustedes está presente en relación con esas posiciones sintácticas. El español se caracteriza por ser una lengua pro drop, es decir, no hay necesidad de explicitar el pronombre a no ser que desambigüe el referente o se use con un carácter contrastivo. Este último rasgo lo asemeja a las funciones de foco, por lo que resulta problemático distinguir en español en qué momento la expresión del sujeto no implica de por sí una focalización.

Pasemos primeramente a ejemplificar algunas oraciones en las que $u s$ tedes se ha explicitado como tópico dislocado en las dos áreas periféricas (33-39) y en el área focal (40-53).

a) Zona $-33 \%$

(33) Ustedes, no tenéis nómina ( $\mathrm{M}$ / NE / Bujalance / 30-60)

(34) Ustedes, habéis desorganizado mi casa (H / NE / Isla Cristina / 30-60)

(35) Ustedes, no sois solventes (H / E / Vélez-Málaga / 30-60)

(36) Ustedes, estáis en paro (H / E / Vélez-Málaga / 30-60) 


\section{b) Zona 33\%-66\%}

(37) Ustedes, me habéis inundado el piso ( $\mathrm{H} / \mathrm{NE} /$ Los Barrios / <30)

(38) Ustedes, no tenéis nómina (M / E / Córdoba / 30-60)

(39) Fuisteis, ustedes (M / NE / Cártama / <30)

c) Zona $+66 \%$

(40) Ustedes, ¿qué hacéis? (M / NE / Alcalá de los Gazules / 30-60)

(41) Ustedes, ¿por qué tenéis que entrar? (M / E / Cádiz / <30)

(42) Ustedes, ¿qué derecho tenéis para entrar? (M / E / Cádiz / <30)

(43) Ustedes, ¿qué hacen otra vez aquí? (M / E / Cádiz / 30-60)

(44) Ustedes, ¿qué problema tenéis? ( H / E / Dos Hermanas / <30)

(45) Ustedes, preguntarme la información que queréis (H / E / Dos Hermanas / <30)

(46) Ustedes, ¿qué se creéis? ( $\mathrm{M} / \mathrm{NE} / \mathrm{El}$ Castillo de las Guardas / <30)

(47) Ustedes, ¿cómo estáis aquí? ( $\mathrm{H} / \mathrm{NE} /$ Sevilla / >60)

(48) Ustedes, ¿de qué se quejáis? (H / NE / Sevilla / <30)

(49) Ustedes, irse (H / NE / Sevilla / <30)

(50) Ustedes, ¿qué derecho tenéis para entrar? (M / E / Cádiz / <30)

(51) Ustedes, ¿no estarían cotilleando? (H / NE / Cádiz / <30)

(52) Ustedes, se vais a meter en vuestros asuntos ( $\mathrm{M} / \mathrm{NE} /$ Ubrique / 30-60)

(53) Ustedes, lo que tenéis que hacer es irse a vuestras casas (H / NE / Alcalá de los Gazules / 30-66)

Cuando el tópico dislocado a la izquierda es un objeto directo o indirecto, también prevalecen las copias pronominales de $2 \mathrm{pl}$, incluso en la zona $+66 \%$, como muestran los ejemplos (54-59):

(54) A ustedes, no os puedo dar el crédito (M / NE / Alcalá de los Gazules $/<30$ )

(55) A ustedes, no os importa mi vida $(\mathrm{M} / \mathrm{NE} / \mathrm{Cádiz} \mathrm{/} \mathrm{<30)}$

(56) A ustedes, no os puedo dar el préstamo (H / NE / Lebrija / <30)

(57) A ustedes, ¿qué les importa? (M / NE / Cádiz / <30)

(58) A ustedes, no os puedo dar el préstamo (H / NE / Lebrija / <30)

(59) A ustedes, no os importa mi vida ( $\mathrm{M} / \mathrm{NE} / \mathrm{Cádiz} \mathrm{/} \mathrm{<30)}$

El planteamiento que surge inmediatamente después de cotejar los datos es por qué se producen estas asimetrías. Según RAE (2009: 646), en zonas de Andalucía se pueden atestiguar construcciones en las que se 
concatenen los dos pronombres (ustedes y vosotros) más un verbo $2 \mathrm{pl}$, como en la frase Ustedes vosotros no la conocéis. Esta aserción nos sirve de punto de partida para una posible explicación. Aunque en nuestros datos no hay ocurrencias con dicha secuencia ustedes vosotros, oraciones de este tipo coinciden con las que señala Givón (1975) del inglés (The man he came) o del criollo francés, en las que un tópico que, en su momento, se encontraba fuera de la oración, se ha reanalizado como parte de la misma, aunque no de forma definitiva. Por ello, el tópico y el sujeto coinciden en la oración sin la pausa prosódica propia de las tematizaciones. De acuerdo con ese análisis, los ejemplos de ustedes vosotros $+2 \mathrm{pl}$ mostrarían uno de los pasos intermedios en el proceso de gramaticalización de ustedes en verdadero pronombre de sujeto. La diferencia entre el inglés o el francés con el español estriba en la obligatoriedad de expresar el pronombre sujeto. Por tanto, es de suponer que en las oraciones en las que aparece ustedes seguido de una concordancia de $2 \mathrm{pl}$, el verdadero sujeto quedaría elidido, como en una oración no marcada propia del español. Ese sujeto fonológicamente no realizado correspondería con los rasgos de $2 \mathrm{pl}$ de vosotros. Ustedes, por tanto, no estaría todavía funcionando como sujeto, sino como un tópico en proceso de reanálisis como sujeto.

Observemos, antes de proseguir con la explicación, otras lenguas con situaciones semejantes en su sintaxis. Pese a la obligatoriedad del sujeto antepuesto en francés, Kayne (2005) hace notar la particularidad de los sujetos pospuestos en oraciones relativas (60-61).

$\begin{array}{llll}\text { La fille } & \text { à qui a } & \text { tout dit } & \text { Jean-Jacques } \\ \text { La chica PREP } & \text { a quien haber-3sG.PRES.IND. } & \text { todo decir-PCP. Jean-Jacques } \\ \text { ('La chica a la que Jean-Jacques le ha dicho todo') } & \end{array}$

(61) Le criminel qu'ont condamné trois juges

El criminal que haber-3PL.PRES.IND. condenar-PCP. tres jueces ('El criminal al que han condenado tres jueces')

También hace ver que los clíticos de sujeto para la tercera persona no son obligatorios (62-63) en contraposición a las demás personas (64-65):
(62) Lui (,)
a
téléphoné
3SG.MASC.
(3SG.MASC.CLIT.) haber-3SG.PRES.IND. telefonear-PCP.
('Él ha llamado') 
(63) $\operatorname{Eux}($,)

ont

téléphoné

3PL.MASC. (3PL.MASC.CLIT.) haber-3PL.PRES.IND. telefonear-PCP. ('Ellos han llamado')

(64) Moi, *(j')

ai téléphoné

1SG. (1SG. CLIT.) haber-1SG.PRES.IND. telefonear-PCP.

('Yo he llamado')

(65) Toi, *(tu)

as

téléphoné

2SG. (2SG. CLIT.)

haber-2SG.PRES.IND. telefonear-PCP.

('Tú has llamado')

Para el autor, ambos casos se caracterizan por tener un elemento silent o covert (encubierto) que no se realiza fonológicamente, pero que sí permanece en la estructura interna de la oración. En el caso de la posposición del sujeto, Kayne argumenta que este se ha desplazado fuera del sintagma flexión al especificador de un sintagma superior (sintagma fuerza), dejando detrás una huella en forma de clítico de sujeto que, simplemente, no se expresa. Es más, tal y como sucede en los doblados de clítico, el sujeto posverbal formaría parte de un sintagma determinante más amplio encabezado por un clítico de sujeto silent.

La inclusión de dos elementos con la misma referencia en un mismo sintagma determinante que produce la expresión de solo uno de los dos elementos o de ambos en francés, puede también relacionarse con la situación que describe Lambrecht $(1980,1981)$ con respecto a esta misma lengua. Para este autor, la cada vez mayor productividad de oraciones como las de (66-67), se debe al hecho de que el francés no estándar actual necesita explicitar el tópico de la oración y una marca de concordancia con este en la oración. Tanto es así que la ubicación de ambos elementos puede intercambiarse: tópico + concordancia de tópico (clítico de sujeto) o concordancia de tópico (clítico de sujeto) + tópico, si bien esta última posibilidad obliga al tópico a colocarse al final de la oración, ya que sigue siendo extraoracional.

(66)
Pièrre, il
mange
des
pommes
Pièrre, 3sG.MASC.CLIT. comer-3sG.PRES.IND. PART. manzanas
('Pièrre come manzanas')

(67) Il

mange

des

pommes,

Pièrre

3SG.MASC.CLIT.comer-3SG.PRES.IND.

PART.

manzanas, Pièrre

('Pièrre come manzanas') 
Para el autor, este tipo de estructuras reflejan el ciclo de la topicalización postulado por Li (1975), quien asegura que las lenguas, desde un punto de vista tipológico, se articulan en su estructura informativa de la siguiente manera: de prominencia topical; sin prominencia ni topical ni de sujeto; de prominencia de sujeto; de prominencia topical y de sujeto. El francés se encontraría en esta última fase, en la que explicita los dos elementos.

Por tanto, la secuencia ustedes [vosotros] $+2 \mathrm{pl}$ podría explicarse como un paso intermedio entre la fase de prominencia del tópico y la fase de prominencia del sujeto, en la que, repetimos, ustedes se comportaría como el tópico y el pronombre nulo con los rasgos de [vosotros] como el sujeto. Su omisión respondería a la estructura no marcada del español. La concordancia del verbo se establece generalmente con el pronombre nulo, sobre todo cuando ustedes aparece en la posición de tópico dislocado a la izquierda o antepuesto al verbo. En la zona focal, hay motivos para pensar que ustedes se está reanalizando como verdadero sujeto y, como resultado, aumenta la concordancia de 3 pl. Ello sucede, sobre todo, cuando se produce el movimiento del verbo a posiciones superiores -interrogativas, imperativas, focalizaciones- o la de los objetos a la derecha.

Otra circunstancia que parece apoyar esta hipótesis se basa en las ocurrencias de otro tipo de series $3 \mathrm{pl}+2 \mathrm{pl}$ : la de los pronombres átonos y las desinencias verbales. Como mostraremos más adelante, ciertas zonas transicionales emplean la secuencia se os, tanto para el reflexivo, el dativo y el acusativo, como se anticipa en (68-70).

(68) Se os queréis ir (H / NE / Antequera / 30-60)

(69) Se os he visto ( $\mathrm{H} / \mathrm{NE} /$ Antequera / 30-60)

(70) Hacer lo que se os dé la gana (M / NE / Écija / <30)

En estas áreas, en las que el uso generalizado de ustedes es todavía incipiente, la concordancia en los clíticos se manifiesta por dos pronombres seguidos de un verbo $2 \mathrm{pl}$. La secuencia, siempre $3+2$, nunca $2+3$, repite el modelo de ustedes vosotros $+2 \mathrm{pl}$.

Por ello, es posible postular que esta secuencia se + os muestra los rasgos del sintagma [ustedes vosotros]. La forma se concuerda con ustedes, mientras que $o s$ haría referencia al sujeto y el verbo se construiría de acuerdo con el verdadero sujeto, una vez más, silent.

Es interesante hacer notar que se + os no solo se da en verbos reflexivos, sino cuando el sintagma [ustedes vosotros] es objeto directo o 
indirecto. Es más difícil de explicar, en estos casos, la génesis de la secuencia $s e+o s$, puesto que el afloramiento de los rasgos de $3 \mathrm{pl}+2 \mathrm{pl}$ obligaría a *les + os y a *los/las +os, formas no documentadas. Sin embargo, la imposibilidad en español de secuencias *les $+l o$, en que el dativo se ve reemplazado por $s e+l o$, podría hallarse en el origen de la asimilación de *les + os y a *los/las + os a se + os. Esta secuencia mostraría, por tanto, la doble concordancia de $3 \mathrm{pl}+2 \mathrm{pl}$ también en los clíticos de objeto.

Sin embargo, esa no es la única prueba que fortalece la hipótesis mantenida aquí. En esas mismas zonas geográficas, hallamos tiempos verbales (en el pretérito perfecto simple, concretamente) híbridos, con dos desinencias sucesivas de $3 \mathrm{pl}$ y $2 \mathrm{pl}$ : de nuevo, una secuencia $3+2$, y no $2+3$, como puede verse en (71-72).

(71) Me abrierois los grifos (H / NE / Alhaurín El Grande / 30-60)

(72) Intentarois entrar ( $\mathrm{H} / \mathrm{NE} /$ Málaga / <30)

La flexión verbal parece expresar de forma mimética la existencia de la doble concordancia [ustedes vosotros] sumando la desinencia de $3 \mathrm{pl}-$ ro a la de $2 \mathrm{pl}-i s$.

En las áreas periféricas, prevalece la concordancia de $2 \mathrm{pl}$ con el pronombre nulo, mientras que ustedes funciona como tópico o sujeto expreso. Cuanto más cercanos nos encontremos al foco, mayor probabilidad hay de que ustedes se esté convirtiendo en el verdadero sujeto y, por tanto, el verbo y sus elementos correferenciales se construyan obligatoriamente en $3 \mathrm{pl}$.

En resumen, la caída de vosotros y el surgimiento de ustedes pasa por una serie de fases que se sintetizan en la tabla 15 .

Tabla 15: Evolución de la concordancia en la nivelación de ustedes.

\begin{tabular}{|l|l|l|l|}
\hline & FASE 1 & FASE 2 & FASE 3 \\
\hline $\begin{array}{l}\text { Discordancia de } \\
\text { ustedes }\end{array}$ & & & \\
\hline $\begin{array}{l}\text { Concordancia parcial de } \\
\text { ustedes } \text { con verbo / reflexivo }\end{array}$ & & & \\
\hline $\begin{array}{l}\text { Concordancia total de } \text { ustedes } \\
\text { con verbo / reflexivo }\end{array}$ & & & \\
\hline
\end{tabular}

La fase 1 se manifiesta en el área -33\%; la fase 2 se atestigua en la zona intermedia con un $33 \%-66 \%$; y la fase 3 es común en la zona de $+66 \%$. Es importante reseñar que la desinencia de $3 \mathrm{pl}$ en el verbo se da en mayor 
proporción en el pretérito perfecto simple, frente a otros tiempos, y en el imperativo. Tal y como afirmaba la bibliografía para el primer caso, el indefinido promueve la flexion de $3 \mathrm{pl}$. Una explicación plausible la hallamos en la falta de distinción fonológica que tiene en Andalucía occidental la 2pl con la 2sg. De acuerdo con Mondéjar (1970), que basa sus observaciones en los mapas del ALEA, la $-s$ de $2 \mathrm{pl}$ (donde no siempre hay diptongación: vosotros fuistes (rara vez fuisteis) convive con la analógica de la 2sg (tú fuistes). En Andalucía occidental, la total eliminación de la $-s$, posterior a su aspiración, tanto en la 2 sg como en la 2 pl, provocó el sincretismo del perfecto simple en ambas personas, por lo que fuiste puede referir a fuiste (2sg) o fuiste (fuistei) $(2 \mathrm{pl})$. El traspaso del perfecto a la $3 \mathrm{pl}$ habría podido ser motivado, por tanto, por una voluntad de desambiguación entre la 2 sg y la $2 \mathrm{pl}$, innecesaria en otros tiempos verbales, si bien ello conduciría al sincretismo con la $3 \mathrm{pl}$.

La explicación para el imperativo se basa en dos argumentos. El primero, de índole comparativa, ya que en otros fenómenos similares, como el voseo, también se apunta a la importancia de la modalidad en la extensión de la concordancia. Aunque el voseo, como ya mencionamos, comenzó en el pronombre, al inicio no inducía la concordancia verbal con desinencias propias de vos. Estas empezaron a surgir en frases imperativas (Abadía de Quant 1992, Bertolotti \& Coll 2003) y, de ahí, se extendieron a otros tiempos donde no hay necesariamente movimiento, como el presente de indicativo. El segundo argumento se correlaciona con el rotacismo del imperativo. La forma imperativa de $2 \mathrm{pl}$ ha arrastrado el rotacismo desde muy temprano en la historia del español y se documenta en gran parte de la Península Ibérica, independientemente del sistema de formas de tratamiento. Tanto es así, que aquellos imperativos reflexivos incluso eligen en muchas ocasiones se en lugar de os con referencia vosotros en áreas no afectadas por la nivelación de ustedes.

Si volvemos por un instante al carácter topical de ustedes, vemos que el español se caracteriza por la posibilidad de colocar un tópico y un sujeto en una posición relativamente libre. Aunque el tópico puede insertarse relativamente en cualquier sitio, es la periferia izquierda la más usual. Es precisamente la que provoca la conversión del tópico en el sujeto, según Lehmann (1975), Li (1975) o Givón (1975). Las estructuras sintácticas que se suelen topicalizar con mayor normalidad en español son los objetos y experimentantes. Comparemos (73-77). 
(73) A mí, me gusta el chocolate

(74) A él, lo vi ayer de compras

(75) Lo que a mí más me molesta es el ruido

(76) A mí, me da igual

(77) Los ordenadores, yo de esas maquinas no sé nada

En (73-77), el experimentante se hace más prominente y se lleva a la periferia izquierda. Esto obliga a recuperarlo con una anáfora que puede o no concordar. Sin embargo, la frecuencia de frases como (73) o (76) han dado lugar a la conversión del elemento topicalizado en una especie de sujeto mediante un cambio de valencia. Actualmente, el español coloquial puede hacer (78-79).

(78) Yo, no me gusta el chocolate

(79) Yo, me da igual lo que digan

Las frases (78-79) demuestran que la antigua construcción de dativo se ha convertido en un pronombre de sujeto aunque se sigue manteniendo en la periferia izquierda y se recupera con el clítico me. Como en el caso de $u s^{-}$ tedes, es el elemento posicionado a la izquierda el que empieza a desplazar al existente, pero no es común que un tópico situado a la derecha o en una posición intermedia se convierta en sujeto. Los ejemplos que se acaban de mostrar parecen estar pasando por una primera etapa como la que sufrieron los verbos estativos ingleses después de la Edad Media.

El portugués no presenta casos de discordancia entre sujeto, reflexivo $\mathrm{y}$ verbo, por lo que inferimos que vocês funciona como sujeto.

\subsection{La concordancia en los pronombres átonos}

El hecho de que la 3pl se extienda antes al reflexivo y pase, posteriormente, a los objetos en ambas lenguas (gráficos 11 y 12) se puede relacionar con las jerarquías que existen de acuerdo con el caso sintáctico. 


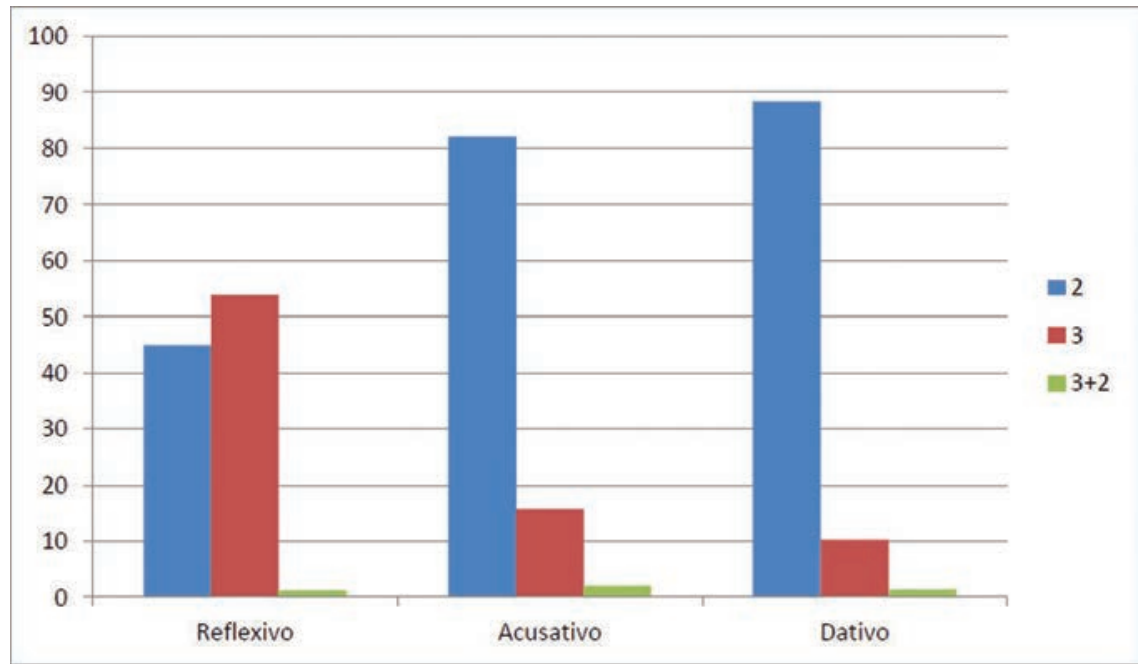

Gráfico 11: Pronombres átonos en la nivelación de ustedes.

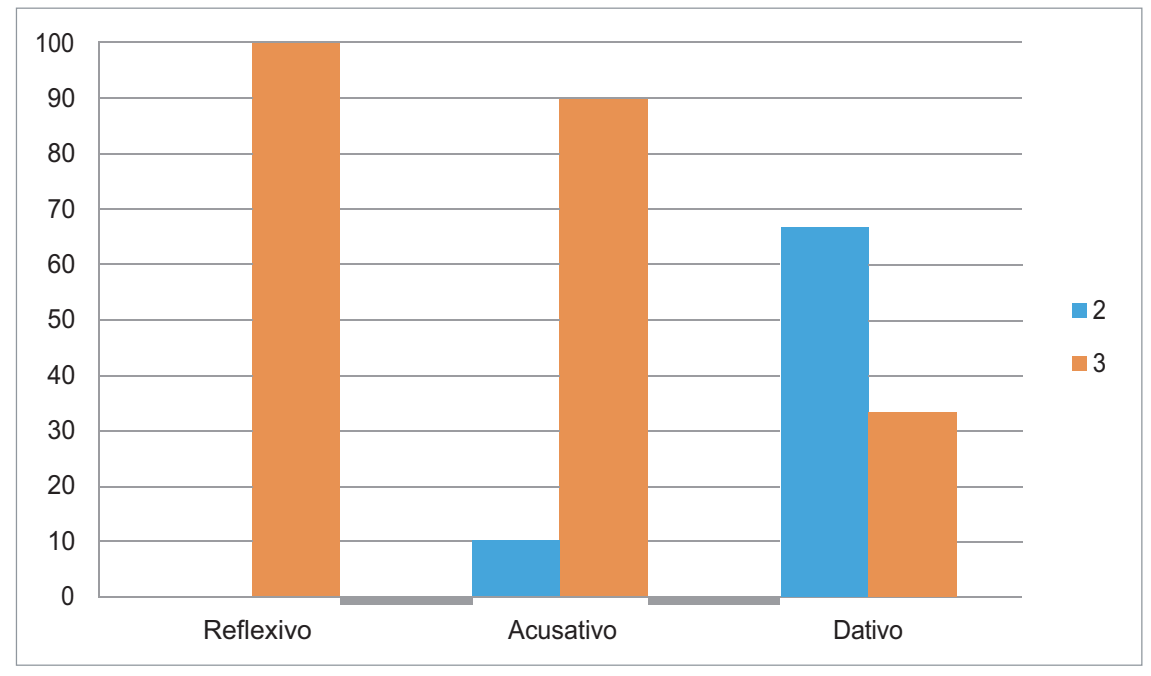

Gráfico 12: Pronombres átonos en la nivelación de vocês.

(80) Vocês vão-se embora? (Serpa / M)

(81) A que horas se levantaram vocês? (Elvas / M)

(82) Não os engano a vocês (Alcácer do Sal / M)

(83) Vi-os a passear (Alcácer do Sal / M) 
(84) Ontem não os vi (Tavira / M)

(85) Não os encontrei (Arraiolos / H)

(86) Digo-lhes a vocês (Odemira / M)

(87) Dou-lhes um beijo (Tavira / M)

(88) A mãe tem-lhes contado alguma história? (Arraiolos / H)

(89) Não lhes digo nada (Serpa / M)

Blake (2004) analiza en su monográfico Case las relaciones gramaticales e implicativas que existen entre los diferentes casos y llega a la conclusión de que estos se rigen por la siguiente jerarquía:

(viii) Sujeto $>$ objeto directo $>$ objeto indirecto $>$ oblicuos (Blake 2004: 87).

En el caso particular de la relativización, se puede postular que si una lengua es capaz de relativizar el objeto indirecto, lo hará obligatoriamente con el directo y el sujeto. En el caso del orden de palabras, el orden no marcado de numerosas lenguas sigue el patrón de izquierda a derecha. Incluso en la formación de pasivas, las lenguas siguen esta jerarquía, de tal manera, que el español puede pasivizar el objeto directo, pero no el indirecto, y el inglés, no obstante, puede hacer una pasiva con el objeto indirecto como sujeto de la misma, lo que necesariamente supone que puede también emplear este recurso para los objetos directos. En latín, no obstante, la jerarquía de caso era la siguiente:

(ix) Nominativo $>$ acusativo $>$ dativo $>$ ablativo $>$ genitivo (Blake 2004: 89).

De acuerdo con lo expuesto, lo esperable tanto en español como en portugués es la extensión de la $3 \mathrm{pl}$ de forma paulatina en los distintos elementos sintácticos a tenor de estos patrones. Es decir, si la innovación aparece en el sujeto, se trasladará antes al acusativo, posteriormente al dativo y, por último, al genitivo. Los reflexivos serán los primeros clíticos en adoptar la morfología del sujeto, ya que en numerosas ocasiones son anafóricos de estos. Como expusimos en el análisis estadístico, la $3 \mathrm{pl}$ se atestiguaba ya en la zona 33\%-66\% (90-94) y $+66 \%(95-101)$, mientras que esta innovación no había alcanzado la zona -33\%. A continuación, exponemos varios ejemplos de la concordancia del reflexivo en esas zonas. 
a) Zona $33 \%-66 \%$

(90) No negarse $(\mathrm{M} / \mathrm{NE} /$ Alosno / <30)

(91) ¿Cómo se llamáis? (H / NE / Ayamonte / >60)

(92) Creo que se deberíais preocupar de vuestros asuntos (M / E / Morón de la Frontera / <30)

(93) Ustedes se imagináis cómo estoy (M / E / Cortegana / 30-60)

(94) No se vayáis ustedes a creer (M / NE / El Castillo de las Guardas / 30-60)

b) Zona $+66 \%$

(95) Se vais al bingo (M / NE / Alcalá de los Gazules / 30-60)

(96) Comprarse un perrito ( $\mathrm{M} / \mathrm{NE} /$ Alcalá de los Gazules / <30)

(97) Estoy harto de que se metáis en mi vida (M / NE / Cádiz / 30-60)

(98) Lo que tenéis que hacer es dedicarse a vuestros asuntos (H / E / Ubrique / 30-60)

(99) Ustedes se vais a meter en vuestros asuntos ( $\mathrm{M} / \mathrm{NE} /$ Ubrique / 30-60)

(100) ¿Ustedes no se hartan de estar todo el día cotilleando? (H / NE / Vejer de la Frontera / 30-60)

(101) Se habéis cargado la pared $(\mathrm{H} / \mathrm{NE} /$ Ubrique / <30)

Como ya expusimos, Wechsler \& Zlatic (2003) han investigado sobre el comportamiento de la concordancia y han concluido que esta se divide en dos tipos: concord e index. La primera obedece a reglas que influyen en el caso, número y género, como en los sintagmas nominales o los adjetivos que dependen de su núcleo. Index, por otra parte, trata de las concordancias de persona, número y, en algunas lenguas, de género. Suele representar la concordancia del verbo con respecto su sujeto o la de los clíticos. Mientras que el entorno de concord es el sintagma nominal, el entorno de index es el sintagma verbal o incluso toda la oración. En el presente estudio, los clíticos reflexivos son los primeros en concordar en persona con su sujeto, ya que representan concordancia index. Su inductor, ustedes, es siempre el sujeto del que dependen, por lo que los postulados de Wechsler \& Zlatic se cumplen (véase también Wechsler \& Hahm 2011 para al concordancia con la cortesía).

Los clíticos de objeto se comportan, en cambio, de manera más independiente. No suelen estar gobernados por un alocutivo previo, como 
en los casos de las dislocaciones de objeto. Casi siempre presentan por primera vez la referencia alocutiva en la oración. Ya que los objetos no se refieren necesariamente a ninguna otra entidad expresada en la oración, no están obligados a concordar con nada más dentro del dominio oracional. De hecho, en casi todas las zonas, excepto en la más focal, los pronombres de objeto se han expresado con morfología de 2 pl, ya sea en su función de complemento directo o indirecto, como se ejemplifica en (102-113):

\section{a) Dativo}

(102) Os tengo dicho que no (M / NE / Alosno / 30-60)

(103) No voy a daros explicaciones (H / E / Cartaya / 30-60)

(104) Si no os gusta, os preparo un té (M / NE / Cártama / >60)

(105) ¿Queréis que sos ponga algo? ( $\mathrm{M} / \mathrm{NE} /$ Málaga / >60)

(106) Os gusta cotillear (M / E / Carmona / 30-60)

(107) ¿Nos os da vergüenza? (H / NE / Osuna / 30-60)

(108) No os creo (H / NE / Málaga / <30)

b) Acusativo

(109) Intenten buscar a alguien que os pueda avalar (M / E / Córdoba / 30-60)

(110) Os he visto a ustedes $(\mathrm{H} / \mathrm{NE} /$ Alosno / <30)

(111) Estoy harto de veros (H / E / Bollullos / 30-60)

(112) Estoy siempre aguantándoos (M / NE / Vélez-Málaga / 30-60)

(113) Os tengo vigilados $(\mathrm{H} / \mathrm{NE} /$ Sevilla / <30)

Los objetos son más autónomos porque no necesariamente poseen un inductor dentro de la oración que los obligue a concordar sintácticamente, de acuerdo con los postulados de Corbett (2006). Este autor afirma que, ante un elemento controlador (controller) que induce dos concordancias, el elemento inducido (target) adoptará una de las dos posibilidades, en función de varios factores. Estos se reducen a la posición del target dentro de la oración con respecto a su controlador y a su estatus sintáctico, reproducido en la siguiente jerarquía: [adjetivo adyacente $>$ predicado $>$ pronombre relativo $>$ pronombre personal]. La probabilidad de concordar sintácticamente aumenta cuanto más a la izquierda se sitúe el elemento en la jerarquía. Si nos movemos hacia la derecha, la concordancia semántica es más probable. Ya que los objetos no están obligados a poseer un inductor dentro de la oración, están menos presionados a adoptar una 
concordancia sintáctica, en este caso, la 3pl, y, por tanto, su comportamiento resulta más conservador, manteniendo una concordancia semántica expresada mediante la $2 \mathrm{pl}$.

El análisis estadístico nos ha permitido observar que los clíticos se iban adhiriendo a la $3 \mathrm{pl}$ de manera jerárquica, siendo el reflexivo el primero, seguido del acusativo y, posteriormente, el dativo. Este mismo continuum se puede apreciar en las diferentes fases de la difusión geográfica. Tal y como hemos concluido, este fenómeno responde a un patrón de contagio por ondas, es decir, las distintas innovaciones se originan en área determinada que las va extendiendo a la periferia poco a poco hasta que se van difuminando, conforme se amplía el radio geográfico. Ello implica que la 3pl, es decir, la innovación, se vaya manifestando en todos los elementos sintácticos con referencia ustedes uno a uno, siendo cada nueva manifestación una innovación dentro del fenómeno. Si comparamos, por tanto, los datos del análisis estadístico, comprobamos efectivamente que, cuanto más alejados del foco, mayor probabilidad de $2 \mathrm{pl}$, mientras que, cuanto más cercanos al mismo, mayor preponderancia de $3 \mathrm{pl}$. Asimismo, el aumento de concordancias en 3pl es liderado por el reflexivo, que siempre proyecta mayor porcentaje que los clíticos de objeto. En este caso, es, sin duda alguna, el acusativo el que antes sucumbe ante la innovación y, por detrás, el dativo. Algunos ejemplos de clíticos de objeto directo e indirecto en $3 \mathrm{pl}$ se reflejan en los ejemplos (114) a (117).

\section{a) Dativo}

(114) Siento no poderles dar a ustedes el crédito (M / NE / Alcalá de los Gazules / 30-60)

(115) ¿A ustedes qué les importa? (M / NE / Cádiz / <30)

b) Acusativo

(116) Estoy harto de tenerlas de vecinas a ustedes (M / NE / Lebrija / 30-60)

(117) Las he visto entrar (M / E / Puerto Real / <30)

Ya desde el inicio, los clíticos de objeto adoptan un comportamiento mucho más independiente que los reflexivos. Su tendencia a la concordancia de $2 \mathrm{pl}$ solo puede deberse al hecho de que carezcan de controller en la misma oración (a no ser que haya un doblado de objeto, en el que ya sí existe una referencia a la cual el pronombre anafórico ha de acoplarse). 


\subsection{La concordancia del posesivo}

Por último, destacaremos el comportamiento conservador del posesivo, cuyo número de ocurrencias ha sido abrumadoramente de 2 pl, a excepción del área focal, que ha producido más ejemplos de $s u$ que las demás zonas (106-109) y casos contados del sintagma de ustedes (110) (gráfico 13).

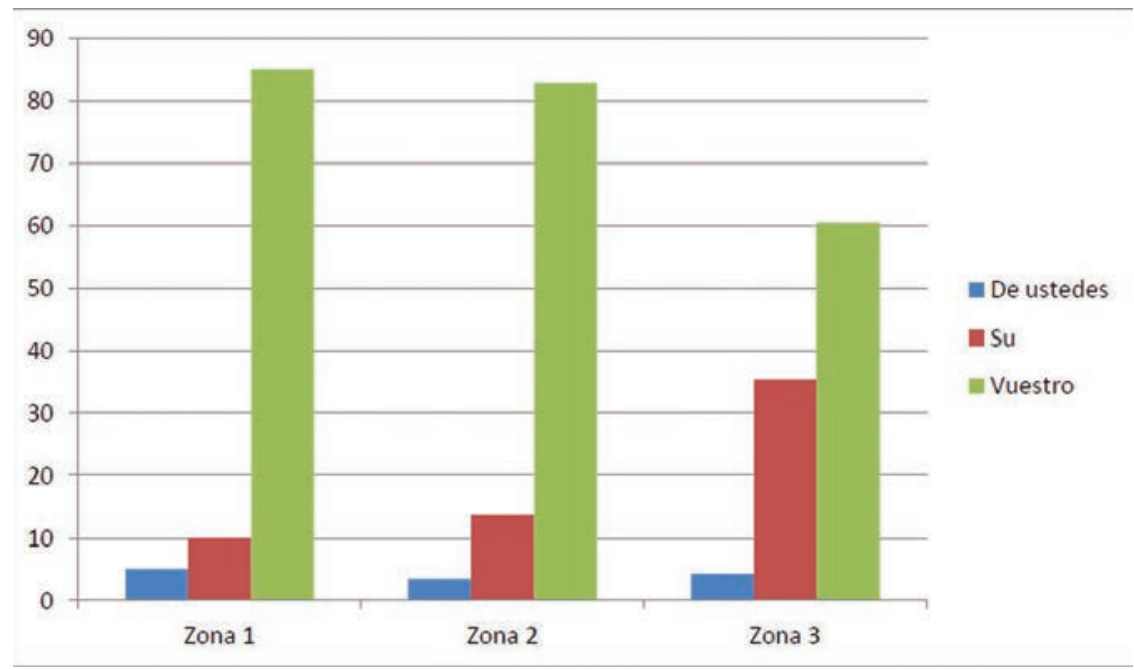

Gráfico 13: Posesivos en la nivelación de ustedes.

Aun así, la forma preferida sigue siendo vuestro, como en el resto de las zonas (118-127).

(118) Irse a sus casas (M / NE / Alcalá de los Gazules / 30-60)

(119) Métanse en su vida (M / E / Cádiz / <30)

(120) No podemos hacernos cargo de su situación financiera (M / E / Tarifa / <30)

(121) Meterse en sus asuntos ( $\mathrm{H} / \mathrm{NE} /$ Ubrique / <30)

(122) Meterse en la vida de ustedes (H / NE / Lucena / 30-60)

(123) Meteros en vuestros asuntos ( $\mathrm{M} / \mathrm{NE} / \mathrm{Montoro} / 30-60)$

(124) Que os metáis en vuestra vida (M / NE / Antequera / 30-60)

(125) Os vais a vuestra casa (M / E / Bollullos del Condado / 30-60) 
(126) No me creo vuestras explicaciones (H / NE / Valverde del Camino / $<30)$

(127) Estoy harto de vuestras tonterías (H / E / Vélez-Málaga / 30-60)

Si bien la inmensa mayoría de ejemplos de $s u$ se ha producido en la zona donde la $3 \mathrm{pl}$ ha saltado a todos los elementos, vuestro permanece en la misma región con mucha virulencia. Tal y como apuntaba Blake (2004) en sus jerarquías de caso, el genitivo era el último elemento del continuum en adoptar un cambio, situación que se ve reflejada en el comportamiento sintáctico de la 3pl. Asimismo, como apuntaban Wechsler \& Zlatic (2003), el posesivo suele formar parte de un sintagma nominal y, por tanto, está gobernado por el núcleo del mismo. En consecuencia, atiende a la concordancia concord, esto es, a los rasgos de caso, género y número, siendo menos susceptible a los de persona. Igual comportamiento ha tenido en el portugués (128).

(128) Como é que estão os vossos pais? (Pombal / H)

Este ha optado por la opción de $2 \mathrm{pl}$ o vosso como marca la norma, a excepción de una pequeña zona donde ya empieza a haber ocurrencias de $3 \mathrm{pl}$ con el sintagma de vocês (129) (gráfico 14).

(129) Como é que estão os pais de vocês? (Serpa / H)

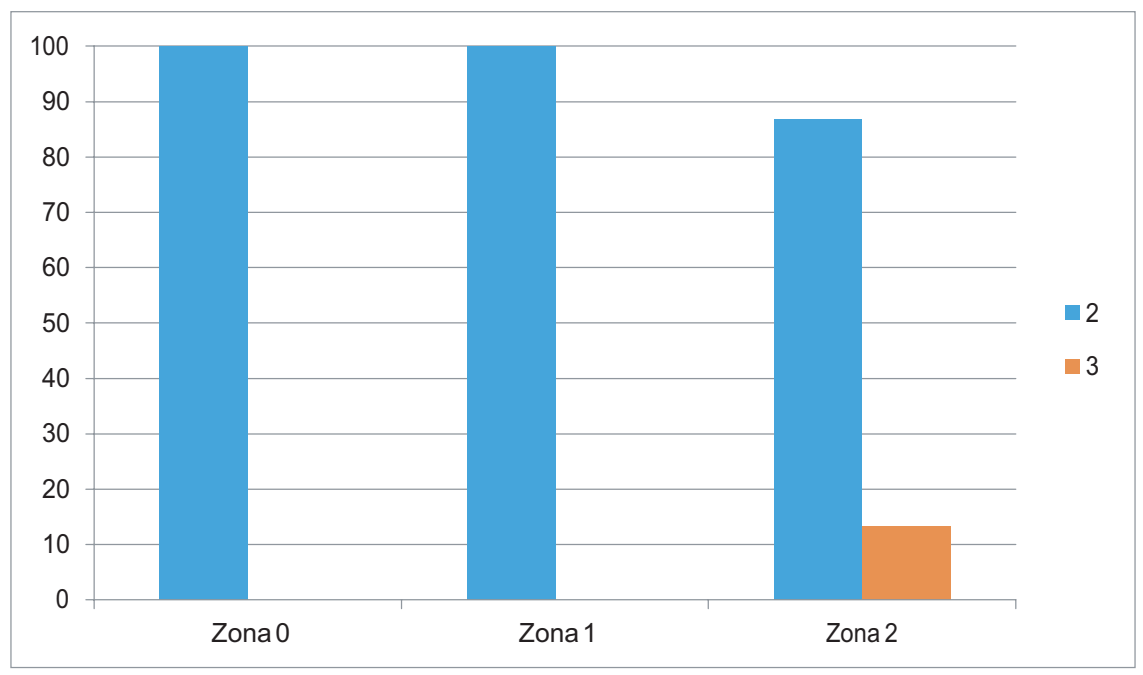

Gráfico 14: Posesivos en la nivelación de vocês. 


\subsection{Situación comunicativa}

La nivelación en ustedes y vocês a expensas de la antigua distinción diafásica entre vosotros - ustedes y vós - vocês ha producido un resultado desigual. En el caso del andaluz occidental, los informantes caracterizados por esta particularidad no han propuesto una nueva alternativa para volver a diferenciar mediante una forma pronominal o una desinencia verbal la formalidad de la informalidad. No obstante, el caso del portugués sí ha propuesto una nueva forma (que, por otro lado, ya existía) que ha desplazado prácticamente el uso de vocês como tratamiento formal en contextos muy deferenciales. Así, el sintagma os senhores es el elegido por todos los informantes de la encuesta y es el alocutivo que la bibliografía siempre ha señalado como manera de ser más cortés, cuando vocês se revela deficitario para dicho contexto.

No es extraño que la distinción diafásica en el plural sea relativamente opcional. Jucker \& Taavinstainen (2003), Siewierska (2004) o Clyne et al. (2009) apuntan que el conflicto mayor a la hora de satisfacer las necesidades de cortesía de un contexto comunicativo aparece en situaciones donde tan solo hay un interlocutor, mientras que el plural, al ser menos individualizador, es, por definición, menos amenazante para la face del alocutario. Si comparamos con otras lenguas, observamos que las mayores diferencias surgen en el singular, mientras que la solución más común es mantener una única forma de tratamiento en plural que no distinga el grado de cortesía. Es el caso del francés con vous, del español de América con ustedes, del sistema griego, del latín tardío o de fases anteriores del alemán y el inglés. No nos ha de sorprender, por tanto, que el andaluz occidental no proponga una estrategia nueva para diferenciar formal de informal en el plural. Tampoco nos puede sorprender que el portugués esté distinguiendo entre vocês y os senhores para marcar la distancia social; como hemos apuntado, es relativamente opcional.

Sin embargo, sí desearíamos mencionar que en la realización de las encuestas, hemos hallado muchos contextos que preveíamos formales y que se han reanalizado como informales por parte de los informantes, a saber: situaciones en las que una persona tenía que dirigirse a un grupo de mayores o en las que un trabajador de banca debía tratar a unos clientes. Es en la zona andaluza y en informantes que distinguen o han empezado a distinguir entre vosotros como pronombre informal y ustedes como estrategia de 
formalidad donde se ha producido un incremento considerable del empleo de vosotros para situaciones que, en principio, rigen socialmente el uso de ustedes. Esta generalización cada vez mayor de la informalidad no solo se ha documentado en español (de hecho, De Jonge \& Nieuwenhuijsen 2012 advierte de la extensión de los usos de tú a costa de usted tras la instauración en España del sistema democrático), pues se ha recogido también en los países escandinavos (Paulston 1984), en Italia (Benigni \& Bates 1977) o en los Balcanes (Kocher 1967). Por tanto, la universalización de vosotros tan solo obedecería a la mentalidad de igualdad que un sistema democrático posee y que ha llevado al mismo fenómeno en la mayoría de los países europeos tras la Segunda Guerra Mundial. Y, aunque es cierto que se documenta un aumento exponencial de los pronombres informales en español, los últimos estudios sugieren que la tendencia de esta lengua, al menos en su variedad peninsular, ha sido esa en mayor o menor medida. Por ejemplo, Molina Martos (en prensa) sostiene que el incremento del pronombre informal tú a costa de usted se produjo a finales del siglo XIX y fue auspiciado por las clases elevadas, generalizándose posteriormente a las clases más desfavorecidas. Lo mismo argumenta Fernández (2012) acerca de la difusión en España de vosotros en contextos en los que ustedes era la norma en el siglo XVIII; según la autora, fue un cambio desde arriba. El portugués, por el contrario, a ambos lados del Atlántico, ha optado por reemplazar el pronombre informal por uno formal que ha terminado convirtiéndose con el tiempo en informal. Así fue con você, cuya reinterpretación como forma de cercanía también se relaciona con las clases altas, aunque más tarde lo adoptaría el resto del espectro social. Y lo mismo sucede en el plural: Faraco (1996) defiende que la imposición de vocês sobre vós en Portugal ocurre en clases elevadas y más tarde se extiende a todas las clases sociales. 



\section{Conclusiones}

El presente estudio ha tratado de avanzar en la investigación de dos fenómenos poco considerados en las variedades europeas del español y del portugués: la desaparición de los tratamientos de $2 \mathrm{pl}$ vosotros a favor de ustedes, y vós a favor de vocês, así como la extensión consiguiente de la concordancia de $3 \mathrm{pl}$ en Andalucía y Portugal.

Para el español, nos propusimos un objetivo geolingüístico al tiempo que diacrónico: acotar la extensión actual del fenómeno y confrontarla con la que se desprende de trabajos anteriores, algunos aún sin elaborar y que hemos también analizado, como los materiales del ALPI. Gracias a esta comparación, hemos podido comprobar que, hace 100 años, el uso de $u s-$ tedes a costa de vosotros se distribuía por las provincias de Cádiz, Huelva, Sevilla, Málaga (excepto el extremo oriental) y Córdoba (salvo el extremo septentrional). Asimismo, la generalización del pronombre ustedes había producido tres innovaciones, basadas en la extensión de su concordancia sintáctica ( $3 \mathrm{pl})$. Estas extensiones se esparcían de acuerdo con un patrón por ondas, cuyo epicentro se localizaba en la provincia de Cádiz y el sur de Sevilla. En él, la 3pl se manifestaba en el pronombre tónico, el reflexivo y el verbo de una subordinada relativa. El área más conservadora, aquella que tan solo reflejaba la $3 \mathrm{pl}$ en el pronombre tónico, se concentraba en el extremo occidental onubense, la mitad oriental de Málaga y el centro de Córdoba. Por último, la zona intermedia, es decir, aquella que ya ha generalizado la $3 \mathrm{pl}$ también en el reflexivo, aunque no en el verbo, cubría el extremo meridional gaditano, se extendía por casi todo Sevilla, Huelva, el sur de Córdoba y el oeste de Málaga (Lara 2010, 2012).

En la actualidad, la extensión geográfica coincide a grandes rasgos con la extraída del ALPI, por lo que el fenómeno se ha mantenido estable. Tan solo algunas áreas del centro de Córdoba han rechazado el uso de ustedes, reduciendo así la presencia de la nivelación en esa provincia. De nuevo, el patrón de difusión se corresponde con un modelo por ondas, cuyo foco se localiza en la provincia de Cádiz, avanza por el resto de Andalucía occidental y se difumina al este de Málaga y norte de Córdoba.

Por otro lado, hemos hallado una tendencia a la norma del español peninsular, que distingue ustedes de vosotros. En este caso, el contagio se 
difunde de manera jerárquica, ya que es más productiva en las zonas urbanas (Sevilla y Málaga), presenta gran oscilación en enclaves de demografía intermedia (Écija, Algeciras), pero es testimonial en municipios muy rurales.

Otro de los objetivos que nos propusimos cumplir fue dilucidar qué características sociales posee el empleo vernáculo en las áreas en las que se atestigua. Para ello planificamos una metodología basada en el doblaje de escenas de series de televisión, cuyos personajes se dirigieran a un grupo de personas. Los resultados han demostrado que la particularidad dialectal depende de tres variables fundamentalmente: la edad, el nivel educativo y la zona geográfica, seguidas muy de cerca por el tamaño de población del enclave. De esta manera, la probabilidad de mantener el modelo vernáculo con ustedes es mayor en hablantes mayores de 60 años, seguidos de los que aún no han cumplido los $30 \mathrm{y}$, por último, de los adultos. Asimismo, el aumento en el uso de ustedes es inversamente proporcional al nivel educativo del hablante. Además, aquellos hablantes originarios del foco (Cádiz) son más propensos al fenómeno que los más alejados del mismo (norte de Córdoba y este de Málaga). Por último, los habitantes residentes en grandes núcleos, como las ciudades de Sevilla y Málaga, se acercan antes al modelo estándar. Aunque nuestro corpus ha proporcionado un número mayor de mujeres sensibles a la distinción entre ustedes y vosotros, las pruebas estadísticas no han otorgado significatividad a este hecho.

Por tanto, en términos diacrónicos, la interpretación de la disposición geográfica y la distribución sociolingüística de los datos conduce a concluir que la nivelación en ustedes se originó en Cádiz y se fue extendiendo por ondas al resto del occidente andaluz, siendo, actualmente, el área que muestra este cambio lingüístico en fase más avanzada. Sus características sociales siguen siendo las mismas que hace siglos, a tenor de la bibliografía consultada (Lapesa 2000; Cano 2004; Menéndez Pidal 2005). Como desde su aparición, el empleo está sobre todo restringido a capas poco letradas y rurales de las provincias más occidentales de Andalucía.

Lingüísticamente, la concordancia de $3 \mathrm{pl}$ se extiende de forma jerárquica en los distintos elementos con referencia a ustedes. Los datos del ALPI, de hace casi un siglo, mostraban un continuum que se iniciaba en el pronombre tónico, seguía en el reflexivo y terminaba en el verbo de la subordinada, sin proporcionar información sobre el resto de contextos sintácticos del verbo, los pronombres de objeto o el propio posesivo. El trabajo de campo desenvuelto en esta investigación ha permitido sacar a la luz todas las fases seguidas en la extensión de la 3pl. Como se había 
postulado, el fenómeno aparece en el pronombre tónico; posteriormente, salta al reflexivo, y de ahí, se implanta sucesivamente en el verbo, los pronombres átonos de acusativo y dativo para finalizar su recorrido en el genitivo. Dentro del verbo, son los tiempos pretéritos los que previamente adoptan la 3pl, mientras que la modalidad que más favorece la concordancia innovadora es la exhortativa.

Desde un punto de vista teórico, todo indica que el surgimiento del nuevo tratamiento ustedes comenzó a través de la topicalización. Una de las características de los tópicos es su encuadre fuera de la oración, por lo que su obligada referencia dentro de esta no tiene por qué atender a todos los rasgos sintácticos del elemento tematizado (Givón 1975). Es por ello que, en los estadios más conservadores, todas las referencias a ustedes son de 2 pl. Asimismo, de acuerdo con los postulados de la tipología lingüística, la forma innovadora iría seguida de un pronombre nulo correferencial de $2 \mathrm{pl}$, vosotros, que representaría el sujeto real de la oración. La reinterpretación de ustedes como sujeto se produciría de manera gradual, conviviendo en primer lugar con el verdadero sujeto (vosotros) hasta su completo reanálisis. El último actuaría como un pronombre silent, pues, en efecto, en ninguno de nuestros datos se ha documentado la emergencia superficial de los dos alocutivos ustedes + vosotros. Sin embargo, hay evidencia indirecta de la existencia de esos dos elementos gracias al testimonio proporcionado por algunos datos de las áreas transicionales. En esas zonas hallamos secuencias de $3 \mathrm{pl}+2 \mathrm{pl}$ tanto en los pronombres átonos se $+o s$ como en la morfología verbal -ro $+-i s$, en las que la primera forma marcaría la concordancia con el elemento ustedes y la segunda denotaría la concordancia del segundo elemento: vosotros. La falta de expresión del pronombre nulo debió de conducir al progresivo reanálisis de ustedes como único elemento presente. Solo cuando ustedes se convirtió en el único sujeto, todos los elementos se flexionarían en 3pl. Por tanto, dentro de las fases geográficas extraídas del corpus, las más alejadas del foco estarían en niveles muy incipientes del fenómeno, mientras que, cuanto más cercanos nos situamos del epicentro, mayor evolución se constata en el reanálisis de ustedes como pronombre.

Seguidamente, una vez que ustedes se va reinterpretando como sujeto, la $3 \mathrm{pl}$ empieza a extenderse por orden en los demás elementos sintácticos concordantes. El reflexivo es el primer elemento en adoptarla, seguido del verbo. A continuación, los pronombres átonos de objeto se acoplan a la 3pl, siendo el acusativo el primero y el dativo, el último. 
Finalmente, el posesivo adopta la 3 pl, solo una vez que las demás posiciones sintácticas ya se han concordado con la persona innovadora. Este continuum responde a las observaciones hechas por Blake (2004), que diseña una jerarquía idéntica para el latín y lenguas derivadas con respecto a otros fenómenos lingüísticos. Dentro del verbo, hemos observado que el pretérito perfecto simple sucumbe con anterioridad a la $3 \mathrm{pl}$, debido a una cuestión fonética, ya que el cambio permite desambiguar el referente (singular o plural) en ese tiempo verbal (Mondéjar 1970). A ello podría añadirse una reflexión tipológica, pues el pretérito es más marcado que el presente, por lo que aceptaría mejor una nivelación ( $3 \mathrm{pl})$ y la pérdida de morfología flexiva. No obstante, esta consideración no encuentra apoyo en el hecho de que la nivelación no se da en el futuro, tiempo tipológicamente más marcado que el pasado, si bien no tenemos suficientes ejemplos de futuro para confrontar dicha hipótesis (Greenberg 2005).

Uno de los objetivos que nos propusimos fue el de dilucidar qué comportamiento pragmático posee actualmente el empleo de ustedes, ya que su generalización ha podido derivar en otras estrategias de cortesía para marcar distancia o formalidad. El resultado ha ofrecido una doble vertiente: en primer lugar, el uso exclusivo de ustedes no ha comportado una innovación de estrategias de cortesía para reemplazar la distinción entre formal e informal, por lo que su nivelación lleva aparejada la eliminación del componente diafásico en plural. En segundo lugar, hemos advertido un descenso pronunciado de la expresión de ustedes en hablantes que sí se rigen por el comportamiento estándar de alocutivos. Es decir, aquellas personas que no han generalizado ustedes para cualquier situación comunicativa, y siguen diferenciando entre vosotros para la informalidad y ustedes para la formalidad, presentan un bajo porcentaje de utilización de ustedes en contextos donde es esperable. Por tanto, como ya se había anunciado en De Jonge \& Nieuwenhuijsen (2012), el empleo del pronombre formal está en claro descenso a favor de la moda solidaria, en la que el alocutivo informal va copando usos en los que, hace unas décadas, era imposible que apareciera. Esta tendencia es análoga a la que ya sucede en otros países del entorno (Brown \& Gilman 1960, Benigni \& Bates 1977, Paulston 1984), cuyos regímenes democráticos han propiciado la regresión de la forma cortés en pro de una idea de igualdad.

En el caso del portugués, como ya expusimos, este diferenciaba la formalidad de la informalidad en el plural mediante dos pronombres, al 
igual que el español estándar. De esta manera, vós $+2 \mathrm{pl}$ denotaba informalidad y vocês $+3 \mathrm{pl}$, formalidad. Sin embargo, hace tres siglos, la forma de cortesía empezó a ocupar los usos de la informalidad, desplazando a vós del paradigma y provocando su estigmatización (Cintra 1972). No obstante, la innovación no se había difundido por todo el país.

En términos geográficos, a diferencia de lo que acontece en el andaluz, la nivelación a favor de vocês ha crecido en todo el portugués europeo continental, debido a su estatus prestigioso. Así, a mediados del siglo pasado, según los datos del ALPI, dicho fenómeno se hallaba tan solo en la mitad meridional del país y alcanzaba los distritos de Faro, Beja, Évora, Setúbal, Lisboa, Portalegre, Santarém, Leiria y Coimbra (Lara 2012). Su patrón de difusión parecía corresponderse con el modelo por ondas, ya que, dentro del fenómeno, se distinguían dos fases: la 3pl expresada en el verbo y reflexivo, en primer lugar, y una posterior en la que la $3 \mathrm{pl} \mathrm{se} \mathrm{mani-}$ festaba también en el acusativo. Esta última fase no había llegado a todas las zonas en las que el fenómeno se atestiguaba y dejaba aisladas algunas (en el extremo nororiental y suroriental) que compartían el mismo estadio evolutivo. Los datos de las encuestas del CORDIAL-SIN mostraron un aumento hacia el norte de vocês en detrimento de vós (Lara 2013). Las nuevas zonas donde se manifestaba eran los distritos de Aveiro y Viseu, si bien la escasez de datos y las discordancias que surgían no terminaban de dar por sentada esa aparente tendencia.

El trabajo de campo desarrollado en el marco de esta investigación ha demostrado que hoy en día, efectivamente, el uso arcaico en la diferenciación diafásica de los pronombres alocutivos plurales está disminuyendo cada vez más. El empleo de vocês como único pronombre se ha extendido hasta las provincias de Aveiro y Viseu y penetra, aunque de forma menos clara, en Castelo Branco, si bien en esta zona su manifestación aún es muy primitiva. A su vez, observamos un modelo de difusión por ondas, en el que se dan cuatro innovaciones, a saber: la nivelación de vocês con la $3 \mathrm{pl}$ en el reflexivo y verbo; la extensión de la 3 pl en el acusativo; la extensión de la $3 \mathrm{pl}$ al dativo y, por último, el salto de la $3 \mathrm{pl}$ al posesivo. El foco del fenómeno se halla en el sureste del país, en la provincia de Beja, más concretamente, alrededor de los enclaves de Serpa y Mértola, fronterizos con la zona andaluza afectada por la nivelación de ustedes.

Según nos alejamos de esa área, las innovaciones que empiezan a afectar a los pronombres de objeto empiezan a ser más débiles, sobre todo, la referente al dativo. Mientras que la $3 \mathrm{pl} \mathrm{del} \mathrm{acusativo} \mathrm{se} \mathrm{manifiesta} \mathrm{en,}$ 
prácticamente, toda el área en la que el fenómeno se daba hace un siglo, la $3 \mathrm{pl}$ en el dativo se restringe a la parte más meridional. En ambos casos, Lisboa representa una isla en la que la 3 pl solo afecta al pronombre tónico, el reflexivo y el verbo, tal y como prescribe el estándar. Esta particularidad pone de manifiesto el estrecho vínculo entre los centros urbanos como sinónimo de sedes que concitan el poder económico, social, cultural y político y que, por tanto, imponen o lideran los rasgos estándares (Wolfram \& Schilling-Estes 2003).

En términos sociolingüísticos, hemos comprobado que, en nuestro estudio en tiempo real, el uso generalizado de vocês ha aumentado progresivamente y tiene visos de seguir expandiéndose. Aunque no hemos podido medir las mismas variables que para el caso andaluz, advertimos una tendencia más pronunciada por parte de las mujeres en imitar el empleo prestigioso.

Si analizamos qué consecuencias ha producido la nivelación de vocês en el aspecto pragmático, observamos un estado más avanzado que en Andalucía. Así, la generalización de vocês parece haber favorecido que la formalidad venga suplida por sintagmas nominales que hacen referencia al rango social de los interlocutores, a su grado de parentesco o a su profesión. En cualquier caso, la forma no marcada de dirigirse cortésmente recae en el grupo os senhores / as senhoras. En este sentido, podemos argüir que vocês empieza a desvalorizarse para un trato formal y cada vez se acota más a la informalidad. Para sustituir esa carencia, os senhores se ha revelado como la estrategia más productiva y menos marcada. A diferencia de los datos que proporcionaba el ALPI, en los que formas arcaicas de la evolución de a vossa mercê hasta você eran utilizadas como manera de marcar formalidad (vossemecês, vomecês), el CORDIAL-SIN y nuestro corpus no han dado (apenas) ocurrencias de dichos pronombres, por lo que puede afirmarse que están en proceso de quedar totalmente en desuso.

En términos lingüísticos, la extensión de la $3 \mathrm{pl}$ en Portugal responde al mismo patrón que el fenómeno andaluz. Se atestigua en primera instancia en el sujeto, reflexivo y verbo, para saltar después a los pronombres de objeto: acusativo y dativo, en ese orden, y terminar por asentarse en el posesivo (Blake 2004). Sin embargo, se observa una disimilitud con respecto al caso español. Mientras que en el último hemos postulado que ustedes funciona como tópico por sus discordancias verbales, en el portugués la aparición de vocês lleva, en la práctica, una adopción automática de la $3 \mathrm{pl}$ en el reflexivo y el verbo. Este hecho parece indicar que vocês ya ha sido 
reinterpretado como sujeto; es por eso que ustedes en español suele ocupar la posición de tópico, mientras que vocês en portugués es abrumadoramente sujeto y, por consiguiente, impone sus rasgos de concordancia.

Cabe mencionar la utilidad de la metodología empleada. Este método ha permitido obtener un gran número de ocurrencias que han podido ser tratadas en estadísticas descriptivas y analíticas. Ante fenómenos cuya aparición no sea tan fecunda en entrevistas sociolingüísticas o semidirigidas, es necesario crear un instrumento propio de recolección de datos, capaz de obtener cualitativa y cuantitativamente todos los elementos sintácticos que son imprescindibles en un análisis profundo. En el caso de la 2pl, los doblajes de escenas en las que se propiciaba un discurso a un grupo de personas han resultado un éxito. La cantidad de las mismas, diferenciadas por el grado de cortesía, y las frases-tipo con el fin de asegurarnos los elementos sintácticos de interés han proporcionado una base de datos no condicionada por la expresión de 2 pl por parte del encuestador.

En cualquier caso, la investigación de los dos fenómenos ha puesto de manifiesto una tendencia clara: la estandarización. Tanto en Andalucía como en Portugal, el avance o retroceso vienen provocados por una presión de la norma, del prestigio, de lo que está bien visto, del estándar. No podemos adivinar si el empleo exclusivo de ustedes con sus discordancias desaparecerá o si el ascenso de vocês hará borrar finalmente del mapa los vestigios del arcaico vós. Solo hay una manera de averiguarlo: recoger el mismo tipo de datos dentro de décadas y verificar si, en ese intervalo, algo ha cambiado o todo ha seguido igual. Esperemos que este trabajo, al menos, haya servido para dar algo más de luz a estos fenómenos y ser una referencia temporal con la que cotejar las realidades venideras. 



\section{Bibliografía}

Aalberse, Suzanne \& Stoop, Wessel (2015), "The exceptional loss of the pronoun T", Journal of Pragmatics, 88, pp. 190-201.

Abadía de Quant, Inés (1992), "La relación pronominal-verbal de segunda persona singular en el español de Corrientes durante el siglo XIX, su comparación con la situación en Buenos Aires", Revista argentina de lingüistica, 8, pp. 31-46.

Adams, Marianne (1987), "From old French to the theory of pro-drop", Natural Language and Linguistic Theory, 5, 1, pp. 1-32.

Allen, Cynthia (1995), Case marking and reanalysis. Grammatical relations from Old to Early Modern English, Oxford: Clarendon Press.

Alvar, Manuel \& Pottier, Bernard (1983), Morfología histórica del español, Madrid: Gredos.

Alvar, Manuel (1996), Manual de dialectología hispánica, Barcelona: Ariel.

Alvar, Manuel et al. (1961-1965), Atlas lingüístico y etnográfico de Andalucía (ALEA), Granada: Universidad de Granada.

Álvarez, Alexandra \& Freites, Francisco (2010), "Los estudios sobre pronombres de segunda persona en Venezuela" en Hummel, Martin et al., Formas y fórmulas de tratamiento en el mundo hispánico, México DF: El Colegio de México / Karl-Franzens-Universität Graz, pp. 325-339.

Alves, Cibelle Corrêa Béliche (2010), O uso do tu e do você no português falado no Maranhão, Universidade Federal do Ceará, trabajo fin de máster.

Bailey, Guy (2003), "Real and apparent time", en Chambers, Jack \& Schilling-Estes, Natalie (eds.), The handbook of language variation, Malden: Blackwell, pp. 312-332.

Basile, Nicola (2001), Sintassi storica del greco antico, Bari: Levante Editori.

Benigni, Laura \& Bates, Elizabeth (1977), "Interazione sociale e linguaggio: analisi pragmatica dei pronomi allocutivi italiani", en Simone, Raffaele \& Ruggiero, Giulianella (eds.), Aspetti sociolinguistici dell'Italia contemporanea, Roma: Bulzoni, pp. 141-165. 
Bertolotti, Virginia \& Coll, Magdalena (2003), "A synchronical and historical view of the túlvos option in the Spanish of Montevideo", en Montrul, Salvador \& Ordóñez, Francisco (eds.) Linguistic theory and language development in Hispanic languages, Somerville: Cascadilla Press., pp. 1-12.

Bertolotti, Virginia (2007), "La cuestión de vuestro/a(s): vitalidad medieval y clásica en el español del Uruguay", Estudios de lingüistica hispánica, Cádiz: Universidad de Cádiz, pp. 17-41.

Bertolotti, Virginia (2015), A mi de vos no me trata ni usted ni nadie. Montevideo: Universidad de la República.

Bertolotti, Virginia (en prensa), "The dismissal of vosotros in Spanish in the Americas", en Hummel, Martin \& Lopes, Célia (eds.), Forms of address in Portuguese and Spanish. Diachronic variation and change. Ámsterdam / Filadelfia: John Benjamins.

Blake, Barry J. (2004), Case, Cambridge: Cambridge University Press.

Blas Arroyo, José Luis (2005), Socioligüística del español, Madrid: Cátedra.

Boléo, Manuel de Paiva (1950), Dialectologia e história da língua: isoglossas portuguesas. Lisboa: Centro de Estudos Filológicos.

Booij, Geert (2002), The morphology of Dutch, Oxford: Oxford Linguistics. Borsley, Robert D. \& Stephens, Janig (1989), "Agreement and the position of subjects in Breton", Natural Language and Linguistic Theory, 7, 3, pp. 407-427.

Bosque, Ignacio \& Gutiérrez-Rexach, Javier (2009), Fundamentos de sintaxis formal, Madrid: Akal.

Bourdieu, Pièrre (1978), Questions de sociologie, París: Minuit.

Braun, Friederike (1988), Terms of address. Problems of patterns and usage in various languages and cultures, Mouton de Gruyter: Berlín.

Britain, David (2010), "Contact and dialectology", en Hickey, Raymond (ed.), Handbook of Language Contact, Oxford: Blackwell, pp. 208229.

Britain, David (2012), "Diffusion", en Bergs, Alexander \& Brinton, Laurel (eds.), English Historical Linguistics: An International Handbook, BerlÍn: Mouton de Gruyter, pp. 2031-2043.

Britain, David (2013), "Space, diffusion and mobility", en Chambers, Jack \& Schilling-Estes, Natalie (eds.), Handbook of Language Variation and Change. Oxford: Wiley-Blackwell, pp. 471-500. 
Brito, Ana Maria et al. (2006), Gramática da língua portuguesa, Lisboa: Caminho.

Brown, Penelope \& Levinson, Stephen C. (1987), Politeness: some universals in language usage, Cambridge: Cambridge University Press.

Brown, Roger \& Gilman, Albert (1960), "The pronouns of power and solidarity”, en Sebeok, Thomas (ed.) Style in language, Cambridge: MIT, pp. 253-276.

Buzaglo Paiva Raposo, Eduardo et al. (2013), Gramática do português, Lisboa: Fundação Calouste Gulbenkian.

Caballero, Alberto \& Caballero, Laura (2003-2006), Aqui no hay quien viva [video], Madrid: Antena 3 Televisión / Miramon Mendi.

Calderón Campos, Miguel (2010), "Los elementos nominales en el sistema de tratamiento del español de Andalucía durante la Restauración (1875-1931)", en Hummel, Martin. et al. (eds.), Formas y fórmulas de tratamiento en el mundo hispánico, México DF: El Colegio de México / Karl-Franzens-Universität Graz, pp. 551-570.

Cano, Rafael. (2004), Historia de la lengua española, Barcelona: Ariel.

Cano, Rafael. (2008), El español a través de los tiempos, Madrid: Arco Libros.

Carrasco Santana, Antonio (2002), Los tratamientos en español, Salamanca: Ediciones Colegio de España.

Carreira, M. H. Araújo (2003), "Les formes allocutives en portugais européen: évolution, valeurs et fonctionements discursifs", Franco-Bristish Studies, 33-34, pp. 35-45.

Carricaburo, N. (1997), Las fórmulas de tratamiento en el español actual, Madrid: Arco Libros.

Catalán, D. (1971), "En torno a la estructura silábica del español de ayer y del español de mañana", en Catalán, Diego (ed.), El español. Orígenes de su diversidad, Madrid: Paraninfo, pp. 77-104.

Chambers, Jack \& Trudgill, Peter (1980), Dialectology, Cambridge: Cambridge University Press.

Chambers, Jack (1997), Sociolinguistic theory, Malden: Blackwell.

Châtelain, Émile (1880), "Du pluriel de respect en latin”, Revue de Philologie, IV, pp. 129-139.

Cintra, Luís Felipe Lindley (1961), "Une frontière lexicale et phonétique dans le domaine linguistique portugais", Boletim de filologia, 20, pp. 31-38. 
Cintra, Luís Felipe Lindley (1962), “Áreas lexicais no território português”, Boletim de filologia, 20, pp. 273-307.

Cintra, Luís Felipe Lindley (1970), "Nova proposta de classificação dos dialectos galego-portugueses", Boletim de filologia, pp. 81-118.

Cintra, Luís Felipe Lindley (1972), Sobre "formas de tratamento" na língua portuguesa, Lisboa: Horizonte.

Clyne, Michael et al. (2009), Language and human relations, styles of address in contemporary language, Nueva York: Cambridge University Press.

Cojocaru, Dana (2003), Romanian grammar, Bucarest: Universidad de Bucarest.

Cook, Manuela (1997), "Uma teoria de interpretação das formas de tratamento na língua portuguesa", Hispania, vol. 80, 3, pp. 451-464.

Corbett, Greville (2006), Agreement, Cambridge: Cambridge University Press.

CORDIAL-SIN - Corpus Dialectal para o Estudo da Sintaxe / The Syntax-oriented Corpus of Portuguese Dialects (A. M. Martins, coord.) $<$ http://www.clul.ul.pt/en/research-teams/212-cordial-sin-syntax-oriented-corpus-of-portuguese-dialects $>$.

Crane, David \& Kauffmann, Marta (1994-2004), Friends [video], Los Angeles: Warner Bros / Bright-Kauffmann-Crane Productions.

Cunha, Celso \& Cintra, Luís Felipe Lindley (1992), Nova gramática do português contemporâneo, Lisboa: João Sá de Costa.

De Jonge, Bob \& Nieuwenhuijsen, Dorien (2012), "Forms of address", en Hualde, José Ignacio et al. (eds.) The handbook of Hispanic linguistcs, Malden: Blackwell, pp. 247-262.

Eberenz, Rolf (2000), El español en el otoño de la Edad Media, Madrid: Gredos.

Elvira, Javier (1993), "La función cohesiva de la posición inicial de frase en la prosa alfonsí", Cahiers de linguistique hispanique médiévale, 18/19, pp. 243-278.

Elvira, Javier (1996), "La organización del párrafo alfonsí", Cahiers de linguistique hispanique médiévale, 21, pp. 325-342.

Elvira, Javier (2014), "Left forever: subject datives and clitic doubling in Old Spanish", en Dufter, Andreas \& Octavio de Toledo y Huerta, Álvaro (eds.), Left sentence peripheries in Spanish: diachronic, variationist and typological perspectives, Ámsterdam / Filadelfia: John Benjamins, pp. 1-29. 
Ernst, Gerhard et al. (2008), Romanische Sprachgeschichte. Berlín / Nueva York: Mouton de Gruyter.

Estrada, Ana (2012), "The Loss of Intervocalic and Final /d/ in the Iberian Peninsula", Dialectologia, Special Issue III, pp. 7-22.

Evans, William (1969), "You and thou in Northern England", South Atlantic Bulletin, vol. 34, 4, pp. 17-21.

Fábregas, Antonio (2008), "Variación en forma morfológica de los pronombres de primera y segunda persona del plural", Revista española de lingüistica, 38, pp. 155-184.

Faraco, Carlos A. (1996), "O tratamento você em português: uma abordagem histórica”, Fragmenta, 13, pp. 51-82.

Fernández, Elisabeth (2012), La oposición vosotros/ustedes en la historia del español peninsular (1700-1931), Granada: Universidad de Granada, tesis doctoral.

Fernández-Ordóñez, Inés (2009), “Orden de palabras, tópicos y focos en la prosa alfonsí", Alcanate VI, pp. 139-172.

Fernández-Ordóñez, Inés (2011), La lengua de Castilla y la formación del español. Madrid: Real Academia Española.

Fernández-Ordóñez, Inés (2016), "Los dialectos del español peninsular", en Gutiérrez Rexach, J. (ed.), Enciclopedia lingüistica hispánica, Londres / Nueva York: Routledge, pp. 387-404.

Fontanella de Weinberg, Beatriz (1979), "La oposición cantes/cantés en el español de Buenos Aires", Thesaurus, XXXIV, na 1, 2 y 3, pp. 72-83.

Fontanella de Weinberg, Beatriz (1992), El español de América. Madrid: Mapfre.

Fontanella de Weinberg, Beatriz (1999), "Sistemas pronominales de tratamiento usados en el mundo hispánico" en Bosque, Ignacio \& Demonte, Violeta (dirs.) Gramática descriptiva de la lengua española, vol. 1, Madrid: Espasa, pp. 1399-1425.

García Godoy, María Teresa (2012), "El tratamiento de merced en el español del siglo XVIII", en García Godoy, María Teresa (ed.), El español del siglo XVIII. Cambios diacrónicos en el primer español moderno, Bern: Peter Lang, pp. 111-152.

García, Érica et al. (1990), “(V)os-(otros): ¿dos y el mismo cambio?”, Nueva revista de filología hispánica, vol. 37, nº 1, pp. 63-132.

Gili Gaya, Samuel (1946), "Nos-ótros, vos-otros", Revista de filología española, vol. 30, pp. 108-117. 
Givón, Talmy (1975), "Topic, pronoun and grammatical agreement", en Li, Charles N. (ed.), Subject and topic, Nueva York: Academic Press Inc, pp. 149-188.

Givón, Talmy (1990), Syntax, a functional-typological introduction, Ámsterdam / Filadelfia: John Benjamins Publishing Company.

Gonçalves, Clézio Roberto (2008), Uma abordagem sociolingüística dos usos das formas você, ocê e cê no português, São Paulo: Universidade de São Paulo, tesis doctoral.

Greenberg, Joseph (2005), Language universals, Berlín/Nueva York: Mouton de Gruyter.

Hammermüller, Gunther (2010), "Evolución de las formas de tratamiento en el español medieval hasta el siglo XVI", en Hummel, Martin. et al. (eds.), Formas y formulas de tratamiento en el mundo hispánico, 507-529. México DF: El Colegio de México / Karl-Franzens-Universität Graz.

Haspelmath, Martin (2001), Language typology and language universals. Berlin: Mouton de Gruyter.

Head, Brian (1978), "Respect degrees in pronominal reference", en Greenberg, Joseph (ed.), Universals of human language, Stanford, Stanford University Press, pp. 151-211.

Heap, David (2003), Atlas lingüístico de la península ibérica (ALPI), University of Western Ontario <http://www.westernlinguistics.ca/alpi/>.

Heine, Bernd \& Song, Kyung-An (2011), "On the grammaticalization of personal pronouns", Journal of Linguistics, vol. 47, pp. 587-630.

Helmbrecht, Johannes (2005), "Typologie und Diffusion von Höflichkeitspronomina in Europa", Folia lingüística, Acta Societatis Linguisticae Europeae, vol. 39, no 3-4, pp. 417-452.

Hickey, Raymond (2003), "The German address system: binary and scalar at once", en Jucker, Andreas \& Taavitsainen, Irma (eds), Diachronic perspectives on address term systems: Pragmatics and beyond, new series, vol. 107, Ámsterdam: John Benjamins, pp. 401-425.

Hopper, Paul \& Traugott, Elizabeth (2003), Grammaticalization, Cambridge: Cambridge University Press.

Howe, Stephen (1996), The personal pronouns in the Germanic languages: a study of personal pronoun morphology and change in the Germanic languages from the first records to the present day, Berlín: Walter De Gruyter. 
Hudson, Richard (2000), La sociolingüistica, Cambridge: Cambridge University Press.

Hummel, Martin et al. (2010), Formas y fórmulas de tratamiento en el mundo hispánico, México DF: El Colegio de México / Karl-FranzensUniversität Graz.

Ide, Sachiko (1993), "Linguistic politeness, III: Linguistic politeness and universality", Multilingua, 8, pp. 223-248.

INE: Instituto Nacional de Estadística, $<$ www.ine.es $>$.

Jucker, Andreas \& Taavitsainen, Irma (2003), Diachronic perspectives on address term systems, Ámsterdam / Filadelfia: John Benjamins.

Kany, Charles Emil (1996), Sintaxis hispanoamericana, Madrid: Gredos.

Kayne, Richard (2005), Movement and silence, Oxford: Oxford University Press.

Kayne, Richard (2009), "Some silent first person plurals", en Brucart, José María et al. (eds.), Merging features. Computation, interpretation and acquisition. Oxford: Oxford University Press, pp. 276-292.

Koch, Peter \& Oesterreicher, Wulf (1990), Gesprochene Sprache in der Romania: Französich, Italienisch, Spanisch, Tübingen: Max Niemeyer.

Kocher, Margaret (1967), "Second person pronouns in Serbo-Croatian", Language, vol. 43, 3, pp. 725-741.

Labov, William (1966), The social stratification of English in New York City, Washington DC: Center for Applied Linguistics.

Labov, William (1978), Sociolinguistic patterns, Filadelfia: University of Pennsylvania Press.

Labov, William (1995), Principles of linguistic change, Cambridge: Blackwell.

Lambrecht, Knud (1980), “Topic, French style: remarks about a basic sentence type of modern non-standard French", Proceedings of the sixth annual meeting of the Berkeley Linguistics Society, pp. 337-360.

Lambrecht, Knud (1981), Topic, antitopic and verb agreement in non-standard French, Amsterdam / Filadelfia: John Benjamins.

Lapesa, Rafael (1981), Historia de la lengua española, Madrid: Gredos.

Lapesa, Rafael (2000), Estudios de morfosintaxis histórica del español, Madrid: Gredos.

Lara, Víctor \& Ana Guilherme, Ana (2015), “Quão cortês é você? O pronome de tratamento você em Português Europeu", Labor Histórico 1 (2), pp. 167-180. 
Lara, Víctor \& Guilherme, Ana (2018), "The politeness of você in European Portuguese", Studies in Hispanic and Lusophone Linguistics, 11 (2), pp. 1-30.

Lara, Víctor \& Díez del Corral, Elena (2015), "Los clíticos de primera persona en las lenguas peninsulares: una visión dialectal", Zeitschrift für Romanische Philologie, 131 (4), pp. 950-977.

Lara, Víctor (2010), El uso de ustedes por vosotros en Andalucía occidental. Madrid: Universidad Autónoma de Madrid.

Lara, Víctor (2011), "The allocutives in the European Portuguese: from ALPI to CORDIAL-SIN", Limits and Areas, Lisboa: Universidade de Lisboa, pp. 283.

Lara, Víctor (2012), "Ustedes instead of vosotros and vocês instead of vós: an analysis through the Linguistic Atlas of the Iberian Peninsula (ALPI)", Dialectologia, Special Issue 3, pp. 57-93.

Lara, Víctor (2013), "Vocês por vós en el portugués europeo: un fenómeno en auge", en Viejo Fernández, X. (ed.), Estudios sobre variación sintáctica peninsular, Oviedo: Trabe, pp. 99-123.

Lara, Víctor (2018), "Imperativos y cortesía en las lenguas romances de la Península Ibérica”, Bulletin of Hispanic Studies, 95 (1), pp. 1-24.

Lass, Roger (1997), Historical linguistics and language change, Cambridge: Cambridge University Press.

Lehmann, Winfred (1975), "From topic to subject in Indo-European", en Li, Charles N. (ed.), Subject and topic, Nueva York: Academic Press Inc., pp. 445-456.

Li, Charles N. (1975), Subject and topic, Nueva York: Academic Press Inc. Líbano Zumalacárregui, Ángeles (1991), "Morfología diacrónica del español: las fórmulas de tratamiento", Revista de Filología Española, vol. LXXI, n 1/2, pp. 107-121.

Lipski, John M. (1996), El español de América, Madrid: Cátedra.

Lipski, John M. (2011), The Spanish of Equatorial Guinea: the dialect of Malabo and its implications for Spanish dialectology. Tübingen: Niemeyer.

Lopes, Célia Regina dos Santos \& Cavalcante, Sílvia Regina de Olivieira (2011), "A cronologia do voceamento no português brasileiro: expansão de você-sujeito e retenção do clítico-te", Lingüística, vol. 25 , pp. $30-65$.

Macaulay, Ronald (1977), Language, social class and education: a Glasgow study, Edimburgo: Edinburgh University Press. 
Matsumoto, Yoshiko (1988), "Reexamination of the universality of face: Politeness phenomena in Japanese", Journal of Pragmatics, 12, pp. 403426.

Menéndez Pidal, Ramón (2005), Historia de la lengua española, Madrid: RAE / Fundación Menéndez Pidal.

Menon, Odete P. S. (2006), "A história de você", en Guedes, Marymarcia et al. (Orgs.), Teoria e análise lingüisticas: novas trilhas, Araraquara (São Paulo): Cult. Acadêmica, pp. 99-160.

Molina Martos, Isabel. (en prensa), "Linguistic change and social transformation: the spread of tuteo in Restoration Spain and Second Republic (1875-1939)", en Hummel, Martin \& Lopes, Célia (eds.), Forms of address in Portuguese and Spanish. Diachronic variation and change. Ámsterdam / Filadelfia: John Benjamins.

Mondéjar, José (1970), El verbo andaluz: formas y estructuras, Madrid: CSIC.

Nascentes, Antenor (1956), "O tratamento "você" no Brasil". Letras, 5-6, pp. 114-122.

Navarro Tomás, Tomás et al. (dir.) (1962), Atlas lingüistico de la Península Ibérica, vol. 1, Fonética, Madrid: CSIC.

Nerbonne, John et al. (2011), Gapmap - A Web Application for Dialectology. Groningen: University of Groningen. $<$ http://www.gabmap.nl/ $>$.

Niculescu, Alexandru (1974), Strutture allocutive pronominali reverenziali in italiano, Florencia: Leo S. Olschki.

Nieuwenhuijsen, Dorien (2006), "Vosotros: surgimiento y pérdida de un pronombre" en Bustos Tovar, José Jesús \& Girón Alconchel, José Luis (eds.) Actas del VI Congreso Internacional de Historia de la Lengua Española, Madrid: Arco Libros, pp. 949-960.

Nowikow, Wiaczeslaw (1994), "Sobre la pluralización de personas gramaticales en las lenguas románicas: 'nos', 'vos' - 'nos alteros', 'vos - alteros”, Anuario de lingüística hispánica, 10, pp. 283-300.

Nwoye, Onuigbo G. (1992), "Linguistic politeness and socio-cultural variations of the notion of face", Journal of Pragmatics, 18, pp. 309-328.

O'Flanagan, Patrick (2008), Port cities of Atlantic Iberia c. 1500-1900. Aldershot: Ashgate.

Paulston, Christina B. (1984), "Pronouns of address in Swedish: social class semantics and a changing system", en Baugh, John \& Sherzer, Joel (eds.), Langauge in use: Readings in sociolinguistics, New Jersey: Prentince Hall, pp. 268-291. 
Penny, Ralph (2004), Variación y cambio en español, Madrid: Gredos.

Pike, Ruth (1972), Aristocrats and traders. Sevillian society in the sixteenth century. Cornell: Cornell University Press.

Pla Cárceles, José (1923), "La evolución del tratamiento de vuestra merced" Revista de Filología Española, X, pp. 245-280.

Puskas, Genoveva (1997), "Focus and the CP domain", en Haegeman, Liliane (ed.), Elements of grammar, Dordrecht: Kluwer.

Raumolin-Brunberg, Helena (2005), "The diffusion of subject you: a case study in historical sociolinguistics", Language variation and change, 17, pp. 55-73.

Real Academia Española \& Asociación de Academias de la Lengua Española (2009), Nueva gramática de la lengua española, Madrid: Espasa.

Rini, Joel (1999), “The rise and fall of Old Spanish 'y'all: vos todos vs. vos otros", en Lloyd, Paul et al., Essays in Hispanic linguistics dedicated to Paul M. Lloyd, Newark: Juan de la Cuesta.

Rohlfs, Gerhard (1968), Grammatica storica della lingua italiana e dei suoi dialetti, Turín: Einaudi.

Roibu, Melania \& Constantinescu, Mihaela N. (2010), "Verbal aggressiveness in the Romanian parliamentary debate. Past and present", Revue roumaine de linguistique, vol. 54, $\mathrm{n}^{\circ}$ 4, pp. 353-364.

Rumeu, Márcia Cristina de Brito (2012), "A inserção do você no português brasileiro oitocentista e novecentista: reflexos de uma mudança lingüística socialmente encaixada", Lingüística, vol. 28, pp. 147-190.

Scherre, Maria Marta Pereira et al. (2009), Usos dos pronomes você e tu no português brasileiro. II SIMELP (Simpósio Mundial de Estudos de Língua Portuguesa). Évora: Universidade de Évora.

Scherre, Maria Marta Pereira et al. (2011), "Tu, você, cê e ocê na variedade brasiliense", Papia, 21, 3, pp. 117-134.

Seara, Izabel Christine (2000), "A variação do sujeito nós e a gente na fala florionapolitana", Organon, 14, pp. 179-194.

Siewierska, Anna. (2004), Person, Cambridge: Cambridge University Press. Silva-Corvalán, Carmen (1979), An investigation of phonological and syntactic variation in spoken Chilean Spanish, Los Ángeles: University of California, tesis doctoral.

Spitzer, Leo (1947), "Vosotros", Revista de Filología Española, 31, pp. 170-175.

Trudgill, Peter (1972), "Sex, covert prestige, and linguistic change in the urban British English of Norwich," Language in Society 1, pp. 17-195. 
Tuten, Donald (2008), "Factores socioculturales en el desarrollo de vuestra merced / usted", en Company, Concepción \& Moreno de Alba, José, Actas del VII Congreso Internacional de Historia de la Lengua Española, vol. II, Madrid: Arco Libros, pp. 2189-2199.

Vázquez, Pilar \& Mendes da Luz, Maria Albertina (1971), Gramática portuguesa, Madrid: Gredos.

Walker, Terry (2007), Thou and you in early modern English dialogues, Ámsterdam / Filadelfia, John Benjamins.

Watts, Richard J. (2003), Politeness, Cambridge: Cambridge University Press.

Wechsler, Stephen \& Hahm, Hyun-Jong (2011), "Polite plurals and adjective agreement", Morphology, 21, pp. 247-281.

Wechsler, Stephen \& Zlatic, Larisa (2000), "A theory of agreement and its application to Serbo-Croatian”, Language, 76, pp. 799-832.

Wechsler, Stephen \& Zlatic, Larisa (2003), The many faces of agreement, Stanford: CSLI Publications.

Weinreich, Uriel et al. (1968), "Empirical Foundations for a Theory of Language Change", en Lehmann, Winfred \& Malkiel, Yakov (eds.), Directions for Historical Linguistics. A Symposium, Austin: University of Texas Press, pp. 95-195.

Werkhofer, Konrad T. (1992), "Traditional and modern views: the social constitution and the power of politeness", en Watts, Richard et al. (eds.), Politeness in Language: Studies in its history, theory and practice, Berlín / Nueva York: Mouton de Gruyter, pp. 155-199.

Wolfram, Walt \& Schilling-Estes, Natalie (2003), "Dialectology and Linguistic Diffusion", en Joseph, Brian \& Janda, Richard (eds.), The Handbook of Historical Linguistics, Malden: Blackwell, pp. 713-735. 



\title{
FONDO HISPÁNICO DE LINGÜÍSTICA Y FILOLOGÍA
}

\author{
Colección dirigida por \\ Juan Pedro Sánchez Méndez \& Ma Teresa Echenique Elizondo
}

La presente colección se hace eco del interés creciente en lingüística hispánica y abordatodos los enfoques teóricos que constituyen hoy día esta materia. Asume el objetivo básico de reunir, bajo un mismo criterio científico riguroso y un mismo epígrafe, la publicación y difusión de un conjunto de obras y trabajos de investigación, tanto de autores consagrados como de jóvenes lingüistas. Sus títulos se dirigen a un público amplio, que va desde el especialista avanzado hasta el estudiante en general que se interesa por un determinado tema 0 enfoque. De esta manera, la colección aspira a consolidarse como una referencia importante dentro de las diversas disciplinas que integran la lingüística hispánica.

Vol. 1 Javier Elvira

Evolución lingüística y cambio sintáctico.

2010. ISBN 978-3-0343-0323-1

Vol. 2 María José Martínez Alcalde

La fijación ortográfica del español: norma y argumento historiográfico.

2010. ISBN 978-3-0343-0481-8

Vol. 3 Catalina Fuentes Rodríguez, Esperanza Alcaide Lara \& Ester Brenes Peña (eds) Aproximaciones a la (des)cortesía verbal en español.

2011. ISBN 978-3-0343-0502-0

Vol. 4 Ester Brenes Peña

Descortesía verbal y tertulia televisiva. Análisis pragmalingüístico.

2011. ISBN 978-3-0343-0522-8

Vol. 5 Mónica Castillo Lluch \& Lola Pons Rodríguez (eds)

Así se van las lenguas variando

Nuevas tendencias en la investigación del cambio lingüístico en español.

2011. ISBN 978-3-0343-0565-5

Vol. 6 Eva Bravo-García \& M. Teresa Cáceres-Lorenzo

La incorporación del indigenismo léxico en los contextos comunicativos canario y americano (1492-1550).

2011. ISBN 978-3-0343-0662-1 
Vol. 7 José Luis Blas Arroyo

Políticos en conflicto: una aproximación pragmático-discursiva al debate electoral cara a cara.

2011. ISBN 978-3-0343-1005-5

Vol. 8 José J. Gómez Asencio

Los principios de las gramáticas académicas (1771-1962).

2011. ISBN 978-3-0343-1057-4

Vol. 9 Enrique Pato y Javier Rodríguez Molina (eds.)

Estudios de filología y lingüística españolas. Nuevas voces en la disciplina.

2012. ISBN 978-3-0343-1049-9

Vol. $10 \quad M^{a}$ Teresa García-Godoy (ed.)

El español del siglo XVIII. Cambios diacrónicos en el primer español moderno. 2012. ISBN 978-3-0343-1058-1

Vol. 11 Victoria Béguelin-Argimón, Gabriela Cordone y Mariela de La Torre (eds.)

En pos de la palabra viva: huellas de la oralidad en textos antiguos.

Estudios en honor al profesor Rolf Eberenz.

2012. ISBN 978-3-0343-1035-2

Vol. 12 Torrens Álvarez, María Jesús y Sánchez-Prieto Borja, Pedro (eds.)

Nuevas perspectivas para la edición y el estudio de documentos hispánicos antiguos.

2012. ISBN 978-3-0343-1142-7

Vol. 13 Mercedes de la Torre y Alberto M. Arias

La ictionimia andaluza en el siglo XVIII: el caso de Cádiz y Pehr Löfling (1753).

2012. ISBN 978-3-0343-1217-2

Vol. 14 Hugo E. Lombardini y M. Enriqueta Pérez Vázquez (coords.)

Núcleos. Estudios sobre el verbo en español e italiano.

2012. ISBN 978-3-0343-1361-2

Vol. 15 Eva Bravo-García y M. Teresa Cáceres-Lorenzo

El léxico cotidiano en América a través de las Relaciones Geográficas de Indias.

(Tierra Firme y América del Sur, s. XVI)

2013. ISBN 978-3-0343-1366-7

Vol. 16 Teresa Bastardín Candón

Vocabulario indígena en la Historia de fray Bernardino de Sahagún.

2013. ISBN 978-3-0343-1432-9

Vol. 17 José Ramón Gómez Molina (coord.)

El español de Valencia. Estudio sociolingüístico.

2013. ISBN 978-3-0343-1465-7 
Vol. 18 José M. Bustos Gisbert y José J. Gómez Asencio (eds.)

Procedimientos de conexión discursiva en español: adquisición y aprendizaje. 2014. ISBN 978-3-0343-1498-5

Vol. 19 Hedy Penner

Guaraní aquí. Jopara allá. Reflexiones sobre la (socio)lingüística paraguaya. 2014. ISBN 978-3-0343-1579-1

Vol. 20 Clara Elena Prieto Entrialgo

Los relativos en el asturiano medieval.

2014. ISBN 978-3-0343-1578-4

Vol. 21 Ana M. Cestero Mancera, Isabel Molina Martos y Florentino Paredes García (eds.)

Patrones sociolingüísticos de Madrid.

2015. ISBN 978-3-0343-1638-5

Vol. 22 Miguel Calderón Campos

El español del reino de Granada en sus documentos (1492-1833).

Oralidad y escritura.

2015. ISBN 978-3-0343-1639-2

Vol. 23 José María Buzón García y José Ramón Gómez Molina

Variabilidad en el paradigma verbal de futuro.

El español de Valencia y de otras sintopías.

2015. ISBN 978-3-0343-2004-7

Vol. 24 Benjamín García-Hernández y Maria Azucena Penas Ibáñez (eds.)

Semántica latina y románica.

Unidades de significado conceptual y procedimental.

2016. ISBN 978-3-0343-2102-0

Vol. 25 Pilar García Mouton \& Isabel Molina Martos

Las hablas rurales de Madrid.

Etnotextos.

2017. ISBN 978-3-0343-2694-0

Vol. 26 Lynn Williams (ed.)

Estudios de lengua y lingüística españolas.

Homenaje a Orlando Alba.

2018. ISBN 978-3-0343-3207-1

Vol. 27 Elena Feliu Arquiola (ed.)

Problemas de demarcación en morfología y sintaxis del español

2018. ISBN 978-3-0343-3406-8 
Vol. 28 David Vásquez Hurtado

Monstruosidad y escepticismo barroco en la España Imperial 2018. ISBN 978-3-0343-3268-2

Vol. 29 Víctor Lara Bermejo

La cortesía en la Península Ibérica

Dialectología del «Sprachbund» suroccidental

2018. ISBN 978-3-0343-3392-4 